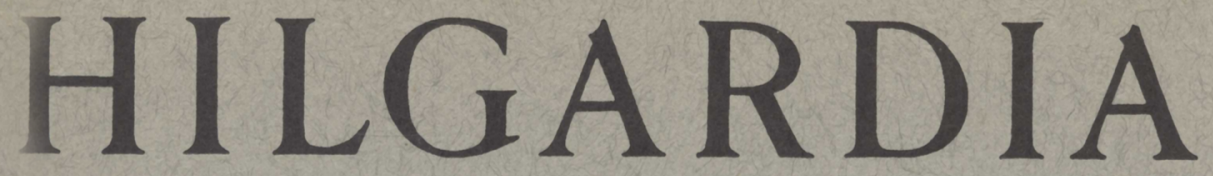

A Journal of Agricultural Science Published by the California Agricultural Experiment Station

\title{
A LYSIMETER INVESTIGATION OF NITROGEN GAINS AND LOSSES UNDER VARIOUS SYSTEMS OF COVERCROPPING AND FERTILIZATION, AND A DISCUSSION OF ERROR SOURCES
}

\author{
H. D. CHAPMAN, G. F. LIEBIG, and D. S. RAYNER
}




\section{THE RESULTS IN BRIEF}

The net gain or loss of soil nitrogen was studied in lysimeters at Riverside for ten years under four series of treatments: (1) fall applications of cereal straw (5,000 pounds per acre); (2) a mustard winter covercrop; (3) purple-vetch winter covercrop; (4) sweet-clover winter covercrop. In each series, one lysimeter was given no fertilizer, one 100 pounds, and one 200 pounds of nitrogen per acre per year as nitrate. A summer-harvested crop (first barley, later Sudan grass) was grown in all lysimeters. Total nitrogen and organic matter in the soil at the outset and at five-year intervals, amounts of nitrogen removed by cropping and leaching, and amounts added in seed, rain, irrigation water, and fertilizer were recorded.

Unaccounted-for net losses of nitrogen, thought to be due to gaseous volatilization, amounted to more than 60 pounds per acre per year with a mustard covercrop when 200 pounds of nitrogen per acre was added in fertilizer. Similar losses occurred with cereal-straw applications and 200 pounds of nitrogen.

Net gains of nitrogen when legume covercrops were grown without fertilization amounted to about 150 pounds per acre per year. These net gains were progressively reduced when 100 and 200 pounds of nitrogen per acre per year was added in fertilizer.

Net gains of nitrogen due to nonsymbiotic fixation amounted to 48 pounds per acre per year when dry cereal straw was applied without fertilization; they amounted to 40 pounds per acre per year when a mustard covercrop was grown without fertilization.

Average loss of nitrogen through leaching varied from 4 to 88 pounds per acre per year. It was highest when no winter covercrop was grown and with heavy nitrogen fertilization, considerably higher with legume covercrops than with mustard. Most of the losses occurred in years of heavy rainfall or when rain fell just after an irrigation, since irrigation was designed to just meet the water requirements of the crops grown.

The nitrogen requirements of Sudan grass-about 125 pounds of nitrogen per acre per year for maximum yields-were fully met through the nitrogen fixed by legume covercrops: yields were not increased by nitrogen fertilizer when legume covercrops were grown, although the fertilizer increased the growth of the legumes. The nitrogen added in cereal straw (22 pounds per acre per year), in rain and irrigation water ( 7 pounds), and by nonsymbiotic fixation ( 48 pounds) was not enough to meet the requirements of the Sudan grass.

These results indicate that bigh-level nitrogen fertilization is wasteful. If much more nitrogen is applied than the crops need, substantial amounts will be lost by gaseous volatilization and by leaching, fixation will be reduced, and luxury consumption of nitrogen by crops may occur without benefit to yield or qual. ity. Therefore, greatest nitrogen economy will be achieved when nitrogen is maintained at the lowest possible point consistent with satisfactory crop performance.

A table of contents for this issue will be found on the inside back cover page. 


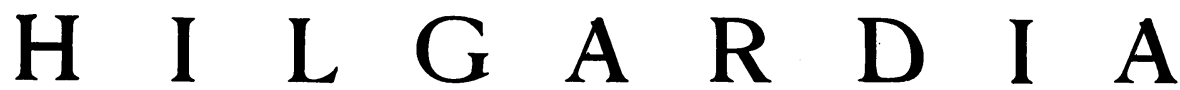

A Journal of Agricultural Science Published by

the California Agricultural Experiment Station

VoL. 19

APRIL, 1949

No. 3

\section{A LYSIMETER INVESTIGATION OF NITROGEN GAINS AND LOSSES UNDER VARIOUS SYSTEMS OF COVERCROPPING AND FERTILIZATION, AND A DISCUSSION OF ERROR SOURCES ${ }^{1,2}$}

\author{
H. D. CHAPMAN, ${ }^{3}$ G. F. LIEBIG, and D. S. RAYNER
}

\section{INTRODUCTION}

Nitrogen is the element most lacking in California soils generally, and repsents the biggest single item of expense in the farmer's fertilizer bill. Experience and experimental evidence have shown that in order to maintain commercial citrus production the application of 200 to 300 pounds of nitrogen per acre annually is required. Many growers use as much as 400 to 500 pounds per acre. The indications are that the amount of nitrogen removed by the crop and needed for the permanent new growth of the citrus tree amounts to but 50 to 60 pounds per acre per year. This large discrepancy between commercial usage and tree requirement has puzzled investigators for many years.

As a part of a general inquiry into this and other nitrogen-economy problems, a lysimeter experiment was initiated some fifteen years ago at this station. The specific questions for which answers were sought were the following: (1) Are there gaseous losses of nitrogen to the atmosphere under soil, fertilization, and cropping conditions simulating citrus culture? (2) What is the magnitude of nitrogen leaching losses under these conditions? (3) How much nitrogen will winter legume crops fix at various levels of nitrogen fertilization? (4) What is the net gain of nitrogen from nonsymbiotic fixation when organic matter of various carbon-nitrogen ratios is added to the soil? (5) What are the effects of various long-term cropping and fertilization practices on the permanent nitrogen and organic content of the soil?

\footnotetext{
${ }^{1}$ Received for publication August 26, 1948.

2 Paper No. 590, University of California Citrus Experiment Station, Riverside, California.

${ }^{3}$ Professor of Soils and Plant Nutrition and Chemist in the Experiment Station.

${ }^{4}$ Associate in the Experiment Station.

${ }^{5}$ Senior Laboratory Technician in the Experiment Station.
} 


\section{REVIEW OF LITERATURE}

There is an enormous amount of literature concerning various phases of the nitrogen problem. Most of the work reported, however, has been carried out under cropping, management, fertilization, soil, and climatic conditions foreign to those common to this region, and hence has little or no local value. Only such work, therefore, as shows the general trend of findings elsewhere is reviewed here.

Relative to unaccounted-for losses of nitrogen, there is evidence that under some conditions considerable nitrogen escapes to the atmosphere. Russel $(1921)^{6}$ reports that on one of the Broadbalk wheat plots receiving 14 tons of farmyard manure per acre annually, nearly 70 per cent of the nitrogen was unaccounted for and presumably disappeared into the air by gaseous volatilization. In the first five years of a study with a group of California soils in galvanized-iron tanks, Burd and Martin (1931) reported unaccounted-for losses of nitrogen averaging about 100 pounds per acre per year from both cropped and uncropped soils.

Lipman and Blair (1921), working in New Jersey, obtained evidence of unexplained losses of nitrogen from a loam soil, amounting to 1,000 pounds in a ten-year period. In lysimeter experiments on New York soils, Bizzell (1944) reports unaccounted-for losses of nitrogen under cropping systems of continuous timothy, as well as in rotations of corn, oats, and timothy, ranging from 289 to 436 pounds of nitrogen per acre for a twelve-year period. In another fifteen-year lysimeter experiment reported by Lyon and Bizzell (1927), the nitrogen loss unaccounted for by crop removal and drainage amounted to 25 pounds per acre per year. In lysimeter experiments at the New York State Agricultural Experiment Station, Collison, Beattie, and Harlan (1933) reported losses ranging from 11 to more than 80 pounds per acre per year.

In a study of nitrogen and organic-matter losses of Utah soils, Bracken and Greaves (1941) noted that amounts of nitrogen considerably in excess of those removed by crops were lost from the soil. They think that leaching or erosion accounts for but a small amount of this loss, and suggest that chemical or biological changes promote the volatilization of nitrogen.

In lysimeter experiments at the Connecticut Agricultural Experiment Station (Morgan, 1936; Morgan and Street, 1939; Morgan and Jacobson, 1942 ; Morgan, Jacobson, and LeCompte, 1942 ; and Morgan, Jacobson, and Street, 1942) unaccounted-for losses of nitrogen amounted in some cases to as much as 70 pounds of nitrogen per acre per year. In a critical analysis of the data of these experiments, however, Allison (1943) has concluded that, save under certain conditions where ammonia gas may have been evolved, these apparent losses can be accounted for by errors of one kind or another in the lysimeter technique, and he has expressed doubt that these losses are due to reactions resulting in the liberation of gaseous nitrogen.

Relative to the possible reactions by which gaseous nitrogen may be lost to the atmosphere, it is well established that in the presence of nitrate and energy material, and under conditions of limited oxygen supply, many organisms are able to decompose nitrate with the liberation of gaseous nitrogen. How-

\footnotetext{
- See "Literature Cited" for citations, referred to in the text by author and date.
} 
ever, it has not been commonly considered that under arable soil conditions much nitrogen is lost by this process. Under alkaline soil conditions, loss of nitrogen in the ammonia form may occur (Jewitt, 1942).

Another means by which nitrogen may be lost is in the reaction between nitrous acid and amines. This reaction may be represented as follows :

$$
\mathrm{C}_{2} \mathrm{H}_{5} \mathrm{NH}_{2}+\mathrm{HNO}_{2}=\mathrm{C}_{2} \mathrm{H}_{5} \mathrm{OH}+\mathrm{H}_{2} \mathrm{O}+\mathrm{N}_{2} \text {. }
$$

Wilson (1943) has reviewed the literature dealing with this subject and reports that nitrous acid reacts not only with certain amines and amides, but also with urea, ammonia, peptides, glucose, formaldehyde, sulfamic acid, hydrogen sulfide, sulfur dioxide, and many other compounds, with the evolution of gaseous nitrogen. Since nitrite is produced in both soils and plants in the course of nitrogen transformations, it is reasonable to suppose that losses of nitrogen occur more or less continuously during nitrogen transformations in soils and during the growth of plants.

The amounts of nitrogen lost by leaching are influenced by so many factors, such as soil type, methods of fertilization; cropping practice, and climate, that the results obtained by various workers are exceedingly diverse. Certain well-known generalizations have emerged from these studies, namely: (1) that greater leaching losses occur from bare soils than from those supporting vegetation; (2) that greater losses occur from sandy or porous, easily leachable soils than from heavier soils in which the ease and rate of water movement are less ; (3) that nitrate is the predominant form of nitrogen in most leachings, though under certain circumstances appreciable amounts of organic and ammonia nitrogen are sometimes found; and (4) that, other things being equal, leaching losses are greater from nitrate fertilizers than from ammonium and organic forms, although on some soils urea, as such, may leach out readily. The best data available on this subject are those from lysimeter studies made in various parts of the world. An excellent discussion, survey, and compilation of lysimeter investigations has been published by Kohnke, Dreibelbis, and Davidson (1940).

Babcock (1938) has published some interesting data on losses of nitrogen from citrus groves. Determinations of nitrate to a depth of 6 feet in a number of California citrus soils in December, 1936, before the winter rains, and again in March, 1937, following winter rains, showed differences of 348 to 396 pounds of nitrogen per acre. Since nitrate absorption by citrus trees is low at this time of year, it can be assumed that a substantial portion of this nitrogen disappearance was due to leaching. Studies of 26 groves in the winter of 1935-36 showed an average disappearance of 506 pounds of nitrogen per acre. The presence of nitrate in cores from deep soil borings is further evidence of leaching loss.

With regard to the nitrogen fixed by legumes, widely divergent results have been obtained, depending on the kind of legume, the effectiveness of the organisms, and on soil and climatic conditions. Schreiner and Brown (1938), discussing nitrogen problems in general, make the statement that, on the average, legume bacteria will fix about 80 pounds of nitrogen per acre per year. In a ten-year experiment, Lyon and Bizzell (1934) report that alfalfa fixed 251 pounds of nitrogen an acre yearly. Decreasing proportions of this 
amount were found for other legumes, as follows : sweet clover, 67 per cent; red clover, 60 per cent ; alsike clover, 56 per cent; soybeans, 42 per cent; hairy vetch, 27 per cent; field beans, 23 per cent ; field peas, 19 per cent. At the New York State Agricultural Experiment Station, Collison, Beattie, and Harlan (1933) reported gains of 188 to 260 pounds of nitrogen an acre yearly from alfalfa.

In a lysimeter experiment in Arizona, Smith (1944) found that where alfalfa was grown during six of the twelve years of cropping, a net gain of a little over 100 pounds of nitrogen per acre per year resulted.

Hopkins' (1910) conclusion, that on the average a legume gets about one third of its nitrogen from the soil and two thirds from the air, has been widely quoted. If one third of the nitrogen remains in the roots and the stubble and two thirds is harvested, the soil would neither gain nor lose nitrogen. However, he goes on to say that on poor soils relatively more would be obtained from the air; thus the poor soil would gain in nitrogen, whereas the reverse would be true of rich soils.

Fred, Baldwin, and McCoy (1932), in their monograph entitled "Root Nodule Bacteria and Leguminous Plants," have presented a summary of data, from many sources, on the amounts of nitrogen fixed by various legumes. The quantities range from 40 to 162 pounds per acre. There is much evidence to show that nodulation of legumes is inhibited or repressed by the presence of nitrates or ammonium salts in the soil. A partial summary of reports bearing on this question is also presented by Fred, Baldwin, and McCoy (1932).

In California it has been commonly thought that, because of the high nitrogen requirement of citrus and the field evidence that winter-legume green manure crops fix insufficient nitrogen to meet citrus needs, little or nothing would be gained from growing legume rather than nonlegume covercrops.

Relative to nonsymbiotic fixation, highly variable results have been obtained. In permanent grass plots where the herbage was cut but not removed, Lyon and Wilson (1928) report an accumulated gain of 415 pounds of nitrogen per acre for a ten-year period, or 41.5 pounds annually. Hall (1905) found that, in the Geescroft field of the Rothamsted Experiment Station, there was a gain of nitrogen during a twenty-year period amounting to 44 pounds per acre annually. This field had been allowed to go back to native vegetation during the period in question. Less than 1 per cent of the vegetation ( 0.43 per cent) was leguminous, as determined by a botanical inventory made in 1903. The presumption is that most of the gain in nitrogen was due to nitrogen fixation by Azotobacter. In a lysimeter experiment in Arizona, Smith (1944), working with a soil initially low in nitrogen, and growing two crops a year-one crop wheat and the other hegari, both of which were harvested-got a twelve-year gain of 3,133 pounds of nitrogen, or 261 pounds annually. In another soil having an initially higher nitrogen content, the same cropping system resulted in a loss of 572 pounds of nitrogen for the same period. Vandecaveye and Villanueva (1934), in laboratory experiments, got figures for nonsymbiotic fixation ranging all the way from 36 to 1,064 pounds of nitrogen per acre. Much further work might be cited, but the foregoing is enough to indicate something of the range of values obtained by various workers. 
The problem of nitrogen and organic-matter maintenance has absorbed the attention of many investigators. It is now generally believed that under any cropping system nitrogen attains a state of equilibrium in which the losses due to decomposition, crop removal, and leaching are counterbalanced by gains due to fixation and rainfall (Jenny, 1930). Whenever there is a change in the system, a change occurs in the nitrogen balance of the soil. The same obtains for the organic matter in the soil. Thus, whenever virgin sod is brought under cultivation, nitrogen and organic matter usually decrease rapidly at first and then at a diminishing rate until eventually a new equilibrium level is established.

The preceding review of the literature reveals something of the widely divergent results obtained in different parts of the world with respect to a number of nitrogen-economy problems, and the need for further information. 


\section{EXPERIMENTAL PROCEDURE}

Lysimeter Installation. The lysimeters (fig. 1, B) used in this investigation were made of 16-gauge Armco galvanized iron, with joints riveted and soldered. They were cylindrical in shape (10 feet in diameter, with side walls

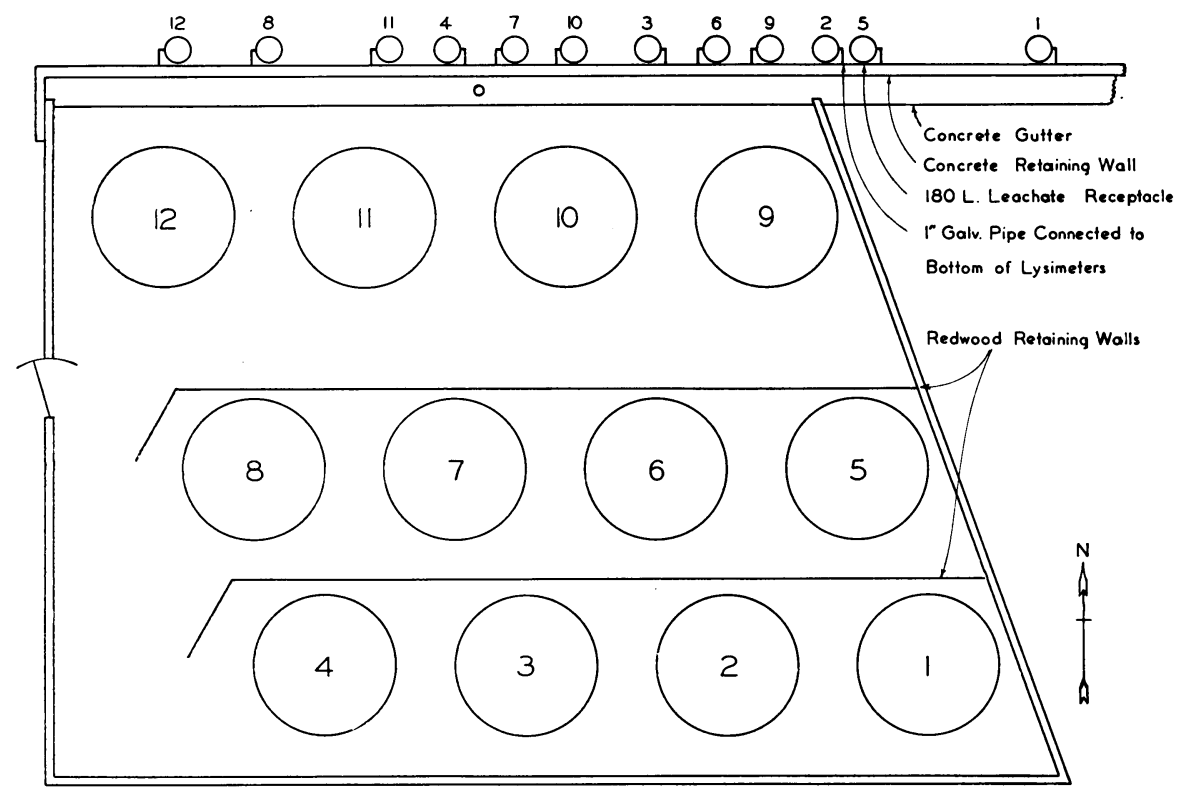

$A$

Location and Numbers of Lysimeter Tanks and Drains

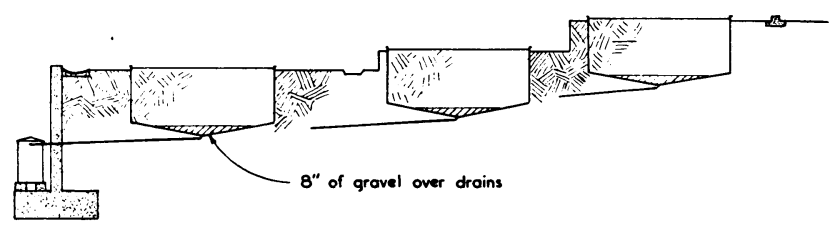

$B$

Sectional View - Lysimeter Experiment

Fig. 1. A, Diagram of lysimeter installation, showing numbering system used for lysimeters and for corresponding leachate receptacles. $B$, Sectional view of installation.

48.5 inches in depth), and each had a conical or funnel-shaped bottom which was 1 foot in depth at the central drainage outlet.

The lysimeters were installed on hillside terraces and were set in the soil at such a depth that the rims extended about 3 inches above the ground surface. A concrete retaining wall was constructed on the northerly side of the terraces, and the galvanized-iron-pipe drainage outlet from each lysimeter was brought through this wall to connect with its own covered 180-liter 
galvanized-iron leachate receptacle (fig. 2). A screen enclosure was built around the lysimeter installation. Diagrams of the arrangement and of the numbering system of the lysimeters are shown in figure 1.

Both the lysimeters and the leachate receptacles were painted inside with asphaltum paint. The leachate receptacles were provided with graduated glass gauges on the outside to facilitate measurement of the leachings. Further

TABLE 1

MISCELLANEOUS DATA AND CONVERSION FACTORS PERTAINING TO LYSIMETER EXPERIMENT*

Lysimeter dimensions:

Diameter, 10 feet

Depth of side walls to base, 48.5 inches

Depth of funnel-shaped bottom at central drainage outlet, 12 inches

Soil measurements:

Surface area, 78.54 square feet $=\frac{1}{554.6218}$ acre

Depth, $\uparrow 49.5$ inches

Volume, 316.303 cubic feet

Weight, $\ddagger 31,458.87$ pounds

Measurement of irrigation and rain water:

1-inch depth applied to lysimeter surface $=6.545$ cubic feet, 48.963 gallons, 185.328 liters

Pounds per lysimeter $\times 554.6218=$ pounds per acre

Grams per lysimeter $\times 1.22273=$ pounds per acre

Gallons per lysimeter $\times 0.020423=$ acre-inches per acre

Liters per lysimeter $\times 0.005395=$ acre-inches per acre

Constituents (nitrogen, for example) in:

Rain water:

Parts per million $\mathrm{N}$ in sample $\times$ inches of rain $\times 0.185328=$ grams $\mathrm{N}$ per lysimeter

Parts per million $\mathrm{N}$ in sample $\times$ inches of rain $\times 0.226606=$ pounds $\mathrm{N}$ per acre

Irrigation water:

Parts per million $\mathrm{N}$ in sample $\times$ gallons of irrigation water per lysimeter $\times 0.0037853=$ grams $\mathrm{N}$ per lysimeter

Parts per million $\mathrm{N}$ in sample $\times$ gallons of irrigation water per lysimeter $\times 0.0046284=$ pounds $\mathrm{N}$ per acre Leachings:

Parts per million $\mathrm{N}$ in sample $\times$ liters of leachings per lysimeter $\times 0.001=$ grams $\mathrm{N}$ per lysimeter

Parts per million $N$ in sample $\times$ liters of leachings per lysimeter $\times 0.00122273=$ pounds per acre

* Decimals have not been carried out to the same extent in all calculations. Slight but inconsequential differences in data would result from the use of decimals of greater or lesser length than those indicated.

$\dagger$ Funnel-shaped bottom of lysimeter filled to depth of 8 inches with no. 3 flint rock varying in diameter from $3 / 8$ inch to $11 / 8$ inches, soil extending from this depth to within 3 inches of top of lysimeter.

$\ddagger$ Soil weight estimated from volume-weight determinations of the horizons $(0-6,6-12,12-24,24-36$, and 36-48 inches) of a representative sample of lysimeter soil placed in two soil columns approximately 1 foot square and 5 feet high, especially constructed for this purpose. Soil columns allowed to settle four years with water enough to promote leaching from time to time. Soil surface kept fallow.

information, given in table 1, includes volume and weight of soil in the lysimeters, and certain conversion factors.

The lysimeters were installed in June, 1926, and filled with soil the latter part of the same month. The conical bottoms were filled to a depth of 8 inches with no. 3 flint rock ranging from $3 / 8$ inch to $11 / 8$ inches in diameter. The soil used was a virgin granitic-derived, residual type classified as Sierra loam. Surface soil, to a depth of 1 foot, from which organic debris had been removed, and which was screened through a $3 / 8$-inch screen, was used. Each wagonload of soil was distributed among 24 lysimeters (only 12 of which were used in the present experiment) in order to attain uniformity of composition. As the lysimeters were filled, the soil was lightly tamped; and upon completion, 
water was added to settle the soil. For seven years, from June, 1926, to June, 1933, the soils were maintained fallow. Leaching occurred in some cases, but no record of losses was kept. The soils were first sampled in the summer of 1933, and the experiment was begun at that time. A chemical analysis of a

TABLE 2

CHEMICAL ANALYSIS OF LYSIMETER SOIL SAMPLE TAKEN IN 1933*

\begin{tabular}{|c|c|}
\hline Constituent & Per cent \\
\hline Organic carbon. ......... & 0.323 \\
\hline Total nitrogen..... & 0.040 \\
\hline $\mathrm{SiO}_{2} \ldots \ldots \ldots \ldots$ & 64.100 \\
\hline $\mathrm{Al}_{2} \mathrm{O}_{3} \ldots \ldots \ldots$ & 16.165 \\
\hline $\mathrm{Fe}_{2} \mathrm{O}_{3} \ldots$ & 4.635 \\
\hline $\mathrm{TiO}_{2} \ldots \ldots \ldots \ldots$ & 0.605 \\
\hline $\mathrm{CaO} \ldots \ldots \ldots \ldots$ & 3.635 \\
\hline $\mathrm{MgO} \ldots \ldots \ldots \ldots$ & 2.030 \\
\hline $\mathrm{K}_{2} \mathrm{O} \ldots \ldots \ldots \ldots$ & 2.250 \\
\hline 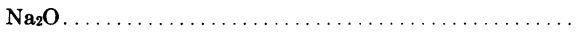 & 2.520 \\
\hline 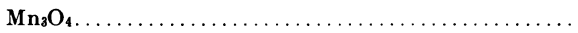 & 0.078 \\
\hline
\end{tabular}

* Composite sample of soil $(\mathrm{pH}, 6.9)$ from all 12 lysimeters $(0-6$ inch horizon).

TABLE 3

CROPPING AND FERTILIZATION TREATMENTS USED IN LYSIMETERS, 1934-1944*

\begin{tabular}{|c|c|c|}
\hline \multirow[b]{2}{*}{$\begin{array}{c}\text { Lysimeter } \\
\text { no. }\end{array}$} & \multicolumn{2}{|l|}{ Fall and winter treatment } \\
\hline & Crop or crop material & $\begin{array}{l}\text { Pounds per acre } \\
\text { nitrogen added } \\
\text { as } \mathrm{Ca}\left(\mathrm{NO}_{3}\right)_{2}\end{array}$ \\
\hline 1 & Cereal straw . . . . . . . . & None \\
\hline 5 & Cereal straw. . . . . . . . & 100 \\
\hline 9 & Cereal straw . . . . . . . . . . . . . . & 200 \\
\hline 2 & Vetch covercrop. . . . . . . . & None \\
\hline 6 & Vetch covercrop $\ldots \ldots \ldots \ldots \ldots \ldots$ & 100 \\
\hline 10 & Vetch covercrop $\ldots \ldots \ldots \ldots \ldots \ldots$ & 200 \\
\hline 3 & Melilotus covercrop... & None \\
\hline 7 & Melilotus covercrop. . . & 100 \\
\hline 11 & Melilotus covercrop... & 200 \\
\hline 4 & Mustard covercrop... & None \\
\hline 8 & Mustard covercrop. . . & 100 \\
\hline 12 & 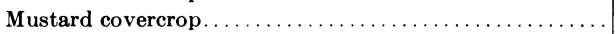 & 200 \\
\hline
\end{tabular}

* Summer-harvested crops of barley (1934 to 1939) and of Sudan grass (1940 to 1943) were used in all lysimeters.

composite sample of soil made up from all 12 of the lysimeters (0 to 6 inch depth) is given in table 2.

Cropping and Fertilizing Treatments and Sampling Dates. The cropping and fertilization treatments decided upon are shown in table 3 . All the lysimeters were cropped in summer in order to approximate conditions obtaining in the field. In this way excessive accumulation of nitrogen was prevented 
and yield data expressive of the variable nitrogen conditions were available. The first crop was grown in the summer of 1934 .

A chronology, from 1926 to 1944, showing dates of soil sampling, cropping history, and periods when leaching occurred, is presented in table 4. It will be noted that six years elapsed between the first sampling of the soil (June to August, 1933) and the second (October, 1939). In the next period (October, 1939, to July, 1944), only five years elapsed. During the first (six-year) period
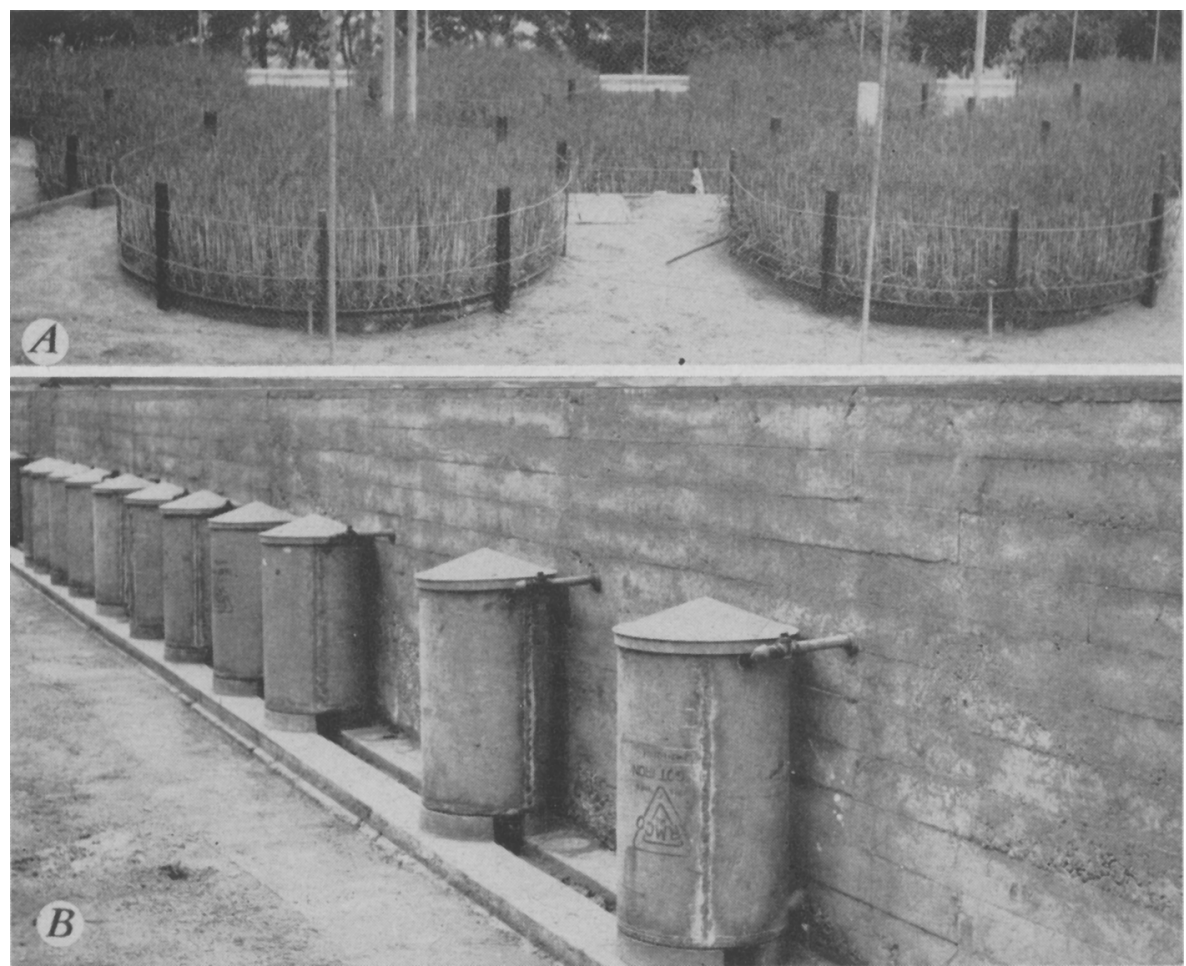

Fig. 2. $A$, Typical summer erop of barley in lysimeters. $B$, Galvanized-iron receptacles for catching leachate from lysimeters. Photographed in summer of 1937.

between sampling dates, six annual summer covercrops (of barley) were grown and harvested, but only five winter covercrops were turned under. In the next (five-year) period between soil samplings, four annual summer crops (of Sudan grass) were grown and harvested, and five annual winter covercrops turned under. Thus, for the eleven-year period between the first and last soil samplings, ten annual summer crops were grown and ten annual winter green manure crops were turned under. The soil was fallow during the greater part of the first year; no seed, fertilizer, or irrigation water was applied and no leaching occurred; hence, for all practical purposes the experimental period under discussion may be regarded as ten years. Throughout this paper the first period (June, 1933, to October, 1939) is therefore spoken of as the "first five years" and the second period (October, 1939, to July, 1944) as the "second five years." 
Soil Sampling and Analysis. In sampling the soil it was arbitrarily decided to take 18 cores with a $3 / 4$-inch soil tube. Prior to the first sampling enough soil was removed from each lysimeter so that the soil surface was exactly 3

\section{TABLE 4}

CHRONOLOGY OF LYSIMETER HISTORY, INCLUDING SOIL SAMPLING, CROPPING PROCEDURE, AND LEACHING LOSSES, 1926-1944

\begin{tabular}{|c|c|}
\hline Date & Record \\
\hline June, 1926 . & Lysimeters installed and filled with soil; maintained fallow \\
\hline Winter, 1931-32. & $\begin{array}{l}\text { Rain produced leaching in a few lysimeters, but no record kept of which } \\
\text { ones or amount of leaching }\end{array}$ \\
\hline June, 1933.. & First "five-year" experimental period begun \\
\hline June, 1933, to Aug., 1933. & $\begin{array}{l}\text { Soil samples taken at five horizons }(0-6,6-12,12-24,24-36 \text {, and } 36-49.5 \\
\text { inches) in each lysimeter (18 cores composited; an average of } 1 \text { core } \\
\text { for each } 4.36 \text { sq. } \mathrm{ft} \text {. of soil) }\end{array}$ \\
\hline Aug., 1933. . & Rainfall and other records begun; also various analyses \\
\hline May, 1934; July, 1934. & First summer crop of barley planted; harvested \\
\hline Sept., 1934; Jan., 1935. & First winter green manure crops planted; turned under \\
\hline Jan., 1935, to May, 1935 . & Some leaching losses in all lysimeters \\
\hline April, 1935; July, 1935. . & Barley planted; harvested \\
\hline Oct., 1935; March, 1936. & Winter green manure crops planted; turned under \\
\hline Jan., 1936, to June, 1936 . & Most lysimeters lost water by leaching \\
\hline April, 1936; July, 1936... & Barley crop planted; harvested \\
\hline Sept., 1936; March, 1937. & Winter green manure crops planted; turned under \\
\hline Jan., 1937, to June, 1937. & All lysimeters lost water by leaching \\
\hline April, 1937; July, 1937. & Barley planted; harvested \\
\hline Sept., 1937; Feb., 1938. & Winter green manure crops planted; turned under \\
\hline March, 1938, to June, 1938. & Most lysimeters lost water by leaching \\
\hline April, 1938; July, 1938. . & Barley planted; harvested \\
\hline Sept., 1938; March, 1939. & Winter green manure crops planted; turned under \\
\hline Dec., 1938, to June, 1939. & Most lysimeters lost water by leaching \\
\hline April, 1939; Aug., 1939. & Barley planted; harvested \\
\hline July, $1939 \ldots$ & "Extra" leaching of all lysimeters to remove excess nitrate \\
\hline \multirow[t]{2}{*}{ Oct., 1939. . } & Second "five-year" experimental period begun \\
\hline & $\begin{array}{l}\text { Soil samples taken at five horizons }(0-6,6-12,12-24,24-36 \text {, and } 36-49.5 \\
\text { inches) in each lysimeter (18 cores composited; an average of } 1 \text { core for } \\
\text { each } 4.36 \text { sq. ft. of soil) }\end{array}$ \\
\hline Oct., 1939; March & Winter green manure crops planted; turned under \\
\hline Jan., 1940 , to June, 1940. & All lysimeters lost water by leaching \\
\hline July, 1940; Aug., 1940.. & Sudan grass planted; harvested \\
\hline Sept., 1940; Feb., 1941. & Winter green manure crops planted; turned under \\
\hline Feb., 1941, to June, 1941 & All lysimeters lost water by leaching \\
\hline June, 1941; Aug., 1941. & Sudan grass planted; harvested \\
\hline Sept., 1941; Feb., 1942. & Winter green manure crops planted; turned under \\
\hline June, 1942; Aug., 1942. & Sudan grass planted; harvested \\
\hline Sept., 1942; Feb., 1943. & Winter green manure crops planted; turned under \\
\hline Jan., 1943, to June, 1943. & All lysimeters lost water by leaching \\
\hline June, 1943; Aug., 1943. & Sudan grass planted; harvested \\
\hline Sept., 1943; Feb., 1944. & Winter green manure crops planted; turned under \\
\hline Feb., 1943, to June, 1944. & Nearly all lysimeters lost water by leaching \\
\hline July, $1944 \ldots \ldots \ldots \ldots$ & $\begin{array}{l}\text { Soil samples taken at five horizons }(0-6,6-12,12-24,24-36 \text {, and } 36-49.5 \\
\text { inches) in each lysimeter (18 cores composited; an average of } 1 \text { core for } \\
\text { each } 4.36 \text { sq. } \mathrm{ft} \text {. of soil) }\end{array}$ \\
\hline
\end{tabular}

inches below the top of the lysimeter rim. The depth of soil down to the gravel was 49.5 inches, and the horizons were sampled separately, as follows : 0 to 6 inches, 6 to 12 inches, 12 to 24 inches, 24 to 36 inches, and 36 to 49.5 inches. The 18 cores of each horizon were composited into one sample for analysis, save that in certain lysimeters, in order to obtain an estimate of sampling 
error, a series of six 3-core composites was made up from the 18 cores. These six 3-core composites were analyzed separately.

A systematic sampling plan was decided upon at the outset in order to avoid taking cores from the same location in later samplings. A permanent

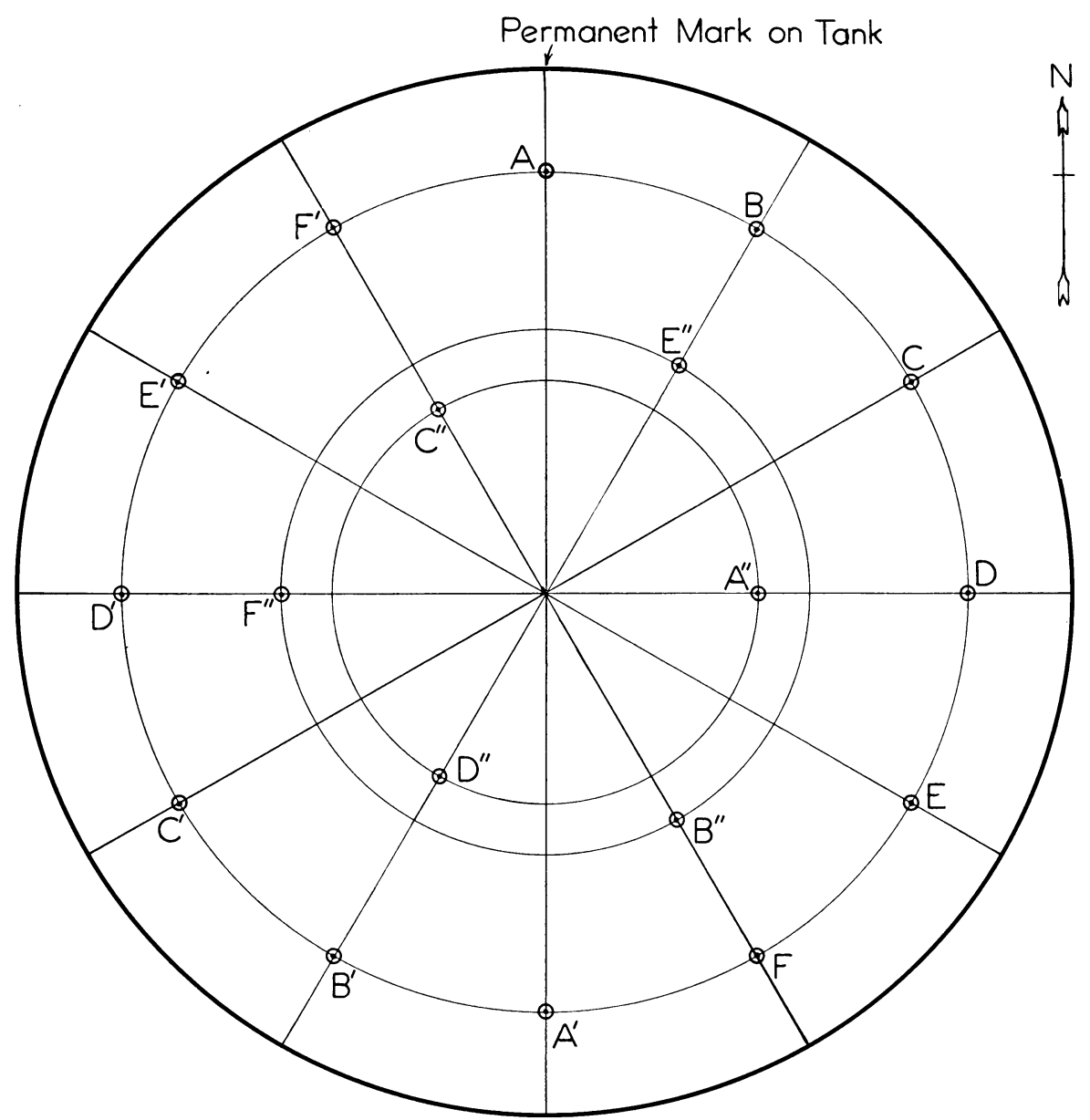

Location of Soil Sample Holes - Lysimeter Experiment

Fig. 3. Location of soil-sample holes in lysimeter.

mark was made on the rim of each lysimeter, and from this base sampling points were established on three circles (fig. 3 ), the outermost circle having a radius of 4 feet, the next, $2 \frac{1}{2}$ feet, and the innermost circle, 2 feet. Twelve sampling points 30 degrees apart were set up on the circle having a 4-foot radius ; and three sampling points 120 degrees apart were set up on each of the circles having $21 / 2$-foot and 2 -foot radii, respectively. These sampling points were then designated by letters, three of them as $A, A^{\prime}, A^{\prime \prime}$; three as $B, B^{\prime}, B^{\prime \prime}$, 
and so on. The cores from the three A points were combined to give a 3-core composite; those from the $\mathrm{B}$ points and others, likewise. For the 1939 sampling, all the sampling points were shifted 4 inches to the left on the circles. For the 1944 sampling, the sampling points were located on three circles having radii of 4 feet 4 inches, 2 feet 10 inches, and 2 feet 4 inches, respectively, instead of 4 feet, $21 / 2$ feet, and 2 feet, as previously.

The 18-core composites for each horizon were placed in separate sacks, and when all had been taken each sample was thoroughly mixed on a piece of canvas. Only enough of the soil sample was retained for analytical needs; the remainder was then returned, by horizons, to the holes. Enough more of the soil originally scraped from the surface was added to each horizon sample to compensate for that held out for analysis. In this way as much soil was returned to the soil-tube holes as had been removed. A calibrated tamping rod was used in filling these sample holes. The purpose of this procedure was to prevent channeling in the soil and to preserve uniformity so far as possible. The degree of contamination introduced by adding the small amount of original soil corresponding to the weight of soil kept for analysis was negligible.

The sample for analysis was dried, ground to pass a 20-mesh screen, and stored in sealed bottles pending determinations of total nitrogen, nitrate, and organic matter. (See Appendix B for details of analytical methods.) Results of the analyses are given in tables 29, 30, and 31 (pages 122-27).

Fertilization and Cropping. Calcium nitrate was used as a source of nitrogen fertilizer. Concentrated stock solutions of this chemical were prepared from time to time, and the amounts applied were based on analysis of the stock solution for its nitrogen content. In applying this fertilizer the requisite amount of the stock solution was accurately measured and then diluted to 2 gallons and sprinkled as uniformly as possible over the surface of the lysimeter. Those lysimeters scheduled to receive nitrogen at the rate of 100 pounds per acre were so treated in the fall just before planting the winter covercrop. A light irrigation was given each of the lysimeters after the nitrogen application in order to distribute the nitrogen through the first 12 to 18 inches of soil. Lysimeters given nitrogen at the 200-pound rate received the first 100 pound application in the fall, as above, and the remainder at the time the covercrop was turned under. In the cereal-straw treatments, all the nitrogen was applied to the straw prior to spading it into the soil.

As stated previously, barley was grown as a summer-harvested crop during the first six years of the experiment. It was usually planted in April and harvested in July. Since the weather at this time of year proved a little too warm for best performance of this crop, and since it allowed only 1 to 2 months between the turning under of the winter covercrop and the planting of the summer crop, Sudan grass was substituted for barley, beginning in 1940. In most years the Sudan grass was planted in June and harvested in August.

In harvesting the summer crop the tops were clipped off at ground level. The green crop was then weighed, and a sample was taken for the determination of dry-matter and nitrogen content. The sampling procedure consisted in selecting two or three whole plants from each large handful of the cut plants. In this way the entire pile of harvested plants was gone over, a handful at a time. The green sample was immediately weighed and spread out to air-dry. 
When fairly well air-dried, the sample was placed in a cloth bag and brought to constant weight in a forced-draft oven at a temperature of $50^{\circ} \mathrm{C}$. After the last weighing, it was immediately ground in a Wiley mill, thoroughly mixed, and a portion was bottled for analysis. At the time of weighing a sample of the ground and bottled material for the nitrogen determination, an additional sample was weighed to determine loss on drying at $105^{\circ} \mathrm{C}$. (See Appendix B for details of analytical technique.) Results of the analyses are given in table 27 (pages 118-19).

To determine the error of this method of securing samples, 10 samples of the green crop were taken as described above, and yield and nitrogen removal were computed on each. This was done on several occasions in different years. The results of this study are presented in Appendix A.

The green-manure crops were planted in the fall, the sweet clover (Melilotus indica) usually in September, and the purple vetch (Vicia atropurpurea) and mustard (Brassica nigra) in October. The cereal straw was applied in October and spaded into the soil. The green manures were usually turned under in February or March ; this corresponds to the practice common in California citrus orchards. At the time of harvest the green-manure crops were cut, weighed, and sampled in a manner comparable to that employed with the summer-harvested crops. This made it possible to determine total dry matter and nitrogen returned to the soil. The covercrops were then chopped into 4- to 6 -inch lengths and spaded in. (See Appendix B for methods of analysis.) Results of the analyses are given in table 28 (pages 120-21).

Water Measurement and Analysis. Rain was measured with a standard 8-inch rain gauge located inside the screened enclosure, and a special pan for collecting enough rain water for analysis was placed within the enclosure. The rain water was analyzed for nitrite, nitrate, and ammonia nitrogen.

Records were kept of the amount and nitrogen content of irrigation water used on each lysimeter, and of the weight and nitrogen content of the seed applied. The water used for irrigation was measured by a Nash water meter. In the early years of the experiment nitrite, ammonia, and organic nitrogen, as well as nitrate nitrogen, were determined in the irrigation water, but the amounts of all save nitrate were so inconsequential that in later years only nitrate was estimated regularly. Occasional analyses for other constituents have been made, but since these vary but little, on the average, there seemed no need for regular analyses. Amounts of water and nitrogen in the leachates are recorded in table 26 (pages 116-17).

As a general practice only enough irrigation water was applied to meet the moisture requirements of the crop. Under this system leaching losses were only such as occur from unusually heavy rains or from rain following an irrigation.

Whenever a full can of leachings was obtained, a sample representing 2 per cent of the volume was removed and placed in an 18-liter glass-stoppered bottle. Duplicate sets of composites were kept. If leaching stopped before a full can was obtained, 2 per cent of the volume was removed. Analysis of the leachate was deferred until the end of the leaching period (usually in June). Determinations of nitrite, nitrate, ammonia, and organic nitrogen were made on the leachate. It was assumed that the sum of these represented total nitrogen. 


\section{NITROGEN ADDITIONS}

From Irrigation Water. A summary showing the average annual volume of irrigation water applied to the variously treated lysimeters, and its nitrogen content, is presented in table 5. The water applied annually for both summer and winter crops amounted to between 24.5 and 27.4 acre-inches per acre ; the summer crop required about two thirds of this total. An average of a little over 10 pounds of nitrogen per acre per year was added in the irrigation water. It will be recalled that irrigation practice was such as to no more than meet the water requirement of the crop. The average usage in commercial citrus groves in the Riverside area is considerably greater than this.

\section{TABLE 5}

AVERAGE ANNUAL VOLUME AND NITROGEN CONTENT OF IRRIGATION WATER APPLIED TO LYSIMETERS, 1934-1944*

\begin{tabular}{|c|c|c|}
\hline Lysimeter no. and winter treatment & $\begin{array}{l}\text { Irrigation } \\
\text { water, } \\
\text { acre-inches } \\
\text { equivalent }\end{array}$ & $\begin{array}{c}\text { Nitrogen } \\
\text { content, } \\
\text { pounds } \\
\text { per acre }\end{array}$ \\
\hline 1. Straw.... & 16.4 & 6.6 \\
\hline 5. Straw plus 100 pounds $N \ldots$ & 17.7 & 7.2 \\
\hline 9. Straw plus 200 pounds $N \ldots$ & 17.5 & 7.1 \\
\hline 2. Vetch covercrop... & 25.8 & 10.2 \\
\hline 6. Vetch plus 100 pounds $N \ldots \ldots$ & 26.6 & 10.8 \\
\hline 10. Vetch plus 200 pounds $N \ldots \ldots$. & 26.7 & 10.8 \\
\hline 3. Melilotus covercrop..... & 25.7 & 10.5 \\
\hline 7. Melilotus plus 100 pounds $\mathrm{N}$. & 25.9 & 10.6 \\
\hline 11. Melilotus plus 200 pounds $\mathrm{N}$. & 26.3 & 10.8 \\
\hline 4. Mustard covercrop... & 24.5 & 10.0 \\
\hline 8. Mustard plus 100 pounds N.. & 27.2 & 11.0 \\
\hline 12. Mustard plus 200 pounds $\mathrm{N} \ldots \ldots \ldots$ & 27.4 & 11.1 \\
\hline
\end{tabular}

* Irrigation water first applied in May, 1934.

From Rainfall. The average rainfall and the average amounts of the various nitrogen fractions (as N) in the rainfall during the period from 1933 to 1944 are shown in table 6 . The nitrogen added in this way averaged a little more than $1 / 2$ pound per acre per year, and was about half nitrate and half ammonia, with a trace of nitrite. The average yearly rainfall for the period was 12.98 inches, which is a little above the long-term average for Riverside, California. In other parts of the world yearly rainfall additions of nitrogen ranging from 4 to 6 pounds per acre have been reported. Thus in this region the nitrogen brought down by rain was only about one tenth that reported for some other areas.

From Seed, Straw, and Fertilizers. Data showing the average annual nitrogen additions to lysimeter soils from seed, straw, and nitrogen fertilizer, 1934 to 1944 , are given in table 7 .

The average amount of cereal straw added to lysimeters 1,5 , and 9 per year (on an acre basis) amounted to 4,724 pounds of dry matter (at $105^{\circ} \mathrm{C}$ ). The 
average nitrogen content of the straw was 0.459 per cent. The total nitrogen thus added per year in the straw was 21.7 pounds. Assuming a carbon content of 45 per cent, the carbon : nitrogen ratio of the straw was 97.9 . The addition of nitrogen at the rate of 100 pounds per acre per year brought the

TABLE 6

AVERAGE RAINFALL AND AMOUNTS OF VARIOUS NITROGEN FRACTIONS (AS N) IN RAIN WATER, 1933-1944*

\begin{tabular}{|c|c|c|c|c|c|c|c|c|}
\hline \multirow{2}{*}{$\begin{array}{c}\text { Average } \\
\text { yearly } \\
\text { rainfall, } \\
\text { inches }\end{array}$} & \multicolumn{2}{|c|}{ Nitrite } & \multicolumn{2}{|c|}{ Nitrate } & \multicolumn{2}{|c|}{ Ammonia } & \multicolumn{2}{|c|}{ Total } \\
\hline & $\begin{array}{l}\text { Parts per } \\
\text { million } \dagger\end{array}$ & $\begin{array}{l}\text { Pounds } \\
\text { per acre }\end{array}$ & $\begin{array}{c}\text { Parts per } \\
\text { million } \dagger\end{array}$ & $\begin{array}{l}\text { Pounds } \\
\text { per acre }\end{array}$ & $\begin{array}{c}\text { Parts per } \\
\text { million } \dagger\end{array}$ & $\begin{array}{l}\text { Pounds } \\
\text { per acre }\end{array}$ & $\begin{array}{c}\text { Parts per } \\
\text { million } \dagger\end{array}$ & $\begin{array}{l}\text { Pounds } \\
\text { per acre }\end{array}$ \\
\hline 12.98. & 0.0030 & 0.009 & 0.0875 & 0.257 & 0.0908 & 0.267 & 0.181 & 0.53 \\
\hline
\end{tabular}

* All the figures in this and succeeding text tables are drawn from the more complete tables of basic data in Appendix C. In many cases decimals have been dropped and the last figure has been rounded off. Slight discrepancies will thus appear in the text tables and in certain calculations based on the text tables, when compared with corresponding basic tables.

$\dagger$ Weighted average.

TABLE 7

NITROGEN ADDITIONS TO LYSIMETER SOILS FROM STRAW, SEED, AND NITROGEN FERTILIZER, 1934-1944*

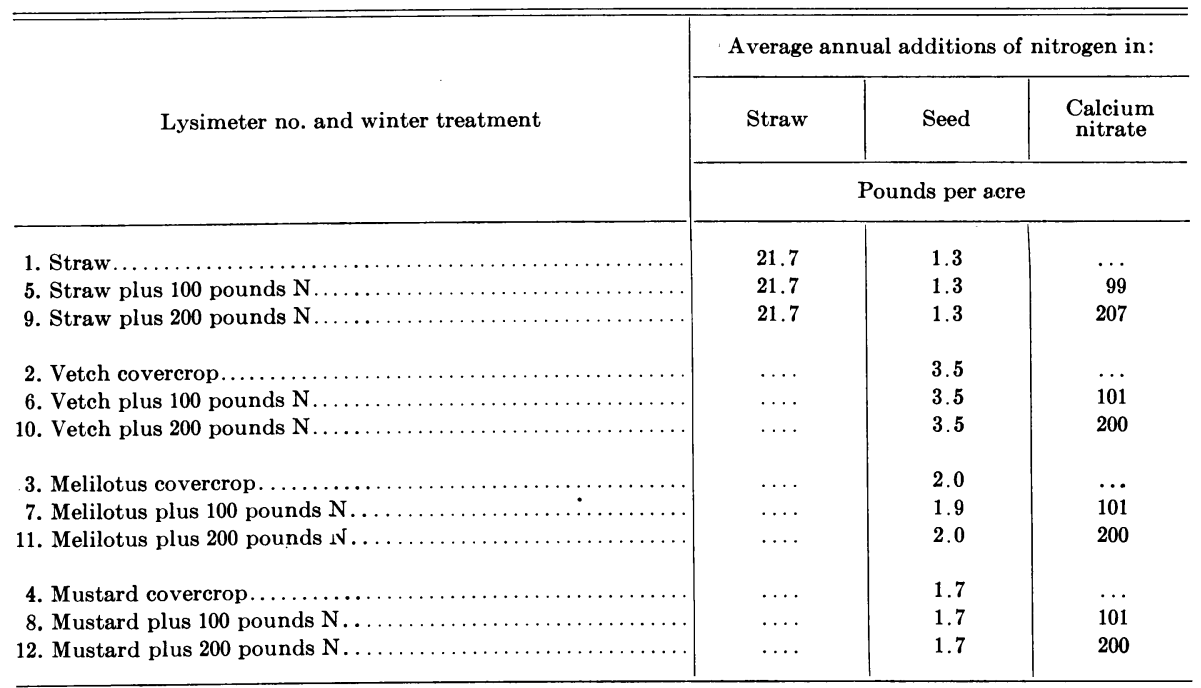

* No crops planted until May, 1934.

carbon : nitrogen ratio down to an average of 17.6 , and the 200 -pound rate gave a carbon : nitrogen ratio of 9.3. (See table 32, Appendix C, for details and basic data.)

The nitrogen additions from the calcium nitrate fertilizer averaged close to the intended 100- and 200-pound rates, but owing to the fact that analysis of the stock solution did not always show exactly the concentration intended, slight variations occurred in the amount added from time to time. 


\section{LEACHING DATA}

$\Lambda$ detailed record illustrating the intermittent and highly variable yearto-year volume and character of the leachings, and also the distribution of the nitrogen losses between the various nitrogen fractions, for three of the lysimeters, is presented in table 8. Leaching losses for all the lysimeters are summarized in table 9 . As might be expected, leaching losses were usually greatest in years of highest rainfall. In most of the years in which rainfall was less than 10 inches, no leaching occurred. As stated above, leaching occurred only during the period from January to June, was intermittent, and depended upon the amount of distribution of rainfall. The volume of leachate as percentage of the total water (rain plus irrigation water) going on the lysimeters was generally less than 10 per cent. The average for the period from 1933 to 1944 varied among the different lysimeters from 3.2 to 8.6 per cent.

It will be noted (table 8 ) that the overwhelming proportion of nitrogen in the leachate was in the nitrate form. Nitrite and ammonia nitrogen were usually present in amounts well under 1 p.p.m.; in many instances they were present only as a trace. Organic nitrogen was variable, amounting in a few cases to as much as 3 p.p.m. Although the leachate was stored in stoppered bottles for some months prior to analysis in most years, analyses of fresh leachate gave essentially the same results, save that the amounts of nitrite and ammonia nitrogen were a trace higher. The nitrate-nitrogen fraction generally constituted better than 99.5 per cent of the total nitrogen.

The lysimeter soils stood fallow from June, 1926, to the beginning of the experiment in June, 1933. During this period considerable quantities of nitrate accumulated in the soils (see analyses for nitrate, June, 1933, table 30, Appendix C). Consequently, large quantities of nitrate nitrogen leached out during the first years of the experiment. Because of the nitrate accumulation in these soils at the outset, and the realization that this was an abnormal soil condition, it was decided prior to the second soil sampling, in October, 1939, to leach all the lysimeters in order to remove excess nitrate and make leaching losses in succeeding years more representative.

The data for the second five-year period (table 9) show that, as might be expected, the greatest nitrogen losses occurred in those lysimeters receiving nitrogen at the rate of 200 pounds per acre. The least nitrogen losses occurred in the lysimeters in which mustard covercrops were grown. The loss of nitrogen from lysimeter no. 4 (mustard covercrop; no nitrogen applied) was low because this soil became progressively nitrogen-deficient. In the mustard lysimeters receiving nitrogen there was heavy crop growth, and the condition in these soils was apparently such that during the winter and spring months very little nitrate nitrogen was present. In the legume-treated soils, more nitrate in general was present; hence leaching losses were greater. The loss of nitrogen in the straw-treated soil receiving no added nitrogen fertilizer was relatively low, as might be expected. However, substantial losses occurred in the straw-treated soil receiving nitrate nitrogen. Decomposition of the straw by organisms was rather slow, and during the fall and winter some of the fertilizer applied with the straw no doubt leached down below the zone of straw incorporation and moved out with the water. 
TABLE 8

AMOUNT OF RAIN AND IRRIGATION WATER AND AMOUN'T AND CHARACTER OF LEACHING LOSSES IN THREE VARIOUSLY TREATED

LYSIMETERS, 1933-1944

\begin{tabular}{|c|c|c|c|c|c|c|c|c|c|c|}
\hline \multirow{3}{*}{ Year } & \multirow{2}{*}{$\begin{array}{l}\text { Total } \\
\text { rain }\end{array}$} & \multirow{2}{*}{$\begin{array}{c}\text { Total } \\
\text { irriga- } \\
\text { tion } \\
\text { water }\end{array}$} & \multirow{2}{*}{$\begin{array}{c}\text { Total } \\
\text { rain and } \\
\text { irriga- } \\
\text { tion } \\
\text { water }\end{array}$} & \multirow{2}{*}{$\begin{array}{c}\text { Total } \\
\text { volume } \\
\text { leaching } \\
\text { loss }\end{array}$} & \multicolumn{5}{|c|}{ Concentration of nitrogen in leachate as: } & \multirow{3}{*}{$\begin{array}{c}\text { Total } \\
\text { nitrogen } \\
\text { loss, } \\
\text { pounds } \\
\text { per acre }\end{array}$} \\
\hline & & & & & Nitrite & Nitrate & $\underset{\text { nia }}{\text { Ammo- }}$ & Organic & $\begin{array}{c}\text { Total } \\
\text { nitrogen }\end{array}$ & \\
\hline & \multicolumn{4}{|c|}{ Acre-inches per acre } & \multicolumn{5}{|c|}{ Parts per million } & \\
\hline
\end{tabular}

Lysimeter no. 9 (straw plus 200 pounds $\mathrm{N}$ per acre)

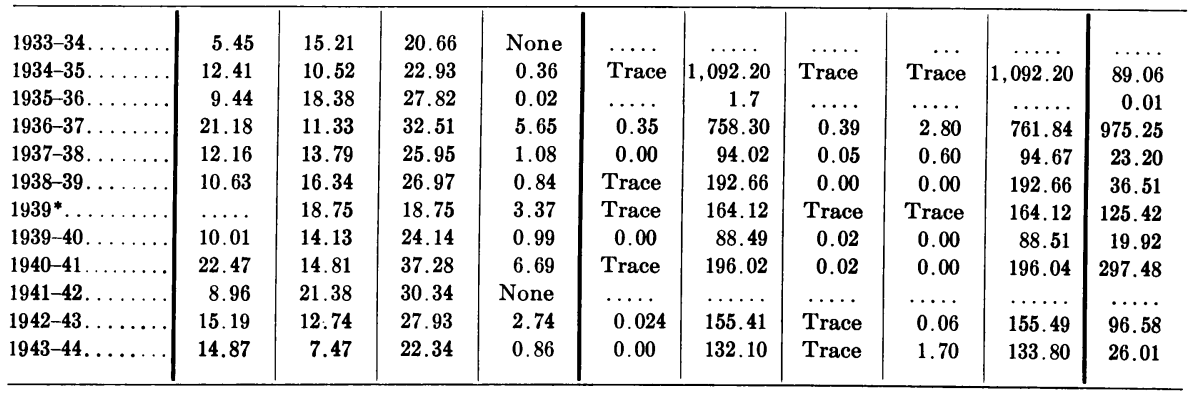

Lysimeter no. 10 (vetch plus 200 pounds $\mathrm{N}$ per acre)

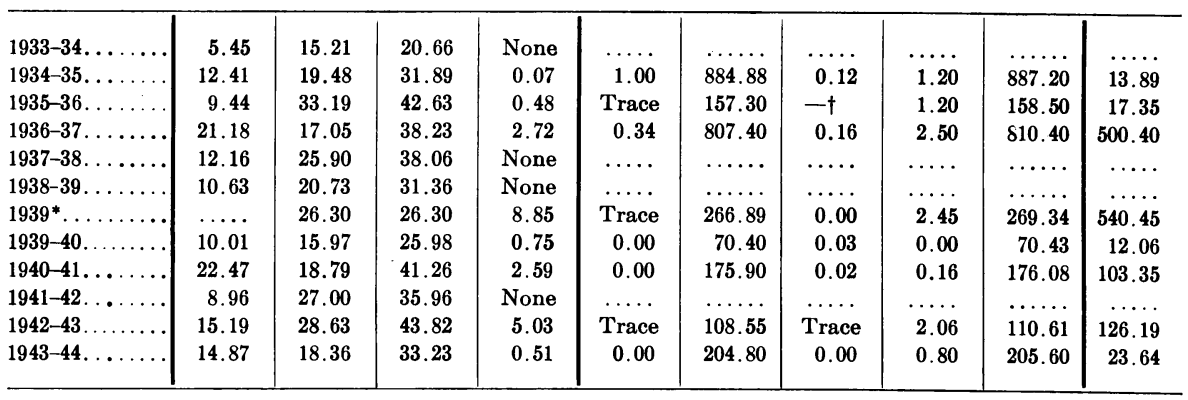

Lysimeter no. 12 (mustard plus 200 pounds $\mathrm{N}$ per acre)

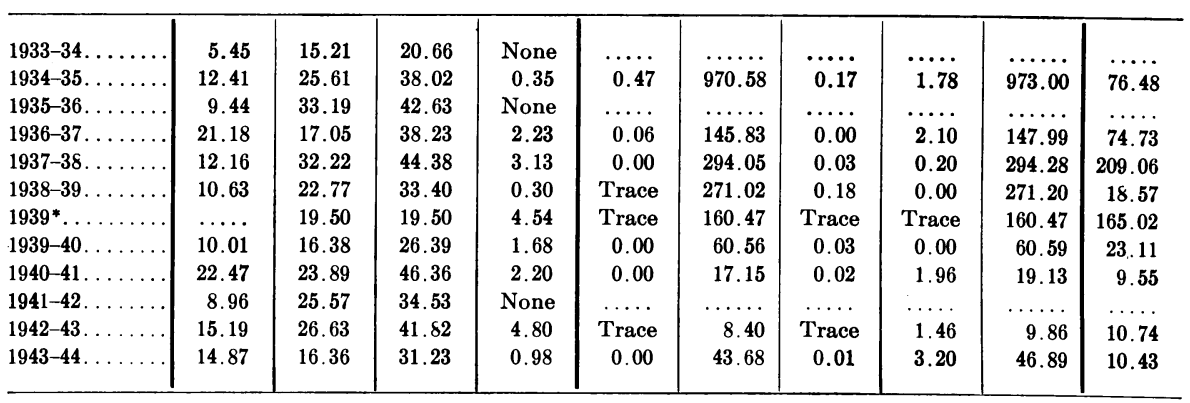

* Extra leaching in 1939 to remove excess nitrate.

† Dash indicates data not determined. 


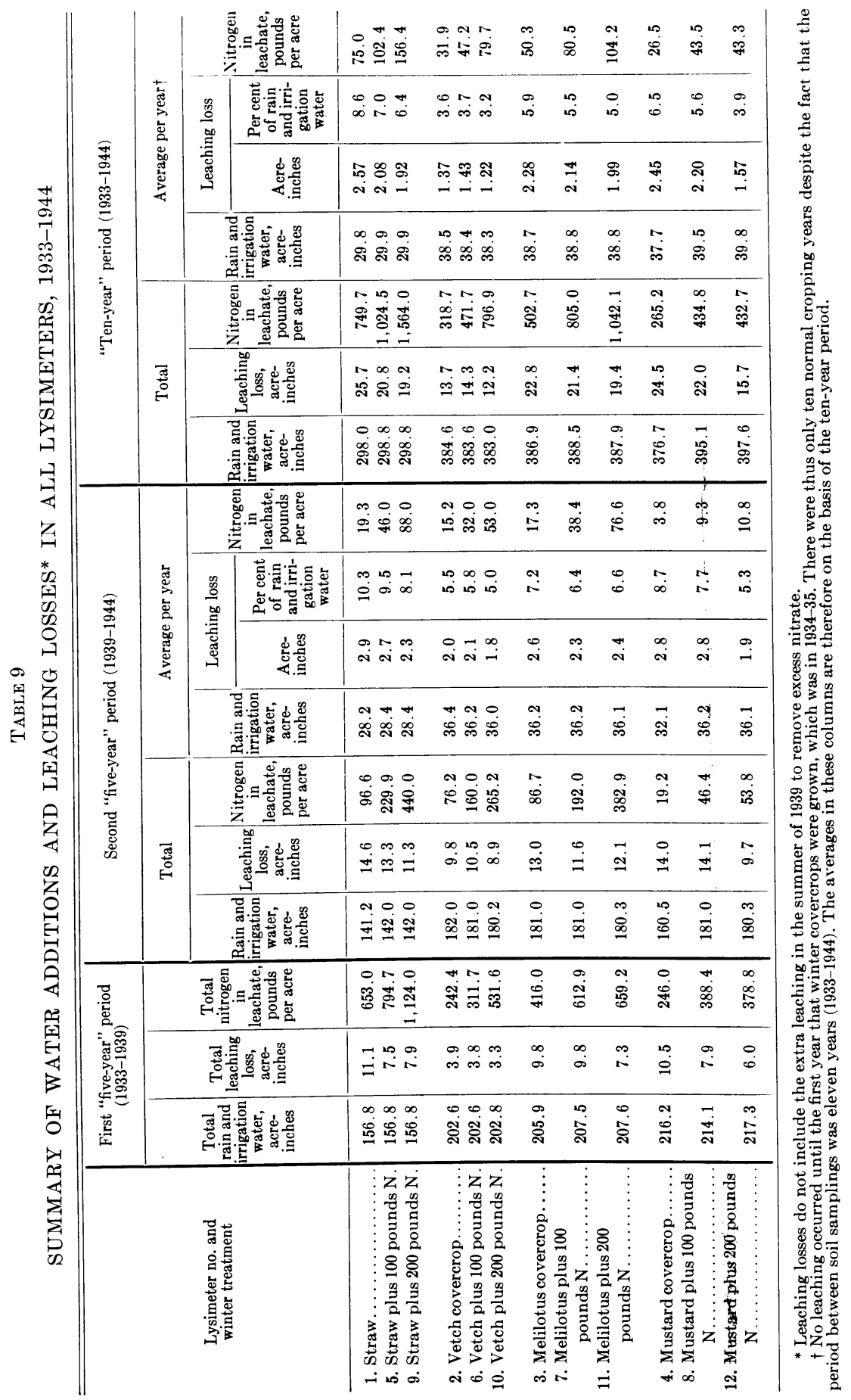


It is unfortunate that, for comparison, no treatments were available in which neither straw nor winter covercrops were added. These would have provided information on the effectiveness of covercrops versus straw in preventing nitrogen leaching losses. The nitrogen leaching losses sustained where nitrogen fertilization was at the 200-pound rate amounted, during the second "five-year" period, to an average of 88 pounds annually in the cereal-straw tank, 53 pounds in the vetch-treated tank, 76.6 pounds in the melilotus tank, and 10.8 pounds in the mustard tank (table 9 ). Considering the conservative irrigation practice followed on these soils, and the fact that many commercial citrus growers apply from 300 to 500 pounds of nitrogen annually, it is reasonable to suppose that, particularly in years of heavy average rainfall, substantial losses of nitrogen by leaching occur under orchard conditions.

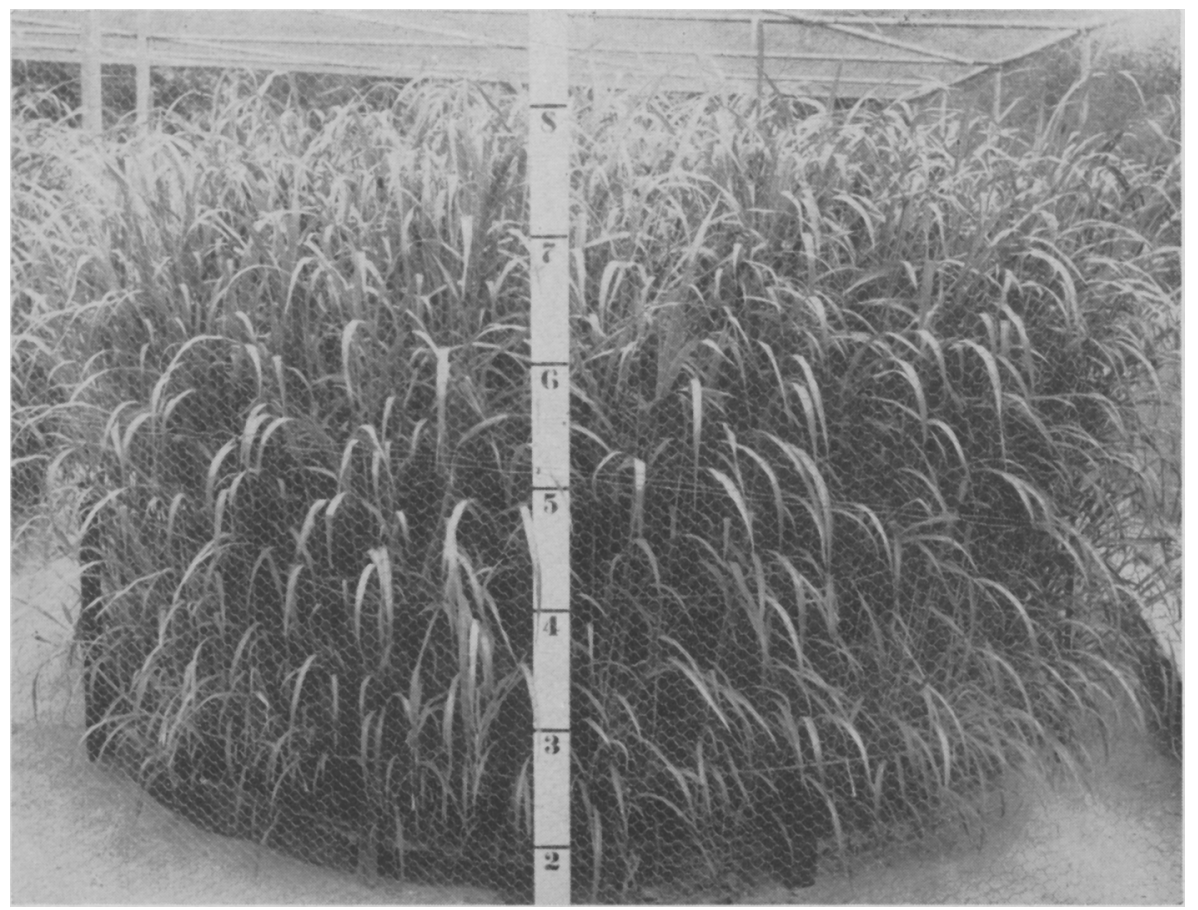

Fig. 4. Typical growth of Sudan grass in lysimeters; average size attained at time of harvest. (Scale, in feet.) 


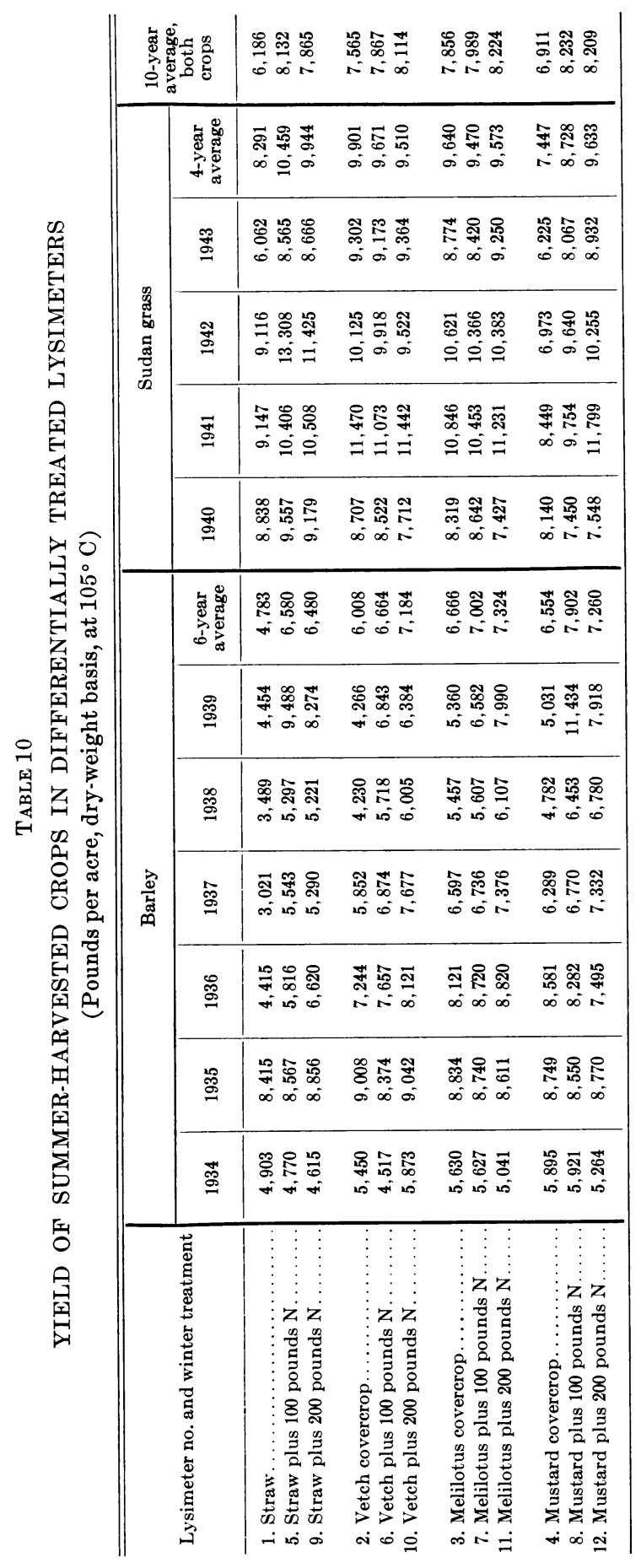




\section{YIELD AND NITROGEN CONTENT OF CROPS AND NITROGEN REMOVAL FROM THE SOIL}

Summer-harvested Crops. Yield data for the summer-harvested crops (barley and Sudan grass) are presented in table 10. The appearance of barley and Sudan grass crops at harvest time is shown in figures 2 and 4.

Because of lack of replication, it is difficult to arrive at an accurate estimate of the yield differences necessary to indicate statistical significance. If it be assumed, however, that the soils were uniform at the outset, then the differences in the first yields of barley in the various lysimeters may be used for this purpose. A coefficient of variation of \pm 9.69 per cent is obtained for the 1934 barley crop and \pm 2.43 for the 1935 crop. Owing to nitrate accumulations in the lysimeters, the 1934 crop lodged badly and there was more or less mildew. In 1935 a much more uniform crop was obtained and because of the careful method of planting and handling the harvested crop generally, it is believed that the figure \pm 2.43 comes close to representing the yield variability arising from causes other than treatment. On this basis it seems safe to regard yield differences of 5 per cent or more as significant.

As might be expected, the yields in lysimeter no. 1, which received an annual application of cereal straw in the fall, without nitrogen, began to decline sharply in the third year. It should be borne in mind that considerable nitrate had accumulated in the lysimeters before the experiment was begun; hence the yield following the first straw application was not significantly impaired (1935). Yields in the succeeding four years $(1936,1937,1938$, and 1939) were depressed, however. In 1940, with the change to Sudan grass, the yield in lysimeter no. 1 was good and only slightly decreased over that of lysimeters no. 5 and no. 9 receiving nitrogen. After that year, yields again declined.

In lysimeter no. 4 (mustard covercrop without nitrogen) yields began to decrease after the third year, but not so sharply as in lysimeter no. 1 (cereal straw without nitrogen). The soil in no. 4 has now (in 1948) reached a nitrogen level in which the winter mustard crop is a virtual failure. Despite the failure of mustard, good crops of Sudan grass continue to be obtained, though they show symptoms of nitrogen starvation. As will be seen later, however, in connection with the data on nitrogen balance (table 14), there is evidence that nonsymbiotic fixation is going on in this lysimeter, and a state of equilibrium appears to be in the process of attainment.

In 1936 yields of barley in the legume lysimeters not receiving supplemental nitrogen (nos. 2 and 3) began to decrease, in comparison with yields in the fertilized legume tanks. Since the change to Sudan grass, however, there has been no evidence of a yield decrease in the nonfertilized legume lysimeters. The explanation for the results with barley, in contrast with those with the Sudan grass, may be that the short interval between the turning under of the winter covercrops (in February or March) and the planting of the barley crop (in April), plus the leaching action of winter rains, deprived the barley in the nonfertilized tanks of a sufficient supply of nitrogen to meet its early needs. With the Sudan grass, a long enough interval elapsed between the turning under of the winter covercrop and the planting of the summer crop to allow for considerable nitrification. 


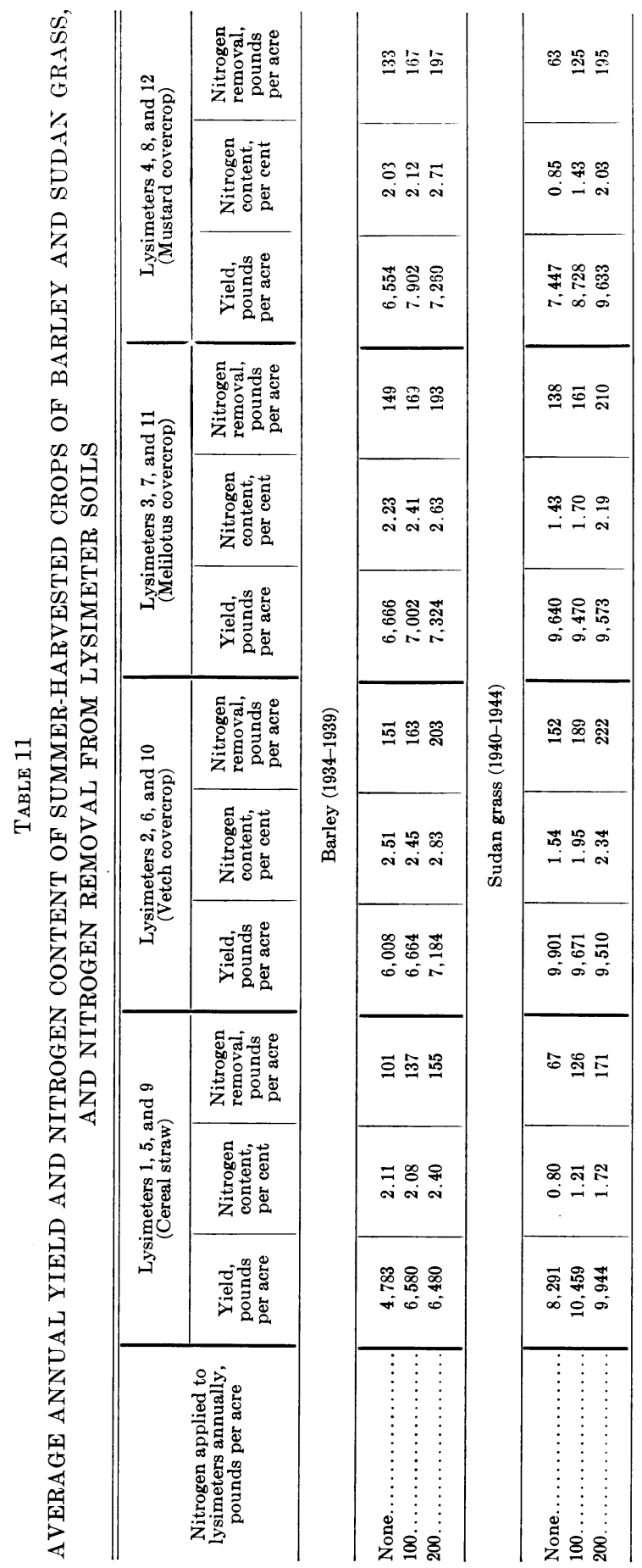




\begin{tabular}{|c|c|c|c|c|}
\hline & 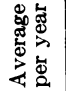 & 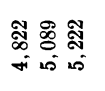 & 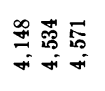 & 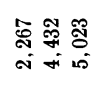 \\
\hline & 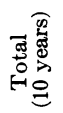 & 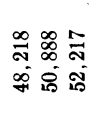 & 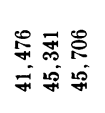 & 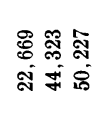 \\
\hline \multirow{2}{*}{ 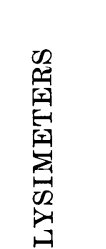 } & $\begin{array}{l}\text { 节 } \\
\text { 寄 }\end{array}$ & 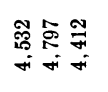 & 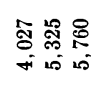 & 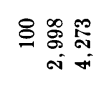 \\
\hline & 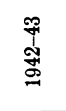 & 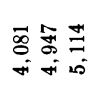 & 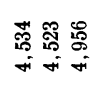 & 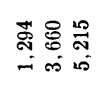 \\
\hline 星 & $\begin{array}{l}\text { ₹ } \\
\stackrel{F}{\Phi}\end{array}$ & 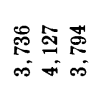 & 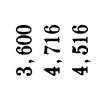 & 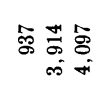 \\
\hline 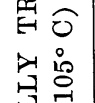 & $\begin{array}{l}\text { Fे } \\
\text { 京 } \\
=\end{array}$ & 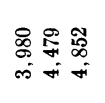 & 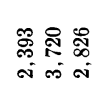 & 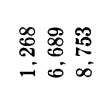 \\
\hline 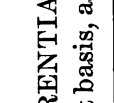 & 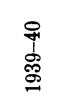 & 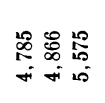 & 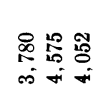 & 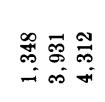 \\
\hline 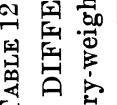 & 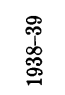 & 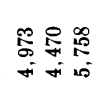 & 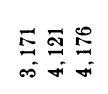 & 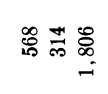 \\
\hline 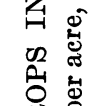 & 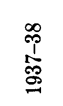 & 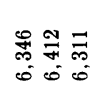 & 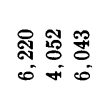 & 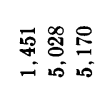 \\
\hline 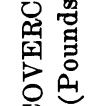 & 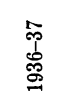 & 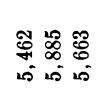 & 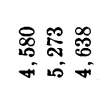 & 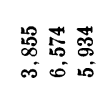 \\
\hline 翼 & 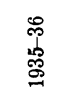 & 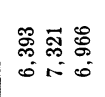 & 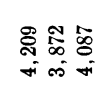 & 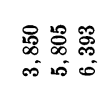 \\
\hline 㕄 & 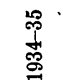 & 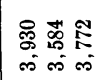 & 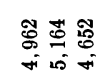 & 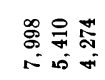 \\
\hline 国 & 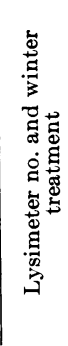 & 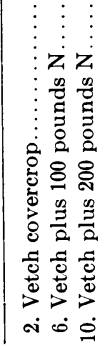 & 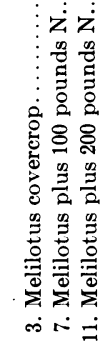 & 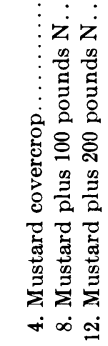 \\
\hline
\end{tabular}


The average yield and nitrogen content of the summer-harvested crops, and the average annual removal of nitrogen from the soils by cropping, are shown in table 11. The application of nitrogen to the legume lysimeters increased the nitrogen content of the harvested crops, but did not increase yields.

Winter Covercrops. The yearly and average yields of the three winter covercrops for the ten years of this experiment are presented in table 12. The typical appearance of these crops is shown in figure 5. Vetch yielded, on the average, more dry matter per acre than melilotus or mustard. The progressive

TABLE 13

AVERAGE ANNUAL YIELD AND NITROGEN CONTENT OF WINTER COVERCROPS, AND AMOUNT OF NITROGEN RETURNED TO LYSIMETER SOILS

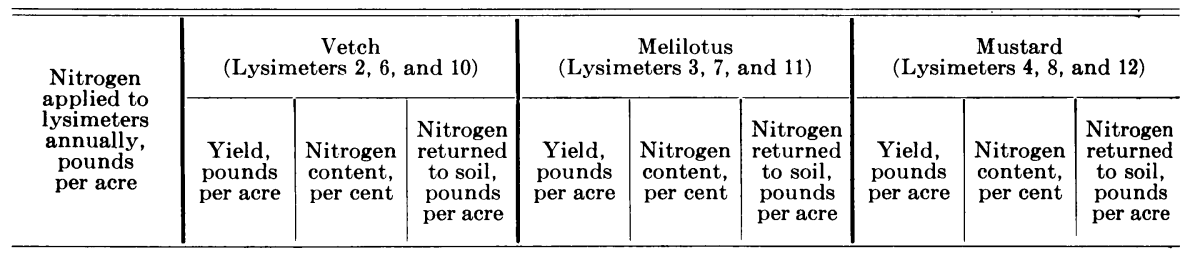

First five years (1935-1939)

\begin{tabular}{l|l|l|l|l|l|l|l|l|l}
\hline None $\ldots \ldots \ldots \ldots$ & $\mathbf{5 , 4 2 1}$ & 3.477 & 188 & 4,628 & 2.984 & 138 & 3,544 & 3.124 & 111 \\
$100 \ldots \ldots \ldots \ldots$ & $\mathbf{5 , 5 3 4}$ & 3.458 & 191 & 4,496 & 3.038 & 137 & 4,626 & 3.093 & 143 \\
$200 \ldots \ldots \ldots \ldots \ldots$ & $\mathbf{5 , 6 9 4}$ & 3.498 & 199 & 4,719 & 3.001 & 142 & 4,716 & 3.262 & 154 \\
\hline
\end{tabular}

Second five years (1940-1944)

\begin{tabular}{r|r|r|r|r|r|r|r|r|r}
\hline None.......... & 4,222 & 3.367 & 142 & 3,667 & 3.090 & 113 & 990 & 1.611 & 16 \\
$100 \ldots \ldots \ldots \ldots$ & 4,643 & 3.419 & 159 & 4,572 & 2.991 & 137 & 4,238 & 2.350 & 100 \\
$200 \ldots \ldots \ldots \ldots \ldots$ & 4.749 & 3.465 & 165 & 4,422 & 2.983 & 132 & 5,330 & 2.700 & 144 \\
\hline
\end{tabular}

Ten-year period (1935-1944)

\begin{tabular}{l|l|l|l|l|l|l|l|l|r}
\hline None.......... & 4,822 & 3.429 & 165 & 4,148 & 3.031 & 126 & 2,267 & 2.794 & 63 \\
$100 \ldots \ldots \ldots \ldots \ldots$ & 5,089 & 3.440 & 175 & 4,534 & 3.014 & 137 & 4,432 & 2.738 & 121 \\
$200 \ldots \ldots \ldots \ldots \ldots$ & 5,222 & 3.483 & 182 & 4.571 & 2.992 & 137 & 5,023 & 2.964 & 149 \\
\hline
\end{tabular}

nitrogen depletion of lysimeter no. 4 (mustard covercrop without nitrogen) is evident. After ten years of continuous cropping, this crop was a virtual failure. Even where 100 pounds of nitrogen per acre annually is added the yield is decreasing.

The average annual yield and nitrogen content of the various winter covercrops, and the average amount of nitrogen returned to the lysimeter soils annually, are summarized in table 13. There has been some inclination to think that, under continuous cropping with mustard or any other crop, gradually decreasing yields would result even though fertility was maintained. Where nitrogen was adequate, mustard yields held up. The yield of vetch was not quite so good in the second five-year period as in the first, but the yield of melilotus did not change. Melilotus shows an average nitrogen content of about 3 per cent, and vetch a little under 3.5 per cent. Additional nitrogen did not increase the percentage of nitrogen in the legumes. With mustard, lack of nitrogen substantially lowered the nitrogen percentage. 

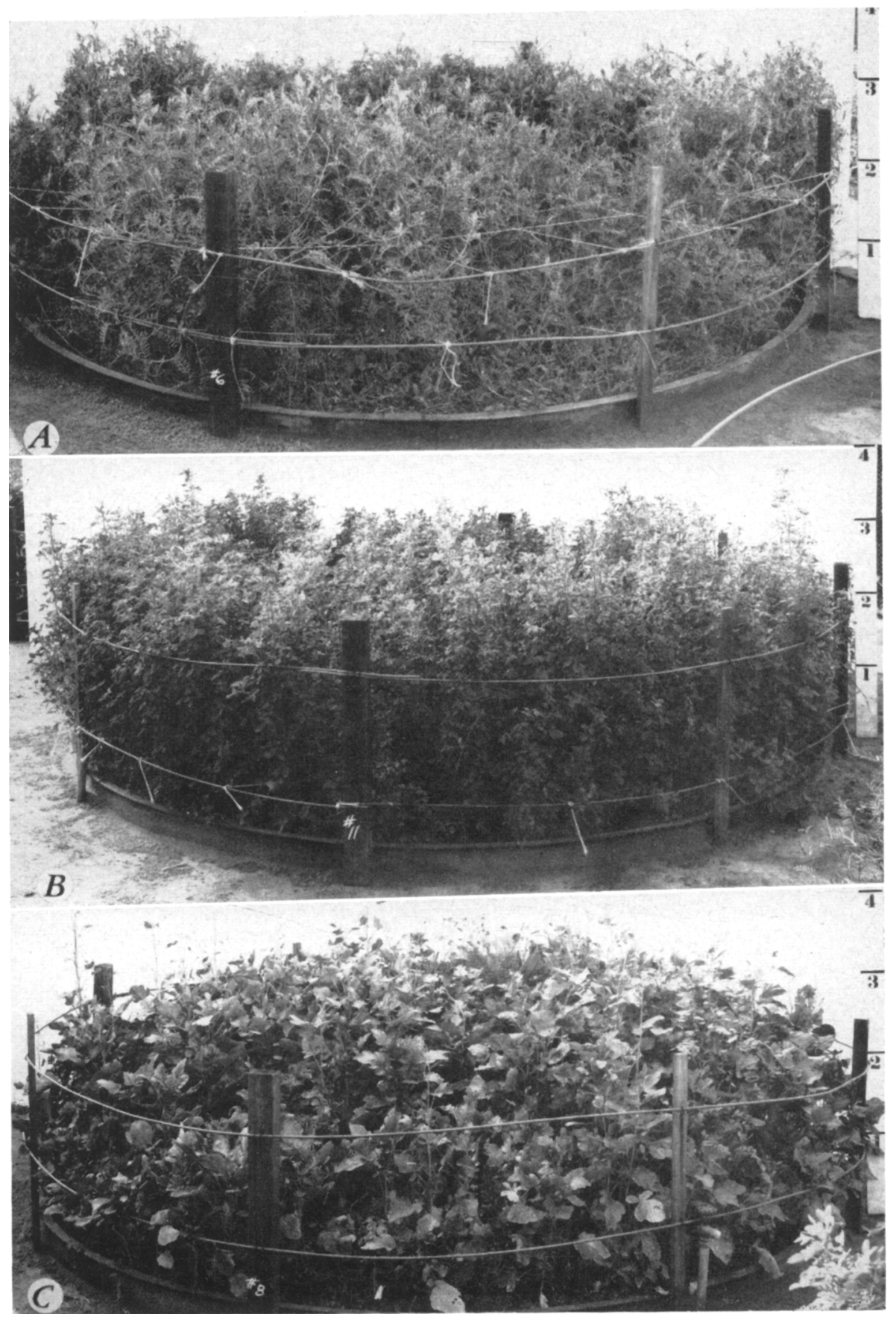

Fig. 5. Typical growth of winter covercrops in lysimeters: $A$, purple vetch (Vicia atropurpurea) ; B, sweet clover (Melilotus indica); $C$, mustard (Brassica nigra). (Seale, in feet.) 


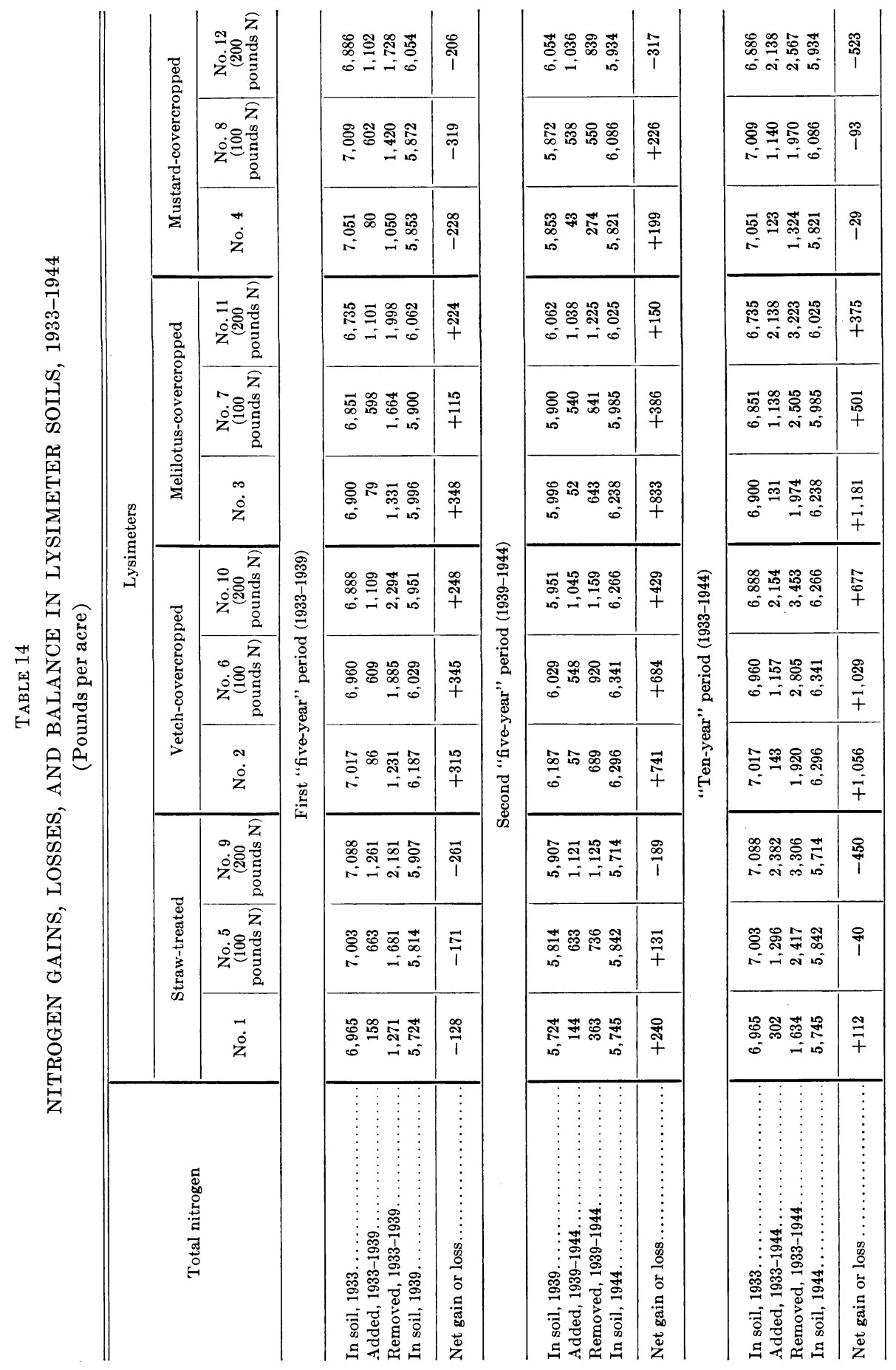




\section{NITROGEN GAINS, LOSSES, AND BALANCE IN LYSIMETER SOILS}

Gains, losses, and balance of total nitrogen in the soils of each of the lysimeters, 1933-1944, are shown in table 14.

Nitrogen Gains through Fixation by Legumes. Reference to table 14 shows that, for the total period 1933-1944, the net gain in soil nitrogen from vetch covercrop without added nitrogen (lysimeter 2) was 1,056 pounds per acre, while that from melilotus without added nitrogen (lysimeter 3) was 1,181 pounds. The net gains in these two lysimeters in the first "five-year" period were 315 and 348 pounds, respectively ; and in the second "five-year" period, 741 and 833 pounds. The difference between these two periods is no doubt due to the high nitrate levels existing in these soils at the beginning of the experiment. The results for the second period are of greater significance as indicating the normal fixation for this soil.

Where nitrogen was added at the rate of 100 pounds per acre annually, the net gain in total nitrogen from vetch covercrop (1933-1944) was only slightly under that where no nitrogen was added, but the gain in corresponding melilotus lysimeters, over the same period of time, dropped more than 50 per cent. Where 200 pounds of nitrogen was added, the net gain from vetch was only 58 per cent of that where no nitrogen was added. Even so, the yearly gain was about 86 pounds of nitrogen per acre. However, in the corresponding melilotus lysimeter, nitrogen fixation was decreased more markedly. For the decrease in net gain where nitrogen was added there may be two explanations : the first is simply that in the presence of nitrate the legume organisms fixed less nitrogen; the second, that nitrogen was lost to the atmosphere in these lysimeters just as in the mustard and cereal-straw lysimeters, and hence net gain and not actual fixation was decreased. Probably, both were operative; that is, the legume organisms actually fixed less nitrogen, and at the same time gaseous losses of nitrogen occurred. Whatever may be the proper explanation, it is significant that even at a high rate of nitrogen fertilization, a substantial amount of nitrogen was fixed by vetch.

In the case of the mustard covercrop with nitrogen fertilizer added at the rate of 200 pounds nitrogen per year, an average of 5,330 pounds of dry matter per acre per year was produced and turned under during the second five-year period. Under this system there was a net unaccounted-for loss of nitrogen amounting to 63 pounds per acre per year. With vetch, on the other hand, to which nitrogen fertilizer was added at the 200 -pound rate, the average yearly dry matter turned under was 4,749 pounds per acre, and there was a net gain of 86 pounds of nitrogen per acre per year. Thus the difference in favor of vetch was 149 pounds of nitrogen per acre per year. Where orchard conditions are such that vetch can be satisfactorily grown, it is clear that a substantial economy in nitrogen will result from the use of this crop in place of mustard.

Nitrogen Gains through Nonsymbiotic Fixation. In the second five-year period (1939-1944) net gains amounting to 240 and 131 pounds of nitrogen per acre (table 14) occurred, respectively, in lysimeters 1 and 5 receiving cereal straw. Lysimeter 5 received nitrogen fertilizer at a rate of 100 pounds nitrogen per acre per year, and as in the legume lysimeters, the rate of fixation was decreased, or unaccounted-for losses increased, or both. With mustard, 


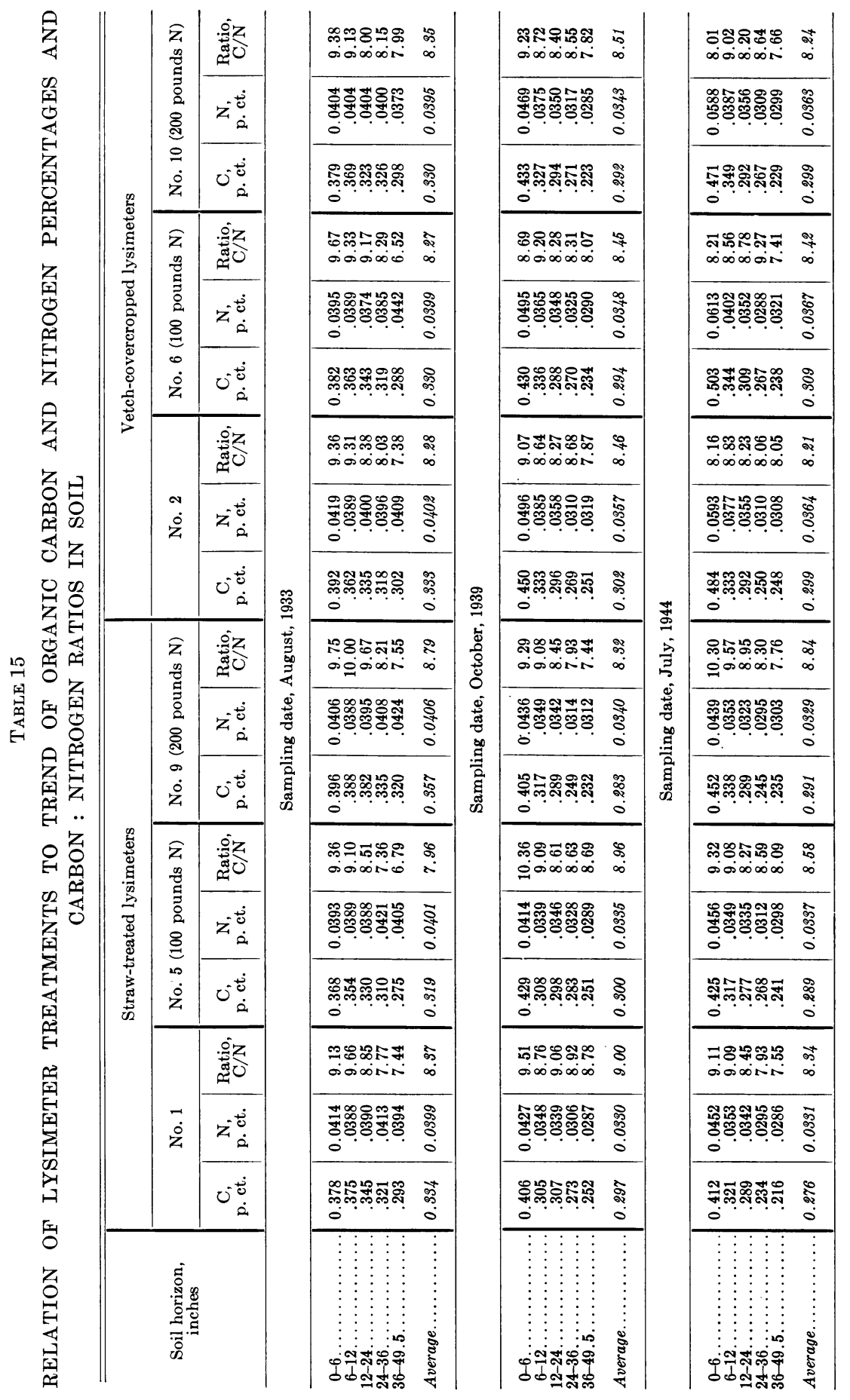




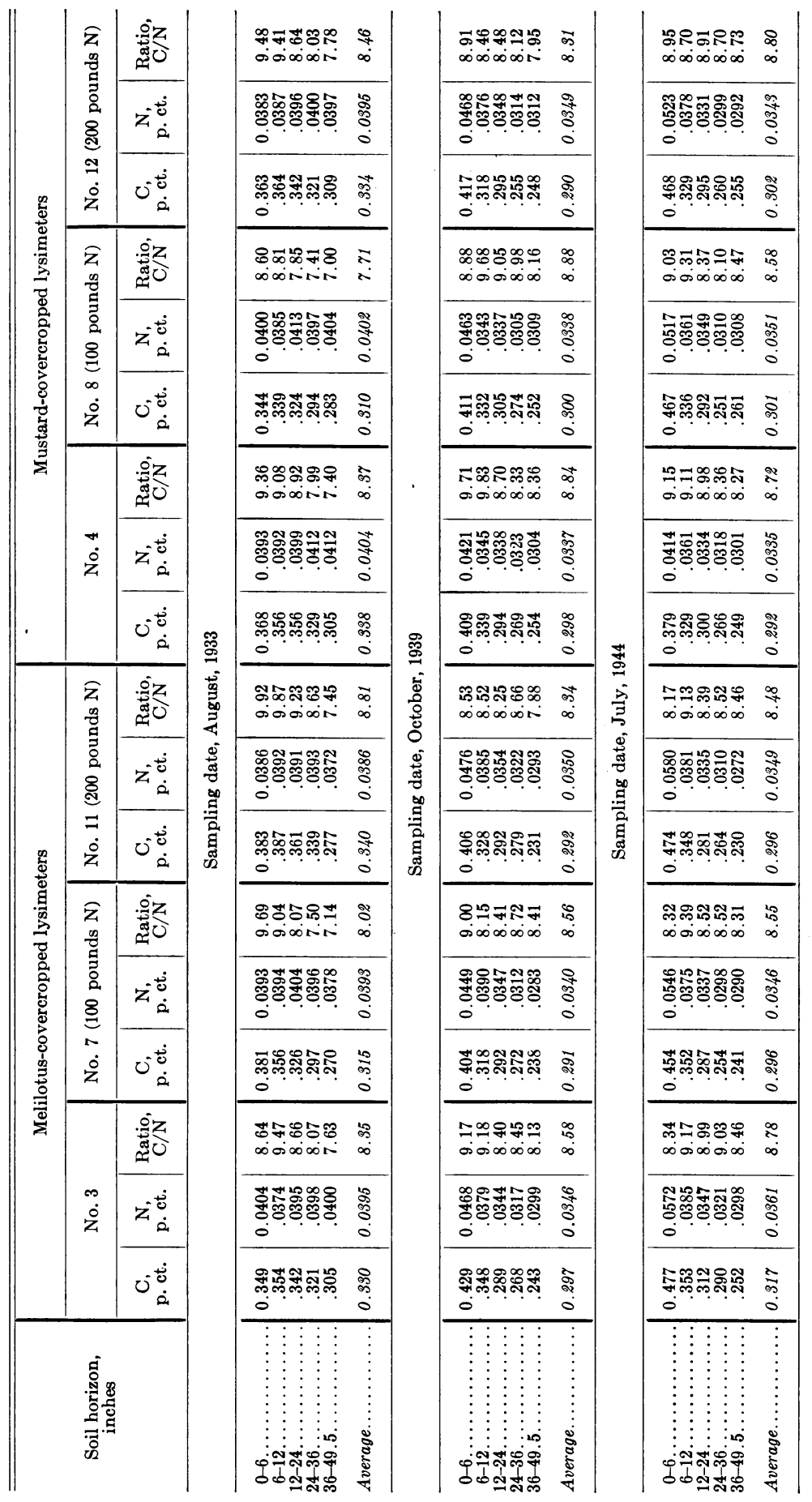


there was a net gain of 199 and 226 pounds of nitrogen in lysimeters 4 and 8 , and the average yearly yield was 990 and 4,238 pounds of dry matter. These results show that under low nitrogen levels and in the presence of crop residues a substantial amount of nitrogen is fixed nonsymbiotically. If, as seems likely, nitrogen is being simultaneously lost to the atmosphere, then the absolute magnitude of nonsymbiotic fixation may be higher than that indicated.

Nitrogen Losses Unaccounted for. It will be noted (table 14) that for the first period (1933-1939) all the cereal-straw and mustard lysimeters showed unaccounted-for losses of nitrogen. In the second period (1939-1944) only

TABLE 16

TOTAL AND NITRATE NITROGEN IN LYSIMETER SOILS, * 1933, 1939, AND 1944 (Pounds per acre)

\begin{tabular}{|c|c|c|c|c|c|c|}
\hline \multirow{2}{*}{$\begin{array}{l}\text { Lysimeter no. and } \\
\text { winter treatment }\end{array}$} & \multicolumn{2}{|c|}{1933} & \multicolumn{2}{|c|}{1939} & \multicolumn{2}{|c|}{1944} \\
\hline & $\begin{array}{c}\text { Total } \\
\text { nitrogen }\end{array}$ & $\begin{array}{l}\text { Nitrate } \\
\text { nitrogen }\end{array}$ & $\begin{array}{c}\text { Total } \\
\text { nitrogen }\end{array}$ & $\begin{array}{l}\text { Nitrate } \\
\text { nitrogen }\end{array}$ & $\underset{\text { nitrogen }}{\text { Total }}$ & $\begin{array}{c}\text { Nitrate } \\
\text { nitrogen }\end{array}$ \\
\hline 1. Straw.. & 6,965 & 747 & 5,724 & 87 & 5,745 & 80 \\
\hline 5. Straw plus 100 pounds $\mathrm{N}$. & 7,003 & 807 & 5,814 & 86 & 5,842 & 131 \\
\hline 9. Straw plus 200 pounds $\mathrm{N}$. & 7,088 & 821 & 5,907 & 196 & 5,714 & 180 \\
\hline 2. Vetch covercrop..... & 7,017 & 652 & 6,187 & 180 & 6,296 & 185 \\
\hline 6. Vetch plus 100 pounds N.. & 6,960 & 855 & 6,029 & 143 & 6,341 & 271 \\
\hline 10. Vetch plus 200 pounds $N$.. & 6,888 & 825 & 5,951 & 154 & 6,266 & 324 \\
\hline 3. Melilotus covercrop.... & 6,900 & 630 & 5,996 & 150 & 6,238 & 185 \\
\hline 7. Melilotus plus 100 pounds $\mathrm{N} \ldots$ & 6,851 & 753 & 5,900 & 147 & 5,985 & 197 \\
\hline 11. Melilotus plus 200 pounds N... & 6,735 & 610 & 6,062 & 193 & 6,025 & 205 \\
\hline 4. Mustard covercrop......... & 7.051 & 713 & 5,853 & 88 & 5,821 & 63 \\
\hline 8. Mustard plus 100 pounds $\mathrm{N}$. & 7,009 & 745 & 5,872 & 100 & 6,086 & 112 \\
\hline 12. Mustard plus 200 pounds $\mathrm{N}$. & 6,886 & 729 & 6,054 & 144 & 5,934 & 192 \\
\hline
\end{tabular}

* Composite soil samples, five horizons, 0 to 49.5 inches.

lysimeters 9 and 12 showed net losses. For the entire ten-year period, lysimeter 9 , receiving an annual application of straw (4,724 pounds per acre) and 200 pounds of nitrogen, showed a net unaccounted-for loss of 450 pounds of nitrogen, or an average of 45 pounds per acre per year. Lysimeter 12, in which a mustard covercrop was grown and the average annual amount of dry matter turned under was 5,023 pounds, and which, like no. 9, received 200 pounds of nitrogen per acre annually, showed a net loss of 523 pounds of nitrogen.

A question immediately arises : Are these losses real? That is, are they due to some chemical or biochemical reaction going on in the soil, which results in the liberation of gaseous nitrogen, or are they due to errors of one kind or another? This question is discussed in detail in Appendix A. Suffice it to say here that we regard these losses as real.

Nitrogen Balance. $A$ further interesting aspect of this experiment concerns the changes in nitrogen content of the soil under the various cropping and fertilizing systems. This can perhaps best be illustrated by the data of two tables, one (table 16) showing the total and nitrate nitrogen in lysimeter soils in 1933, 1939, and 1944, and the other (table 15) showing the changes, by soil horizons, in total nitrogen and in ratio of carbon to nitrogen. Between 
1933 and 1939 there was a large reduction in the total nitrogen of the soil. This is accounted for in large measure by the leaching out of the nitrate which had accumulated. In the second period much less change occurred. All but one of the legume lysimeters showed some gain of nitrogen. Some of the nonlegume lysimeters showed slight gains; others showed slight losses.

Changes in total nitrogen in the various soil horizons are shown in table 15. With the exception of lysimeter 4, in which the winter mustard crop is now (in 1948) a virtual failure, there was a clear-cut increase in the percentage of nitrogen in the first soil horizon ( 0 to 6 inches) of all the lysimeters. This increase was greatest in the legume lysimeters. However, there was no increase of nitrogen in the subsurface horizons. In the first five years there was a decrease of nitrogen in these lower horizons, which was largely the result of the nitrate leaching. In the second five-year period no significant trend in these deeper layers is apparent. If we discount the first five-year period, which from nearly every point of view was abnormal because of the heavy nitrate accumulations in the soils before the experiments began, and consider only the second five-year period, it is evident that, under those cropping systems in which a substantial amount of organic matter was turned back to the soil annually, the nitrogen content of the surface soil increased, the increase being greatest in the legume lysimeters. The tonnage of dry matter returned to the soils in the nonlegume lysimeters $5,9,8$, and 12 , and the rate of nitrogen fertilization, were as high in these as in the legume lysimeters, but despite this, the increase in total nitrogen was greatest in the legume treatments. The addition of nitrogen fertilizer to the legume lysimeters has not increased the total nitrogen of the soil, however.

The increases in soil nitrogen were accompanied, as was to be expected, by a corresponding increase in organic matter. A trend toward a lower carbon : nitrogen ratio is apparent in the legume lysimeters, as compared with the nonlegume lysimeters. 


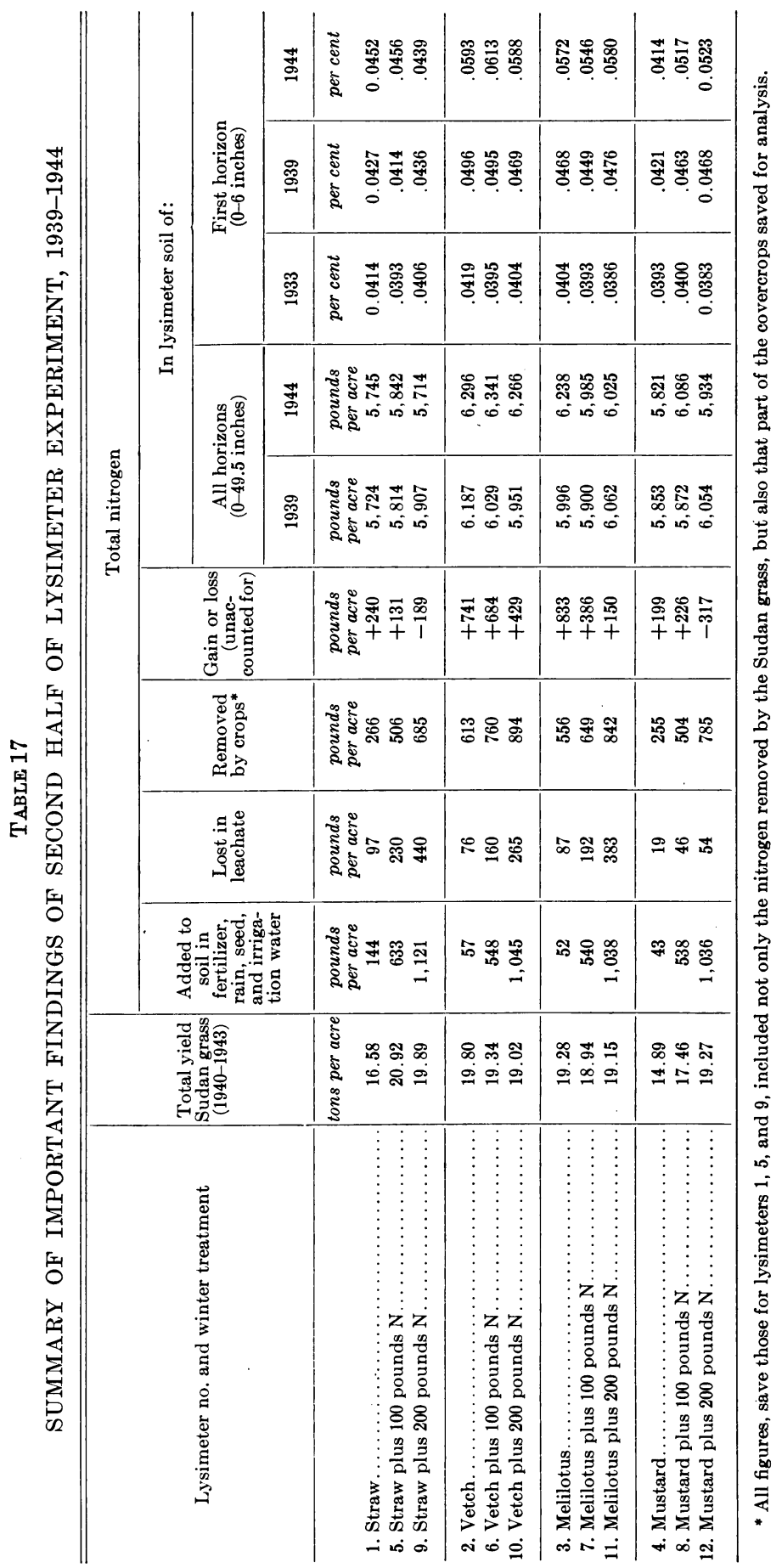




\section{DISCUSSION}

Because of the nitrate accumulations at the outset of this experiment (in 1933), the second "five-year" period (1939 to 1944) is the more representative of the two in indications of normal trends in nitrogen gains and losses in the variously treated lysimeter soils. The findings for this period are summarized in table 17.

It is apparent that, under the conditions of this experiment, no benefit was derived from adding nitrogen fertilizer to legumes. No increase in yield of harvested crops resulted from this practice, nor was there any increase in the permanent nitrogen percentage of the soil. Part of the added nitrogen was leached out of the soil, and part was removed by the harvested crop. But since not all of the added nitrogen can be accounted for by leaching loss, crop removal, or nitrogen remaining in the soil, it is evident that large unaccountedfor losses were sustained. For example (see table 17), 988 pounds more nitrogen per acre was added to lysimeter no. 10 than to no. 2. Leaching losses and crop removal of nitrogen were 470 pounds per acre greater in no. 10 than in no. 2. This leaves 518 pounds of nitrogen to be accounted for. In 1939 lysimeter no. 10 had 236 pounds less nitrogen per acre than no. 2, and in 1944, 30 pounds less ; hence a total of 206 pounds was added to the soil of no. 10, in comparison with that of no. 2 . If we subtract this amount from the 518 pounds unaccounted for by leaching and crop removal, a total of 312 pounds of nitrogen remains unaccounted for. In a comparison of lysimeters no. 11 and no. 3 (table 17), it will be noted that the former received 986 pounds more nitrogen per acre than the latter. Leaching losses and crop removal of nitrogen were 582 pounds per acre greater in no. 11 than in no. 3. This leaves 404 pounds of nitrogen to be accounted for. In 1939 lysimeter 11 had 66 pounds more nitrogen per acre than no. 3 , and in 1944,213 pounds less ; hence, a total of 279 pounds of nitrogen disappeared from the soil of no. 11, in comparison with that of no. 3 . If we add this amount to the 404 pounds unaccounted for by leaching and crop removal, a total of 683 pounds of nitrogen remains unaccounted for, as compared with 312 pounds for the comparable vetch treatments.

It is thus evident that the extra nitrogen added to the legume lysimeters was dissipated in (1) leachings, (2) luxury consumption by the harvested crop, and (3) unaccounted-for losses (probably gaseous volatilization).

In order to sustain good crop yields of mustard covercrop, it is clear that a high nitrogen level must be maintained. The addition of 200 pounds of nitrogen per acre annually to this covercrop was required to secure as good a yield as was obtained with the nonfertilized legume covercrops. Although leaching losses were especially low with mustard, soil nitrogen did not increase as much as with the legumes, and unaccounted-for loss of nitrogen was rather large.

With the straw treatment, yields of harvested crops were consistently depressed in those soils to which no additional nitrogen was applied, but with adequate nitrogen, yields were as good as with any treatment. However, from the point of view of nitrogen economy, the straw-plus-nitrogen treatments were not good. When sufficient nitrogen was added to maintain yields, leaching losses were high, and at the 200-pound fertilization rate unaccounted-for losses were substantial. 
The results of this experiment show that it is the interplay of a number of factors which determines yields, leaching losses, the trend of nitrogen in the soil, and over-all nitrogen economy.

It seems certain that, under the conditions of this experiment, chemical or biochemical reactions resulted in a loss of gaseous nitrogen to the atmosphere. There are no indications at present of the exact nature of this process. The data show losses ranging from 40 to 60 pounds of nitrogen per acre per year, where abundant nitrate and organic matter were present; in absolute magnitude the loss probably exceeded 100 pounds.

The net gain from nonsymbiotic fixation amounted to between 40 and 50 pounds of nitrogen per acre per year where the annual application of straw was close to 5,000 pounds, and where no nitrogen fertilizer was added. The net gain from legumes amounted to between 130 and 160 pounds of nitrogen per acre per year where no additional nitrogen fertilizer was added.

Leaching losses, as might be expected, were greatest where the level of nitrogen fertilization was high, and where no winter covercrop was grown. Under these conditions an average loss of nearly 90 pounds of nitrogen per acre per year was sustained.

On the basis of the above information it is evident that greatest nitrogen economy will be achieved where available nitrogen is maintained at the lowest possible point consistent with satisfactory crop yields. In this way, leaching losses will be at a minimum, gaseous losses will be reduced, and opportunity for nonsymbiotic and symbiotic fixation will be greatest. 


\section{SUMMARY}

A detailed account of the technique and results of the first ten years of a lysimeter investigation carried out under cropping, fertilization, and irrigation conditions common to this region is set forth herein. The amounts of nitrogen removed by cropping and leaching, and the amounts added in seed, rain, irrigation water, and fertilizer, together with analyses for total nitrogen and organic matter in the soil at the outset and at five-year intervals thereafter were recorded. The major findings to date are as follows :

1. Unaccounted-for losses of nitrogen occurred in the lysimeter covercropped to mustard and fertilized heavily with nitrate fertilizer. Similar losses were sustained by lysimeters receiving cereal straw in the fall together with nitrogen fertilizer. Better than 60 pounds of nitrogen per acre per year were unaccounted for in some cases, and the loss is thought to be due to gaseous volatilization. The absolute magnitude of loss may be considerably higher than this since more or less nitrogen fixation probably took place in these same lysimeters and only the net effect of these opposing processes was measurable under the conditions of this experiment.

2. The growth of purple vetch (Vicia atropurpurea) and sweet clover (Melilotus indica) as winter covercrops annually (turned under in spring) produced net gains of nitrogen amounting to approximately 150 pounds of nitrogen per acre per year. The absolute magnitude of nitrogen fixation by these crops probably exceeds this figure since more or less nitrogen was no doubt concurrently lost by gaseous volatilization. When nitrogen fertilizer was added to these legumes at rates of 100 and 200 pounds of nitrogen per acre per year, the net gains were progressively reduced, the sweet clover being more affected than the vetch. The average annual tonnage of the legume crop turned under amounted to 4,822 pounds per acre of dry matter for the vetch, and 4,148 pounds for the sweet clover.

3 . The incorporation of close to 5,000 pounds of dry cereal straw per acre annually in the fall without additional nitrogen produced during the second five-year period average net nitrogen gains (nonsymbiotic fixation) of 48 pounds of nitrogen per acre annually. The net gain during this same period where an annual winter mustard covercrop was grown without nitrogen fertilization was close to 40 pounds of nitrogen per acre per year. The average annual, per-acre tonnage of mustard turned under during this period was low (988 pounds) due to progressive nitrogen depletion of the soil.

4. Irrigation practice was such as to just meet the water requirements of the crops grown, and in general leaching through the 4-foot depth of soil occurred only in years when rainfall exceeded 10 inches annually. However, considerable nitrogen leached out in years of heavy rainfall or at times when rain fell immediately after an irrigation. Better than 99 per cent of the soluble nitrogen was in the nitrate form, and leaching losses were greatest in the noncovercropped lysimeters and in those receiving nitrogen fertilizer at the 200-pound rate. Average annual losses for the second five-year period of the experiment ranged from a low of 3.8 pounds nitrogen per acre per year in the nitrogen-deficient "nonfertilized, mustard-covercropped" lysimeter to 88 pounds in the "cereal straw, 200 pounds of nitrogen fertilizer" treatment. 
Leaching losses were much greater from the legume-covercropped lysimeters than the comparable mustard-covercropped lysimeters.

5. Although nitrogen fertilizer increased somewhat the yield of the legumes, no benefit carried through to the summer-harvested Sudan grass. Thus far, enough nitrogen continues to be fixed by the annual legume crops to meet the full needs of the annual harvested crop. The annual addition of nearly 5,000 pounds of cereal straw per acre (which carried about 22 pounds of nitrogen) plus rain and irrigation water (which added 7 pounds of nitrogen), and nonsymbiotic fixation (which amounted to 48 pounds) (total, 77 pounds of nitrogen) was insufficient to meet the nitrogen requirements of the Sudan grass. The nitrogen requirement for maximum yield of this crop is about 125 pounds of nitrogen per acre per year.

6 . While there was a substantial decrease of total nitrogen in the lysimeters during the first five years of the experiment, this appears to have been due entirely to the leaching out of accumulated nitrate. In the second five-year period, increases in the total nitrogen of the lysimeters occurred and the surface 6-inch horizon in nearly every treatment showed significant gains. Greatest increases were in the legume lysimeters. Organic carbon increased concurrently with total nitrogen.

7. It is evident that, under any given system of management, nitrogen economy is conditioned by the interplay of many factors. The results of this experiment highlight the wastefulness of high-level nitrogen fertilization. Under these conditions $(a)$ substantial amounts of nitrogen are likely to be lost by gaseous volatilization, $(b)$ leaching losses are likely to be high, $(c)$ fixation will be reduced, and $(d)$ luxury consumption of nitrogen by growing crops may occur without any ensuing benefit to yield or quality. Therefore, greatest nitrogen economy will be achieved where available nitrogen is maintained at the lowest possible point consistent with satisfactory crop performance.

A discussion of error sources is presented in Appendix A.

\section{ACKNOWLEDGMENTS}

Plans for a lysimeter study of nitrogen gains, losses, and balance under conditions of irrigation agriculture were formulated by W. P. Kelley in the early 1920's. Pursuant to this plan, a series of 24 lysimeters was installed at the University of California Citrus Experiment Station, Riverside, in June, 1926, by the late E. E. Thomas. The lysimeters were filled with soil at this time. In 1932, a set of cultural treatments was worked out by W. P. Kelley, E. E. Thomas, and the senior author, and in 1933 the experiment was started.

The authors of this paper are indebted to E. E. Thomas for his early work in connection with this investigation, and to W. P. Kelley for his many suggestions, his helpful advice, and sustained interest. The authors also wish to express their gratitude to L. D. Batchelor, Director of the University of California Citrus Experiment Station, who has at all times encouraged and supported this investigation. 


\section{LITERATURE CITED}

Allison, F. E.

1943. A critical analysis of the nitrogen recovery data from the Connecticut Lysimeter Experiment. U. S. Bur. Plant Indus., Soils, and Agr. Engin., Div. Soil and Fertilizer Investigations. Beltsville, Maryland. Special Report No. 5.

BABCOCK, WillaRd G.

1938. Seasonal nitrogen losses from the root zone. California Citrog. 23:298-300.

Bizzell, J. A.

1944. Lysimeter experiments VI. The effects of eropping and fertilization on the losses of nitrogen from the soil. New York (Cornell) Agr. Exp. Sta. Mem. 256:1-14.

Bracken, A. F., and J. E. Greaves.

1941. Losses of nitrogen and organic matter from dry-farm soils. Soil Sci. 51:1-15.

Burd, J. S., and J. C. MARTin.

1931. Secular and seasonal changes in soils. Hilgardia 5(15):455-509.

Collison, R. C., H. G. Beattie, and J. D. Harlan.

1933. Lysimeter investigations III. Mineral and water relations and final nitrogen balance in legume and nonlegume crop rotations for a period of 16 years. New York State Agr. Exp. Sta. Tech. Bul. 212:1-81.

Fred, Edwin Broun, Ira Lawrence Baldwin, and Elizabeth McCoy.

1932. Root nodule bacteria and leguminous plants. Univ. Wisconsin Studies in Seience No. 5, 343 p. Madison, Wisconsin.

HaLL, A. D.

1905. The book of the Rothamsted experiments. 294 p. (See pp. 139-40.) John Murray, Albemarle Street, Lopdon.

Hillebrand, W. F., and G. E. F. Lundell.

1929. Applied inorganic analysis; with special reference to the analysis of metals, minerals and rocks. xix +929 p. (See specifically pp. 142, 144.) John Wiley \& Sons, Inc., New York.

Hopkins, CYrIL G.

1910. Soil fertility and permanent agriculture. 653 p. Ginn and Company, Boston.

JENNY, HaNs.

1930. A study on the influence of climate upon the nitrogen and organic matter content of the soil. Missouri Agr. Exp. Sta. Res. Bul. 152:1-66.

JEWITT, T. N.

1942. Loss of ammonia from ammonium sulfate applied to alkaline soils. Soil Sci. $54: 401-9$.

Kohnke, Helmut, F. R. Dreibelbis, and J. M. Davidson.

1940. A survey and discussion of lysimeters and a bibliography on their construction and performance. U. S. Dept. Agr. Misc. Pub. 372:1-67.

Lipman, J. G., and A. W. BLAIR.

1921. Nitrogen losses under intensive cropping. Soil Sci. 12:1-19.

Lyon, T. L., and J. A. BizzelL.

1927. Nitrogen economy in Dunkirk silty clay loam. Proc. and Papers, First Internatl. Cong. Soil Sci. III: $619-27$.

1934. A comparison of several legumes with respect to nitrogen accretion. Jour. Amer. Soc. Agron. 26:651-56.

LYoN, T. L., and B. D. WILson.

1928. Some relations of green manures to the nitrogen of a soil. New York (Cornell) Agr. Exp. Sta. Mem. 115:1-29.

MoRGan, M. F.

1936. Soil changes resulting from nitrogenous fertilization. A lysimeter study. Connecticut (State) Agr. Exp. Sta. Bul. 384:367-449. 
Morgan, M. F., and O. E. Street.

1939. Seasonal water and nitrate leachings in relation to soil and source of fertilizer nitrogen. (A second report on Windsor lysimeter series "A.") Connecticut (State) Agr. Exp. Sta. Bul. 429:1-43.

Morgan, M. F., and H. G. M. JACOBSon.

1942. Soil and crop interrelations of various nitrogenous fertilizers. Windsor lysimeter series "B." Connecticut (State) Agr. Exp. Sta. Bul. 458:269-328.

Morgan, M. F., H. G. M. JACoBson, and S. B. LeCompte, JR.

1942. Drainage water losses from a sandy soil as affected by eropping and cover crops. Windsor lysimeter series C. Connecticut (State) Agr. Exp. Sta. Bul. 466:727-59.

Morgan, M. F., H. G. M. JACobson, and O. E. Street.

1942. The neutralization of acid-forming nitrogenous fertilizers in relation to nitrogen availability and soil bases. (A report of Windsor lysimeter series D.) Soil Sci. $54: 127-48$.

RUSSELL, EDWARD J.

1921. Soil conditions and plant growth. 4th ed. 406 p. Longmans, Green and Co., London, New York.

Schreiner, Oswald, and B. E. Brown.

1938. Soil nitrogen. In: Soils and men. U. S. Dept. Agr. Yearbook of Agr. 1938:361-76.

SMITH, H. V.

1944. A lysimeter study of the nitrogen balance in irrigated soils. Arizona Agr. Exp. Sta. Tech. Bul. 102:255-308.

VANDECAVEYe, S. C., and B. R. Villanueva.

1934. Microbial activities in soil: I. Nitrogen fixation by azotobacter and activity of various groups of microbes in Palouse silt loam. Soil Sci. $38: 191-205$.

VANSELOW, A. P.

1940. Preparation of Nessler's reagent. Ind. Eng. Chem., Anal. Ed. 12:516-17.

WILson, J. K.

1943. Nitrous acid and the loss of nitrogen. New York (Cornell) Agr. Exp. Sta. Mem. $253: 1-36$. 


\section{APPENDIX A: DISCUSSION OF ERROR SOURCES}

The unaccounted-for losses of nitrogen which came to light when the nitrogen balances were calculated (table 14) raise the question whether these represent losses due to some chemical or biochemical reaction going on in the soil, or due to errors.

TABLE 18

MAGNITUDE OF TOTAL NITROGEN ADDITIONS, REMOVALS, AND LOSSES IN TWO LYSIMETERS, 1933-1944

(Pounds per acre)

\begin{tabular}{|c|c|c|}
\hline Total nitrogen & $\begin{array}{l}\text { Lysimeter no. } 9 \\
\text { (Straw plus } \\
200 \text { pounds } N \text { ) }\end{array}$ & $\begin{array}{l}\text { Lysimeter no. } 12 \\
\text { (Mustard plus } \\
200 \text { pounds } N)\end{array}$ \\
\hline In lysimeter soil in $1933 \ldots \ldots \ldots \ldots \ldots$ & $7,088.2$ & $6,886.3$ \\
\hline \multicolumn{3}{|l|}{ Additions (1933-1944) in: } \\
\hline Rain $\ldots \ldots \ldots \ldots \ldots \ldots \ldots \ldots \ldots \ldots \ldots \ldots \ldots \ldots \ldots \ldots$ & 5.8 & 5.8 \\
\hline Irrigation water $\ldots \ldots \ldots \ldots \ldots \ldots \ldots \ldots$ & 70.8 & 110.7 \\
\hline 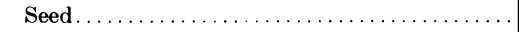 & 13.5 & 16.9 \\
\hline Fertilizer..... & $2,291.7$ & $2,004.8$ \\
\hline Total. ...... & $2,381.8$ & $2,138.2$ \\
\hline \multicolumn{3}{|l|}{ Removals (1933-1944) in: } \\
\hline Summer-harvested crops. . & $1,617.1$ & $1,962.7$ \\
\hline Winter covercrop samples. . & $\ldots \ldots$ & 7.1 \\
\hline Leachate............... & $1,689.4$ & 597.7 \\
\hline Total. . & $3,306.5$ & $2,567.5$ \\
\hline In lysimeter soil in 1944. & $5,714.0$ & $5,934.0$ \\
\hline Loss (1933-1944) unaccounted for. & -449.5 & -523.0 \\
\hline
\end{tabular}

Anticipating that this question might arise, we made various studies in the course of the experiment to determine the magnitude of soil- and plantsampling errors, as well as to check on other discrepancies. It is our purpose here to present these data and to discuss the problem of error in some detail.

It was with a certain amount of reluctance that this experiment was launched without provision for replication. However, the particular treatments chosen are replicative in nature and it was thought that with the exercise of due care more information would emerge from the 12 unreplicated treatments decided upon than from 6 duplicated or 4 triplicated treatments.

With regard to the management and conduct of the experiment, all operations such as harvesting of crops and measurement of amounts of irrigation water and leachings were executed with great care according to a predetermined plan. Techniques for the determination of nitrogen were carefully chosen and followed closely. The methods used to standardize solutions were constant throughout. With minor exceptions, all chemical determinations and calculations were made by the two senior authors. All cultural and soilsampling operations were carried out by the junior author. All calculations were double-checked so that another source of error might be eliminated. 
In an experiment of this kind there are certain types of error which cannot be evaluated easily, and for which data are lacking. For example, winds not only bring in a certain amount of soil but also take it away, and although we are certain that these processes of soil accumulation and erosion were of negligible consequence in this experiment, they are sources of error for which we have no measure. Insects have occasionally done minor damage to crops,

TABLE 19

ESTIMATE OF SAMPLING ERRORS IN DETERMINATION OF TOTAL NITROGEN CONTENT OF LYSIMETER SOILS

(Pounds per acre)

\begin{tabular}{|c|c|c|c|}
\hline Date & Method of determination & $\begin{array}{l}\text { Standard } \\
\text { error* }\end{array}$ & $\begin{array}{l}\text { Difference } \\
\text { required for } \\
5 \text { per cent } \\
\text { significance }\end{array}$ \\
\hline Aug., 1933 & Variability in soil samples of each of the 12 lysimeters $\dagger . . . \ldots$ & $\pm 98 \ddagger$ & 216 \\
\hline \multirow[t]{2}{*}{ Aug., 1933} & 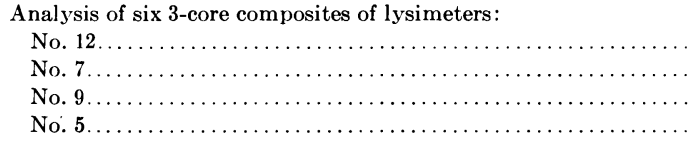 & $\begin{array}{r} \pm 56 \\
\pm 67 \\
\pm 86 \\
\pm 105\end{array}$ & \\
\hline & Average..... & \pm 78 & 200 \\
\hline \multirow[t]{2}{*}{ Oct., 1939} & 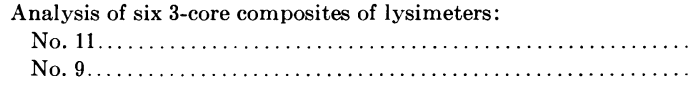 & $\begin{array}{l} \pm 15 \\
\pm 32\end{array}$ & \\
\hline & Average............ & \pm 23 & 62 \\
\hline \multirow[t]{2}{*}{ July, $1944^{\circ}$} & 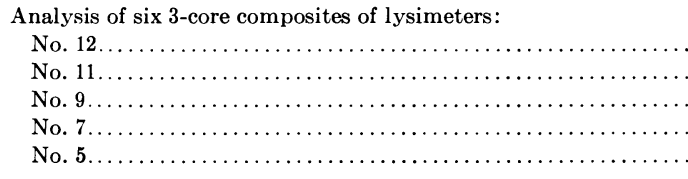 & $\begin{array}{l} \pm 38 \\
\pm 21 \\
\pm 53 \\
\pm 42 \\
\pm 31\end{array}$ & \\
\hline & Average... & \pm 37 & 95 \\
\hline
\end{tabular}

* Error of the mean of the six samples.

$t$ Assuming the $\mathrm{N}$ content in each lysimeter the same at the beginning of the experiment in 1933.

t Standard deviation.

rodents have now and then gotten into the dense and matted vetch covercrop and made their nests, and minor fungus infestations have at times affected the crops. We are inclined to regard these, also, as of minor importance, but no measures of the magnitudes involved are available or were attempted.

With regard to the more tangible items, reference is made to table 18 , which summarizes for lysimeters 9 and 12 the total nitrogen additions to and subtractions from the soil for the period 1933-1944. It is evident that the only likely errors of sufficient magnitude to account for discrepancies of 450 to 523 pounds of nitrogen over the entire period are the following: (1) errors in the determination of the total nitrogen content of the lysimeter soils, (2) errors in the measurement of the nitrogen added in fertilizer, (3) errors in the estimate of nitrogen removed by the crop, and (4) errors in the measurement of nitrogen leaching losses. 
The ordinary plus-and-minus errors common to all analytical procedures are self-canceling over a period of years. Moreover, any systematic error in the determination of the soil nitrogen would cancel out if the soils, from one sampling period to the next, were essentially unchanged in nitrogen content. Also, systematic errors in the same direction and of approximately the same magnitude, such as minus errors in the various determinations, would cancel to the extent that the nitrogen added was equal to the nitrogen removed. In short, small plus-and-minus analytical errors completely cancel each other in the course of time, and systematics errors are to some extent compensating.

Errors in the Determination of Total Nitrogen Content of Lysimeter Soils. The largest and most likely source of error is in the determination of the total nitrogen content of the soil. A summary of the various estimates is shown in table 19. If it is assumed that the soils in the 12 lysimeters were identical in composition at the beginning of this experiment (in 1933), it is possible to compute the error of a single determination - that is, the standard deviation of the figure for total nitrogen in any given lysimeter. This value is \pm 98 pounds of nitrogen, and a difference between two lysimeters of more than 216 pounds nitrogen, or a change of this amount in any given lysimeter from one sampling period to the next, would be significant at the 5 per cent level. That is, the odds would be 20 to 1 that a difference of 216 pounds (per acre) of nitrogen between lysimeters at the outset, or between successive samplings of any one lysimeter, is real and not just normal variability. Since some of the lysimeters leached during the early, fallow period (1926 to 1933), it is probable that the soil was not entirely uniform in all the lysimeters in 1933; hence this estimate of sampling error is doubtless high. The determination of sampling error based on the analysis of six 3-core composites taken from each of four lysimeters in 1933 gave error values for the nitrogen of each lysimeter (pounds-per-acre basis) ranging from \pm 56 to \pm 105 , or an average of \pm 78 pounds nitrogen. In 1939 and again in 1944 somewhat smaller errors were obtained by this same method. This is thought to be due to the fact that, the excess nitrate having been leached out, the soil horizons within the lysimeter were more homogeneous and thus led to more uniform nitrogen values on the six 3-core composites and hence to a smaller error. The soil-sampling error is therefore of such a magnitude that differences greater than 150 to 200 pounds of nitrogen per acre from one sampling period to the next are probably real.

Another possible source of error in determining the total nitrogen content of the lysimeter is in the estimate of the weight of the soil in the lysimeter. As indicated in table 1, soil weight was calculated from the volume-weight determinations of the horizons at 0 to 6 inches, 6 to 12 inches, 12 to 24 inches, 24 to 36 inches, and 36 to 48 inches of a sample of the original lysimeter soil placed in metal containers approximately 1 foot square and 5 feet high, especially constructed for the purpose. The soil columns were allowed to settle for four years and were watered enough to promote some leaching from time to time. The soil surface was kept fallow. The volume occupied by the soil in the lysimeter down to the gravel was calculated as 316.3 cubic feet, and the weight of soil computed from the aforementioned volume-weight determination was 31,459 pounds. If the weight of soil was actually 10 per cent higher than the figure of 31,459 pounds, then the unaccounted-for loss in lysimeter 
no. 9, for example, would turn out to be -587 , instead of -450 , pounds of nitrogen. If the weight of soil was 10 per cent less than calculated, then the unaccounted-for loss would be -313 rather than -450 pounds. Taking into consideration this possible error and that of sampling, we cannot completely rule out the possibility that errors in estimating the nitrogen content of the soil might account for discrepancies of the magnitude found. However, the consistency of the nitrogen-balance data for treatments of similar type (see table 14), and the "in-line-with-expectation" nature of the results, are evidence that the unaccounted-for losses are not the result of errors inherent in estimating the nitrogen of the soil from period to period.

TABLE 20

SAMPLING ERROR IN DETERMINATION OF NITROGEN

REMOVAL FROM SOIL OF LYSIMETER 12 BY

BARLEY CROP IN 1938

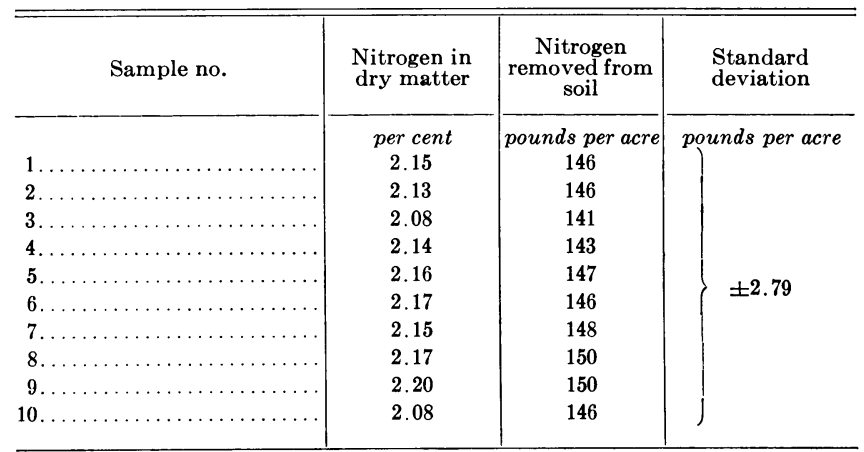

Errors in the Measurement of Nitrogen Added in Fertilizer. The analyses of the stock solutions of calcium nitrate were carefully made, as were measurements of the calculated volume, in order to supply the requisite amount to each lysimeter. Studies of the method used for determining the nitrogen content of the calcium nitrate solution gave recoveries of between 97.5 and 99.6 per cent. Though such an error would increase the unaccounted-for loss of nitrogen, it is insufficient of itself to account for the quantities involved.

Errors in Estimate of Crop Removal of Nitrogen from Soil. The ordinary plus-and-minus errors incident to sampling, handling, and determination of nitrogen content of crops would, as stated, cancel over a period of years. Two possible systematic errors, however, are : $(a)$ in the Kjeldahl determination of nitrogen; and $(b)$ in the possible loss of some nitrogen in the interval between the cutting of the green crop and the analysis.

Any systematic error in the Kjeldahl procedure would, in all probability, be operative in the total nitrogen determination of the soils as well. For example, taking lysimeter 12 , if by the $\mathrm{Kjeldahl}$ procedure there was failure to recover all the nitrogen in the soil by as much as 10 per cent, and if we assume this error to be the same in the nitrogen determination of the crop samples, then the net unaccounted-for loss would calculate -422 pounds of nitrogen instead of -523. It is highly improbable, therefore, that the unaccounted-for losses can be ascribed to any systematic error in the Kjeldahl procedure. 
To determine possible nitrogen losses from the crop material incident to drying and handling, a special experiment was carried out. A sample of the fresh covercrop was cut up into fine pieces. After mixing, 6 samples of the fresh material were weighed, and nitrogen was determined immediately; the rest of the green material was dried, ground, and analyzed in the usual manner. Expressed on a dry-weight basis, the average nitrogen content of the material analyzed green was 2.985 per cent, and that of the dried material, 2.982 per cent.

Still further evidence indicating that no nitrogen was lost from the plant material during the drying process is to be found in special studies of plantsampling error. As stated previously, a series of 10 plant samples was taken in each of a number of years in a manner comparable to that employed for the

TABLE 21

SUMMARY OF DATA ON DETERMINATION OF SAMPLING ERRORS

\begin{tabular}{|c|c|c|c|c|}
\hline \multirow[b]{2}{*}{ Year } & \multirow[b]{2}{*}{$\begin{array}{l}\text { Lysimeter no. and } \\
\text { crop sampled }\end{array}$} & \multirow{2}{*}{$\begin{array}{c}\text { Number } \\
\text { of } \\
\text { samples }\end{array}$} & \multicolumn{2}{|c|}{ Standard deviation } \\
\hline & & & Crop yield & $\begin{array}{l}\text { Nitrogen } \\
\text { removed from } \\
\text { lysimeter }\end{array}$ \\
\hline 1934 & No. 11 , barley.... & 10 & $\begin{array}{c}\text { pounds per acre } \\
\quad \pm 37.1\end{array}$ & $\begin{array}{c}\text { pounds per acre } \\
\pm 2.16\end{array}$ \\
\hline 1935 & No. 12, barley.... & 10 & \pm 125.7 & \pm 5.81 \\
\hline 1936 & No. 12, barley. . & 10 & \pm 207.2 & \pm 6.42 \\
\hline 1937 & No. 12 , barley... & 10 & \pm 129.8 & \pm 6.42 \\
\hline 1938 & No. 12 , barley... & 10 & \pm 91.4 & \pm 2.79 \\
\hline 1943 & No. 12 , Sudan grass.... & 10 & \pm 219.9 & \pm 4.10 \\
\hline
\end{tabular}

usual 1 sample. Nitrogen-removal data were calculated from the results on each sample. Table 20 shows the results obtained for barley in the year 1938, and table 21 contains a summary of standard deviation data for harvested summer crops in all the years in which sampling errors were determined. The low error involved and the consistency of the results imply that no loss of nitrogen occurred during the drying, storage, and grinding operations.

Errors in the Measurement of Nitrogen Leaching Losses. In these measurements there are three possible sources of error, namely: (a) failure to determine the total nitrogen in the leachate, $(b)$ errors inherent in the analytical methods used, and $(c)$ losses of nitrogen to the atmosphere during the storage of the leachate prior to analysis.

Separate determinations were made for nitrite, nitrate, ammonia, and organic nitrogen, and the sum of these was considered to represent total nitrogen. It seems rather unlikely that forms of combined nitrogen other than those indicated were present, or present in sufficient amount to account for the losses noted.

With regard to the accuracy of the methods used, the only one in which the error might be of some magnitude is that for nitrate. Where the nitrate of the leachate was high, the zinc-ferrous-sulfate method was used. $\Lambda$ s noted under the determination of nitrogen in calcium nitrate, recoveries of 97.5 to 99.6 per cent were obtained in tests of this method. Where nitrate was low, the phenol-disulfonic-acid method was used. It is improbable that the un- 
accounted-for losses of nitrogen are due to failure to recover all of the nitrogen by these particular methods. Ordinary plus-and-minus errors would, as stated, cancel over a period of years.

There remain the possible losses of nitrogen to the atmosphere in the interval between the emergence of the leachate from the lysimeter and the analysis. It will be recalled that the leachate was collected in asphalt-painted, galvanized-iron receptacles of 180 -liter capacity. When these were full, or when leaching had ceased, a 2 per cent sample of the volume of leachate was transferred to an 18-liter glass-stoppered bottle. Duplicate samples were taken, and at the end of the leaching season (usually in June) the samples were analyzed for nitrogen. Thus the original sample sometimes stood in the leaching receptacle for as long as a month before removal to the bottle, and in the bottle the composite sample sometimes stood for as long as 6 months before analysis.

A number of experiments were carried out to determine the changes in form of nitrogen and possible losses in standing. In one experiment a sample of fresh leachate from one of the lysimeters was analyzed for nitrite, nitrate, and ammonia nitrogen. Samples of this solution were then placed in covered, but not sealed, galvanized cans of about 1-gallon capacity. The interiors of these cans were not painted with asphalt. The leachate stood outdoors for approximately 5 months (from September 11, 1936, to February 24, 1937). Water lost by evaporation was added to restore the volume to the original amount prior to taking aliquots for analysis. The total nitrogen at the outset was 351 p.p.m., and at the end of 5 months it was 336 p.p.m., a difference of less than 5 per cent.

The results of a series of tests conducted in various ways to test the loss of nitrogen from leachate which had been stored in stoppered bottles showed in most cases no losses at all. In one experiment, however, composite samples of leachate contained in stoppered 18-liter glass bottles and allowed to stand at room temperature in the laboratory for 4 months gave the following results:

Leachate sample
from lysimeter
no.
1
9
11

\begin{tabular}{cc}
\multicolumn{2}{c}{ Total nitrogen } \\
$\begin{array}{c}\text { At beginning } \\
\text { of test, } \\
\text { p.p.m. }\end{array}$ & After \\
73 & months, \\
97 & p.p.m. \\
187 & 68 \\
& 91 \\
& 180
\end{tabular}

$\begin{gathered}\text { Loss, } \\ \text { per cent }\end{gathered}$
6.8
6.0
3.7

These results show slight nitrogen losses. Discrepancies of this magnitude are, however, insufficient to account for the greater losses noted over the ten-year experimental period.

Although the evidence presented is perhaps insufficient to prove conclusively that the unaccounted-for losses of nitrogen are real and not due to some combination of errors, the consistency of the data rules out all save some sort of systematic error, and here the most likely source is loss of nitrogen incident to the storage of the leachings prior to analysis. In this connection, reference to table 18 shows that the total unaccounted-for losses in two somewhat similarly treated lysimeters (nos. 9 and 12) are respectively -450 and -523 pounds of nitrogen for the ten-year period. It will be noted, however, that the total leaching loss of nitrogen in lysimeter 9 was 1,689 pounds, whereas that in lysimeter 
12 was 598 pounds. Now, if the unaccounted-for losses are due in reality to nitrogen losses from the leachings or to errors of nitrogen measurement in the leachings, then it is unlikely, indeed, that the results for these somewhat comparable treatments would be so nearly the same. A somewhat parallel case is that of lysimeters 5 and 8 , which showed unaccounted-for losses of -40 and -93 pounds of nitrogen, respectively, for the ten-year period, whereas the leaching losses were 1,088 and 459 pounds of nitrogen, respectively.

In the light of the foregoing evidence and considerations, the authors are confident that the unaccounted-for losses of soil nitrogen noted in table 14 are not the result of chance or systematic errors but are rather the result of loss of gaseous nitrogen to the air through some chemical or biochemical process.

\section{APPENDIX B: METHODS OF ANALYSIS USED IN LYSIMETER INVESTIGATION \\ TOTAL NITROGEN IN SOILS, SEEDS, AND PLANT MATERIAL \\ (Kjeldahl Method Modified to Include Nitrates)}

\section{Reagents :}

Sulfuric-salicylic acid: 1 gram salicylic acid to $30 \mathrm{ml}$ concentrated sulfuric acid.

Sodium thiosulfate : about 20-mesh dried powder.

Sulfate mixture : 10 parts potassium sulfate, one part ferrous sulfate, onehalf part copper sulfate; about 40 mesh.

Sodium hydroxide : 450 grams in 1 liter of water.

Mossy zinc : large pieces.

Boric acid solution : 2 per cent.

Standard sulfuric acid : approximately $0.1 N$.

Prepare constant-boiling hydrochloric acid according to directions given by Hillebrand and Lundell (1929). Standardize carbonate-free sodium hydroxide against the hydrochloric acid, using phenolphthalein indicator. Prepare approximately $0.1 N$ sulfuric acid and determine exact strength by titration with the freshly standardized sodium hydroxide, using phenolphthalein indicator.

Brom cresol green-methyl red indicator.

Prepare 0.1 per cent brom cresol green, adding $2 \mathrm{ml} 0.1 \mathrm{~N}$ sodium hydroxide per 0.1 gram of indicator; prepare 0.1 per cent methyl red in 95 per cent ethyl alcohol, adding $3 \mathrm{ml} 0.1 \mathrm{~N}$ sodium hydroxide per 0.1 gram. Mix $75 \mathrm{ml}$ brom eresol green indicator with $25 \mathrm{ml}$ methyl red indicator. Dilute to $200 \mathrm{ml}$ with ethyl alcohol.

\section{Procedure:}

Transfer weighed sample of dry material to an 800-ml Kjeldahl flask (10 grams of soil, 1 gram of plant tissue, and 0.5 gram of seed are sufficient amounts). Material should pass through a 20-mesh sieve.

Add $50 \mathrm{ml}$ of the sulfuric-salicylic acid mixture and swirl so as to bring the dry sample quickly into intimate contact with the reagent. Allow to stand overnight. Add 5 grams sodium thiosulfate and heat gently for about 5 minutes, taking care to avoid frothing. Cool, add 10 grams of the sulfate mixture, 
and digest in Kjeldahl apparatus at full heat. With soils, the digestion is continued 2 hours after the solution has cleared. With plant and seed material, the digestion is continued for 1 hour after the solution has cleared.

When digestion is complete, cool and add $300 \mathrm{ml}$ distilled water and 100 $\mathrm{ml}$ of concentrated sodium hydroxide. Add a large piece of mossy zinc and, with soils, two large teaspoons of glass beads ( $5 \mathrm{~mm}$ in diameter). Connect to distillation head, agitate, and distill off $150 \mathrm{ml}$ into $50 \mathrm{ml}$ of 2 per cent boric acid solution. Add 10 drops of the brom cresol green-methyl red indicator and titrate to the first faint pink with standard sulfuric acid. Blanks should be run and the titration carried to the same end point.

Moisture determinations are made on 4-gram samples of the soil and 2-gram samples of plant material by drying in an oven at $105^{\circ} \mathrm{C}$ for exactly 5 hours.

\section{Notes:}

1. The mixed indicator is green on the alkaline side and red on the acid side. The end point is gray to colorless.

2. Asbestos guards are unnecessary for the digestion flasks, provided the flame is not allowed to come in direct contact with the flask above the level of the acid mixture.

3. Rubber connections in the distillation apparatus should be adjusted so that as little rubber as possible is exposed. There is some ammonia contamination from this source.

4. Small differences in the amount of boric acid and in volume are without influence on the titration figure. Fifty milliliters of 2 per cent boric acid will combine with about $45 \mathrm{mg}$ of ammonia nitrogen. However, there is an increasing salt error in the titration end point with increasing amounts of ammonium sulfate; this is a minus error which amounts to less than 0.5 per cent with $15 \mathrm{mg}$ nitrogen.

5. Repeated determinations by this method on soil from the same bottle gave values ranging from 0.0502 to 0.0518 per cent total nitrogen. The probable error of the average to two determinations would be \pm 0.0002 per cent nitrogen. In terms of percentage error this would amount to \pm 0.39 . The difference between the highest and the lowest values was 3.1 per cent.

\section{NITRATE NITROGEN IN FERTILIZER AND LEACHINGS}

(Ferrous Sulfate-Zinc-Soda Method)

\section{Reagents :}

Granular zinc.

Ferrous sulfate : fine crystals.

Sodium hydroxide : specific gravity 1.33 ; 397 grams $\mathrm{NaOH}$ in 1 liter.

Standard sulfuric acid : approximately $0.1 \mathrm{~N}$.

Boric acid solution : 2 per cent.

Brom cresol green-methyl red indicator.

Prepare as described on page 101.

\section{Procedure:}

Transfer to an 800-ml Kjeldahl flask an amount of the solution or salt to be analyzed containing not more than $30 \mathrm{mg}$ nitrogen. Add 5 grams granular zine 
and 2 grams ferrous sulfate. Make to a volume of $300 \mathrm{ml}$ with distilled water. Then add $50 \mathrm{ml}$ sodium hydroxide (specific gravity 1.33) and attach immediately to distillation head, agitate flask gently, and light burner. Distill off $150 \mathrm{ml}$ into $50 \mathrm{ml}$ of 2 per cent boric acid solution. Titrate with standard sulfuric acid, using 10 drops brom cresol green-methyl red indicator. Run blanks and titrate to same end point.

\section{Notes:}

1. When the mixture in the Kjeldahl flasks reaches the boiling point, turn down the flame, as there is danger of foaming when the mixture first begins to boil.

2. Recovery of known amounts of nitrate by this method ranged from 97.5 to 99.6 per cent, with quantities between 5 and $50 \mathrm{mg}$ nitrogen.

\section{NITRATE NITROGEN IN SOILS, IRRIGATION WATER, RAIN, AND LEACHINGS}

\section{Reagents :}

(Phenoldisulfonic Acid Method)

Phenoldisulfonic acid.

Dissolve 25 grams pure white phenol in $150 \mathrm{ml}$ pure concentrated sulfuric acid. Add $75 \mathrm{ml}$ of fuming sulfuric acid ( 15 per cent $\mathrm{SO}_{3}$ ), stir well, and heat 2 hours at about $100^{\circ} \mathrm{C}$.

Ammonium hydroxide : 1 part concentrated ammonium hydroxide to 2 parts water.

Standard nitrate solution.

Dissolve 0.7216 gram pure potassium nitrate in 1 liter of water. This solution contains 100 p.p.m. of nitrogen as nitrate.

Copper sulfate solution : $1 N$.

Calcium hydroxide powder.

Magnesium carbonate powder.

Alumina cream.

Dissolve 30 grams potassium aluminum sulfate in 1 liter of water and filter. Pour slowly into $25 \mathrm{ml} \mathrm{NH}_{4} \mathrm{OH}$ diluted to $250 \mathrm{ml}$. Transfer to a 4-liter bottle and wash by decantation until free of sulfate. Dilute precipitate to 1 liter.

Silver sulfate : $0.02 \mathrm{~N}$.

Dissolve 3.12 grams in 1 liter of water.

\section{Procedure :}

For Soils. To 50 grams of soil in a bottle suitable for shaking, add $250 \mathrm{ml}$ of water containing $5 \mathrm{ml}$ of $1 \mathrm{~N}$ copper sulfate solution. Shake for 10 minutes. Add 0.4 gram of calcium hydroxide and 1 gram of magnesium carbonate, and shake for 5 minutes. Filter on a dry filter paper and discard the first $20 \mathrm{ml}$ of filtrate. Determine the chloride content ; if the amount present exceeds $0.1 \mathrm{mg}$ in the aliquot to be used, it should be removed by precipitation with silver sulfate (see below). Transfer 10- to 25-ml portions, the amount depending on the nitrate content, to an evaporating dish and evaporate to dryness on a steam or water bath. When the dish is cool, add $2 \mathrm{ml}$ of the phenoldisulfonic acid 
rapidly so as to cover the residue quickly. Let the reagent react 10 minutes, add $15 \mathrm{ml}$ water, stir with a glass rod, and add enough of the 1-2 ammonium hydroxide to make the solution alkaline. Compare with similarly prepared standards in Nessler tubes.

For Irrigation Water, Rain, and Leachings. Proceed as with soil extracts, making sure that the solutions are alkaline and that the chloride content does not exceed $0.1 \mathrm{mg}$ in the sample taken for analysis. If the chloride content is higher than this, chloride should be removed by precipitation with silver sulfate, using slightly less than required to precipitate the chloride. (Silver sulfate is often contaminated with nitrate. The latter may be removed by preparing a saturated solution of the salt in concentrated sulfuric acid. Boil to dispel the nitric acid. Cool, dilute with water, and filter off the silver sulfate crystals. Wash once or twice to remove excess acid.) Remove the excess silver chloride with alumina cream by adding $10 \mathrm{ml}$ of the latter; make to $100 \mathrm{ml}$, filter through a dry filter, and discard the first portion. Take $50 \mathrm{ml}$ for the nitrate determination.

\section{AMMONIA NITROGEN IN RAIN, IRRIGATION WATER, AND LEACHINGS}

\section{Reagents :}

(Nessler Method)

Nessler's Reagent.

Dissolve 45.5 grams mercuric iodide and 34.9 grams potassium iodide in as little water as needed. Add 112 grams potassium hydroxide $(140 \mathrm{ml}$ of an almost saturated solution, specific gravity $\left.\frac{15^{\circ}}{4^{\circ}}=1.538\right)$. Dilute to 1 liter. Allow to stand several days for any precipitate to settle. Use $5 \mathrm{ml}$ of the clear reagent to $100 \mathrm{ml}$ final volume of test solution. This is the method described by Vanselow (1940).

Sodium carbonate : 5 per cent solution.

Standard ammonium chloride solution.

Make a slightly acid ammonium chloride solution from redistilled hydrochloric acid and redistilled ammonia. Evaporate on a water bath and dry at $100^{\circ} \mathrm{C}$. Dissolve 3.819 grams ammonium chloride in ammoniafree water and dilute to 1 liter. This solution contains $1 \mathrm{mg}$ nitrogen per milliliter.

\section{Procedure:}

Place $500 \mathrm{ml}$ distilled water in an 800-ml Kjeldahl flask and add $10 \mathrm{ml} 5$ per cent sodium carbonate solution. Distill off $300 \mathrm{ml}$ to free solution and apparatus of ammonia. Then add $500 \mathrm{ml}$ or less of the water to be tested to the Kjeldahl flask, and distill at the rate of 6 to $10 \mathrm{ml}$ per minute in $50-\mathrm{ml}$ aliquots. Make to a volume of $95 \mathrm{ml}$ with ammonia-free water, add $5 \mathrm{ml}$ Nessler's reagent, allow to stand 30 minutes, and compare with standards (in Nessler tubes) made from ammonia-free water and known amounts of ammonium chloride solution. 


\section{Notes:}

1. The delivery tube need not be immersed in water as no ammonia comes over until the water condensate appears.

2. If the first $50 \mathrm{ml}$ of distillate contains too much ammonia, use a smaller aliquot of water for the determination. Dilution of the nesslerized solution should be avoided.

\section{NITRITE NITROGEN IN IRRIGATION WATER, RAIN, AND LEACHINGS}

\section{Reagents :}

(Sulfanilic Acid-Alpha Naphthylamine Method)

Sulfanilic acid.

Dissolve 8 grams sulfanilic acid in 1 liter of $5 N$ acetic acid. Heat gently to dissolve.

Alumina cream.

Prepare as directed on page 103.

Alpha naphthylamine.

Dissolve 5 grams of solid alpha naphthylamine in 1 liter of $5 \mathrm{~N}$ acetic acid. Heat gently and stir. Cool and place in a brown bottle. Good for 2 to 3 days.

Standard nitrite.

Dissolve 10 grams silver nitrate in $20 \mathrm{ml}$ hot water. Dissolve 10 grams sodium nitrite in $15 \mathrm{ml}$ water and heat. Mix both solutions while hot. Filter the precipitate of silver nitrite and wash with ice-cold water. Place between blotting papers, wrap in filter paper, and dry in a desiccator for a week. Keep in dark. Dissolve 0.55 gram of the silver nitrite in $50 \mathrm{ml}$ water by heating. In another beaker dissolve 0.3 gram sodium chloride in $25 \mathrm{~m}]$ water. Mix both solutions, stir, cool, and filter into a 500-ml volumetric flask. Wash precipitate thoroughly. Add $1 \mathrm{ml}$ chloroform, make to mark, and store in the dark. This solution contains 100 p.p.m. nitrogen as nitrite. Dilute as needed to make standards for nitrite determination.

\section{Procedure:}

Place $50 \mathrm{ml}$ of the solution to be tested, or less, in a 50-ml Nessler tube. (Decolorize solution if necessary with alumina cream.) Add $1 \mathrm{ml}$ sulfanilic acid and stir. Then add $1 \mathrm{ml}$ alpha naphthylamine and stir. Let stand $10 \mathrm{~min}$ utes before reading. Compare with similarly and simultaneously prepared standards.

\section{Notes:}

1. Dilute standards must be prepared fresh daily. However, a sodium nitrite standard containing 100 p.p.m. N stored in the dark did not perceptibly change after storage for one year.

2. Salts in amounts present in leachings from the lysimeters or in the irrigation water used in this experiment were not sufficient to influence results materially. 


\section{ORGANIC NITROGEN IN IRRIGATION WATER, RAIN, AND LEACHINGS}

\section{Reagents:}

(Kjeldahl Method)

Sulfuric acid : concentrated, nitrogen-free.

Granular pumice.

Ignite to destroy organic matter.

Sodium carbonate : 5 per cent solution.

Sodium hydroxide.

Dissolve 450 grams and make to 1 liter.

Nessler's Reagent.

Prepare as directed on page 104.

\section{Procedure:}

Transfer an amount of solution containing not over $0.2 \mathrm{mg} \mathrm{N}$ to an $800-\mathrm{ml}$ Kjeldahl flask. Add sufficient sodium carbonate solution to make alkaline. Add a few granules of pumice. Boil to rid solution of ammonia. Cool and carefully add $20 \mathrm{ml}$ concentrated sulfuric acid. Digest until copious fumes of sulfur dioxide appear and until solution is clear. Cool and add $300 \mathrm{ml}$ water. Make alkaline with sodium hydroxide solution. Distill and determine ammonia by nesslerization, as directed under determination of ammonia nitrogen. Run blanks.

\section{Reagents :}

\section{CARBONATE AND ORGANIC CARBON IN SOILS}

(Wet Combustion-Volumetric Method)

Sodium hydroxide : approximately $0.5 \mathrm{~N}$.

Hydrochloric acid : $0.5 N$, standardized.

Hydrochloric acid : approximately $1.0 \mathrm{~N}$.

Chromic acid : 40 per cent $\mathrm{CrO}_{3}$ in distilled water.

Sulfuric acid : concentrated.

Sulfuric acid : constant-boiling.

Boil concentrated $\mathrm{H}_{2} \mathrm{SO}_{4} 2$ hours in a Kjeldahl flask. After boiling, stopper with a connection to a soda-lime tube until cool. Store in glassstoppered bottle.

Carbon dioxide-free water.

Barium hydroxide : saturated solution.

Barium chloride : approximately $1 N$, neutral.

Phenolphthalein indicator : 1 per cent solution in ethyl alcohol.

\section{Apparatus :}

The apparatus for determination of earbonate and organic carbon in soil samples is illustrated schematically in figure 6 . $A$, wash bottle containing 50 per cent $\mathrm{NaOH}$ solution. $B$ and $C$, drying towers; $B$ contains granular pumice saturated with constant-boiling sulfuric acid; $C$ contains soda-lime, the lower layer being 4-mesh, the upper layer 12-mesh. The purpose of this purifying train is to remove $\mathrm{CO}_{2}$ and $\mathrm{NH}_{3}$ from the air drawn through the apparatus. $D$ is a trap on the delivery tube leading into flask $F$; this trap is a safety in 
case the reaction proceeds too rapidly in $F$ forcing reactants back into the delivery tube. $F$ is a $500-\mathrm{ml} \mathrm{Kjeldahl}$ flask with a jacketed neck through which water is circulated during a determination. $\boldsymbol{E}$ is a cylindrical separatory funnel through which a measured amount of sulfuric acid is added to the reagents and soil in flask $F$. $G$ is a West condenser on the lower end of which is sealed a glass tube containing a coarse-sintered-glass disk. This sintered-glass disk

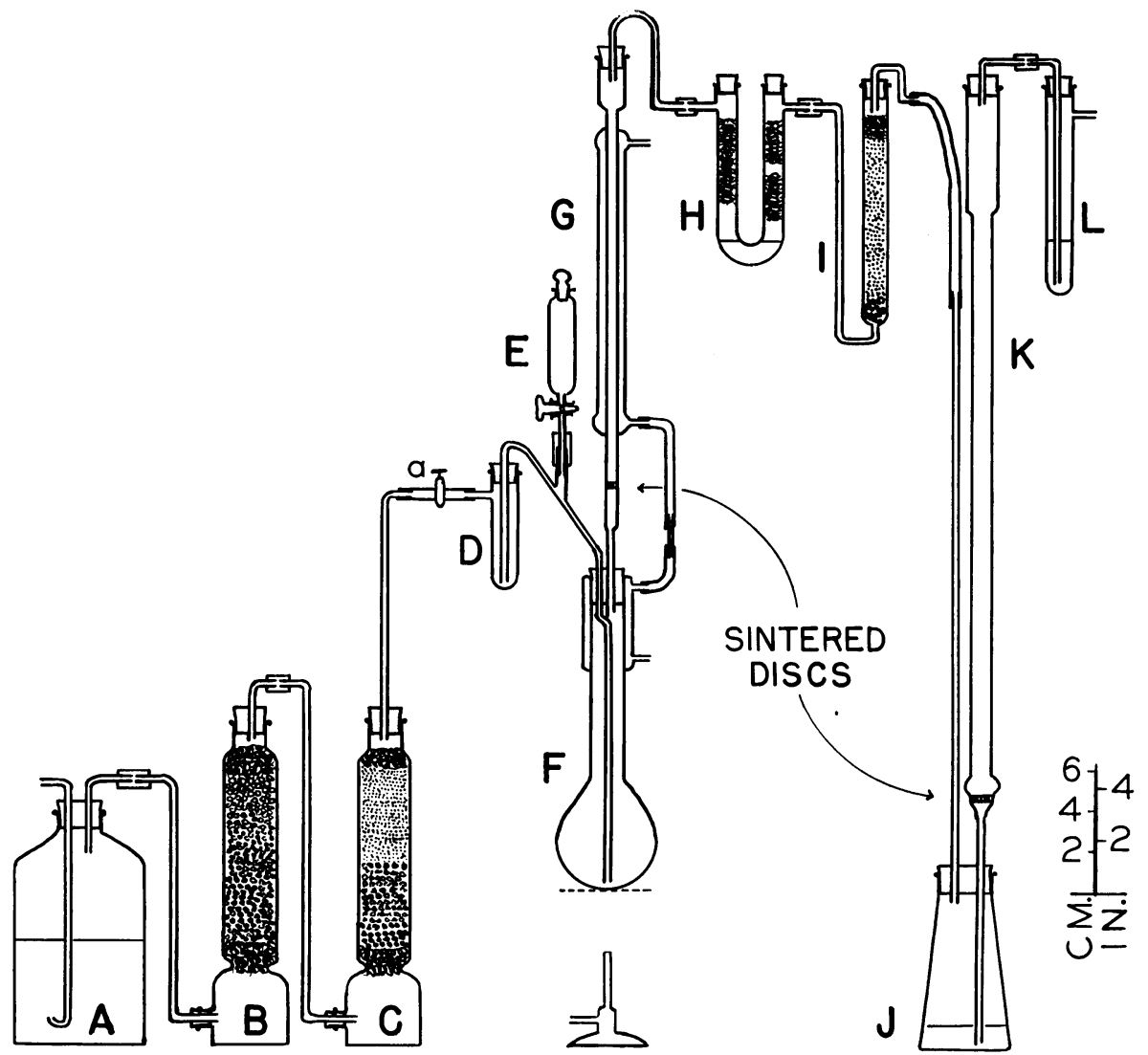

Fig. 6. Diagram of apparatus for determination of carbonate and organic carbon in soils. (For detailed description see text p. 106-8.)

has been found to be the most effective means of condensing the fumes of $\mathrm{SO}_{3}$ which are copiously emitted from the boiling reagents in flask $F$. The lower end of the tube from the condenser touches the delivery tube in flask $F$, thus allowing cold condensate to flow down the delivery tube and thereby preventing a violent reaction, which occurs when cold condensate falls directly on the boiling reagents. $H$ is a U-shaped drying tube with side arms; this tube is loosely packed with glass-wool plugs which are moistened with constant-boiling sulfuric acid; sufficient sulfuric acid is added to just seal off the lower end of the tube. This U-tube traps any moisture or vapor which passes through the condenser; replacement is made when necessary with a 
U-tube similarly prepared. $I$ is a tube filled with 30 -mesh granular zinc; the purpose of this tube is to remove acid vapors liberated from the reaction in flask $F . J$ is a $400-\mathrm{ml}$ Erlenmeyer flask with a calibration mark for a $175-\mathrm{ml}$ volume. $K$ is an absorption tower with a fine-sintered-glass disk located as shown in the diagram. In the operation of the apparatus the standard $\mathrm{NaOH}$ solution from flask $J$ is drawn up into tower $K$. The glass disk splits up the gas into fine bubbles, and thus facilitates the $\mathrm{CO}_{2}$ absorption by the $\mathrm{NaOH}$ solution. $L$ is a test tube with a side arm, containing a small amount of clear $\mathrm{Ba}(\mathrm{OH})_{2}$ solution; the side arm of this tube is connected to a source of vacuum for drawing gas through the apparatus. Any turbidity developing in the $\mathrm{Ba}(\mathrm{OH})_{2}$ solution indicates incomplete absorption of the $\mathrm{CO}_{2}$ in the gas passing through the $\mathrm{NaOH}$ absorption tower $(K)$. A straight drying tube filled with 12-mesh soda-lime, and fitted with a rubber stopper the same size as the opening on the top of absorption column $K$, is also prepared.

\section{Procedure:}

Determination of Carbonate Carbon. Carbon dioxide-free air is drawn through the apparatus (fig. 6) at a rate of about $3 \mathrm{ml}$ per second for $10 \mathrm{~min}$ utes. Flasks $F$ and $J$ are dried by a hot-air blast before the apparatus is assembled for a determination. The suction is then shut off, screw clamp $a$ is closed, and flask $F$ is disconnected from the apparatus. The soil sample is then transferred to the bottom of the flask through a paper-tube funnel. The flask is then reconnected to the apparatus. The operation of transferring the sample to the flask is done as rapidly as possible to minimize $\mathrm{CO}_{2}$ contamination from the air. Flask $J$ is then removed, $50 \mathrm{ml}$ of standard $\mathrm{NaOH}$ solution is added from a burette, and the flask and its contents are then quickly reconnected to the apparatus. Ten milliliters of clear barium hydroxide solution is added to tube $L$, screw clamp $a$ is opened, and suction is applied again.

Fifty milliliters of $N \mathrm{HCl}$ is placed in funnel $E$ and slowly added to the sample in flask $J$. Care is taken not to allow any air to be drawn through the funnel into the apparatus after the delivery of the acid. Air is drawn through the apparatus for 30 minutes at a rate of about $3 \mathrm{ml}$ per second.

The suction is turned off, screw clamp $a$ is closed, and a drying tube with soda-lime is inserted in the top of column $K$. The connection to the top of tube $I$ is removed, and if the solution in the column does not drain rapidly enough, gentle suction can be applied to the connection. The absorption tower is washed down with several successive 25 -ml portions of $\mathrm{CO}_{2}$-free distilled water. The Erlenmeyer flask $(J)$ is then disconnected, and the tip of the absorption tower is washed off into the flask by a jet of $\mathrm{CO}_{2}$-free water from a wash bottle ; $25 \mathrm{ml}$ of neutral $\mathrm{BaCl}_{2}$ is added to the contents of the Erlenmeyer flask, and the volume is made up to $175 \mathrm{ml}$, using $\mathrm{CO}_{2}$-free water. Three drops of phenolphthalein indicator are also added.

The titration of the $\mathrm{NaOH}$ solution in the Erlenmeyer flask $(J)$ is carried out in a $\mathrm{CO}_{2}-\mathrm{NH}_{3}$-free atmosphere. A two-hole rubber stopper containing a glass tube, the lower end of which is bent at right angles and is long enough to reach to the bottom of the flask, is inserted into the flask. Air passed through a sulfuric-acid-solution and a sodium-hydroxide-solution purifying train to remove $\mathrm{CO}_{2}$ and $\mathrm{NH}_{3}$, is bubbled through the solution which is being titrated 
at such a rate as to insure adequate stirring. Through the other hole in the stopper is inserted a small glass tube connected to the burette containing the standard $\mathrm{HCl}$. This glass tube is long enough to deliver the acid below the surface of the liquid.

The standard hydrochloric acid is added slowly in order to avoid any decomposition of the $\mathrm{BaCO}_{3}$ in the solution. The end point is indicated by the disappearance of the red color of the phenolphthalein. A blank determination is run on the apparatus and reagents, using exactly the same technique as outlined for the actual determination on the unknown sample.

It is unnecessary to standardize the $\mathrm{NaOH}$ solution, as the hydrochloric acid titration of the blank subtracted from the $\mathrm{HCl}$ titration of the unknown sample equals the hydrogen equivalent of the carbon contained in the sample.

Determination of Organic Carbon. The apparatus (fig. 6 ) is freed of $\mathrm{C}_{2}$, and the $\mathrm{NaOH}$ solution is added to the flask $(J)$ and the $\mathrm{Ba}(\mathrm{OH})_{2}$ solution to the tube $(L)$ as in the determination of carbonate carbon. ${ }^{7}$ The sample is transferred to flask $F, 10 \mathrm{ml}$ of 40 per cent $\mathrm{CrO}_{3}$ solution is pipetted in, the mixture is agitated slightly, and flask $F$ quickly reconnected to the apparatus. The upper opening of the water jacket of flask $F$ is connected to the lower openings of the West condenser $G$, and cold water is passed into the lower opening of flask $F$ and discharged from the upper opening of the condenser.

Fifty milliliters of concentrated $\mathrm{H}_{2} \mathrm{SO}_{4}$ is placed in funnel $E$, and purified air is sucked through the apparatus. Approximately $40 \mathrm{ml}$ of the concentrated $\mathrm{H}_{2} \mathrm{SO}_{4}$ is added slowly. The flask may need shaking occasionally if the lower end of the delivery tube becomes plugged with the sample. A wire gauze with asbestos center is slipped under the flask, and a moderate flame applied.

Care should be exercised during the initial heating period. If the reaction becomes too violent and the reactants begin to back up into the delivery tube, the flame should be removed until the reaction subsides. During this initial period, enough gas is evolved from the reactants to prevent any air from being drawn into the apparatus through the air-purifying train.

When the rapid evolution of gas ceases, air again passes into flask $F$, and at this time the remainder of the $\mathrm{H}_{2} \mathrm{SO}_{4}$ in funnel $E$ is admitted to the flask, care being taken to prevent any outside air from being drawn into the apparatus. This addition of sulfuric acid serves to wash down any of the sample that might have been forced up into the delivery tube.

The rate of heating is increased at this time until the reactants are boiling vigorously. The heating is continued for 20 minutes, and then the flame is extinguished and the wire gauze removed. The flask is allowed to cool for 5 minutes, the screw clamp $a$ is closed, and the suction is shut off.

The rest of the procedure is the same as for the determination of carbonate carbon. A blank must also be run on the reagents.

The percentage of organic carbon is calculated by subtracting the titration figure for the unknown from that of the blank, multiplying this by the carbon factor, and dividing by the percentage of dry matter in the sample. If the sample contains carbonate carbon, this must be corrected for.

\footnotetext{
${ }^{7}$ When the apparatus (fig. 6) is to be used for determining organic carbon, it is necessary to moisten the glass disk in condenser $G$ with a few drops of concentrated $\mathrm{H}_{2} \mathrm{SO}_{4}$ before the first run. A small amount of liquid is held by the glass disk; hence in subsequent runs no further moistening is necessary.
} 


\section{Notes:}

1. The apparatus (fig. 6 ) should be carefully checked for leaks.

2. Greater accuracy may be achieved by using less-concentrated alkali for the $\mathrm{CO}_{2}$ absorption, but the rate of aeration must then be reduced in order to insure complete absorption of the $\mathrm{CO}_{2}$.

3 . With the sintered-glass-disk absorption tower $(K)$, it is unsatisfactory to use $\mathrm{Ba}(\mathrm{OH})_{2}$ as an adsorption agent because the $\mathrm{BaCO}_{3}$ formed clogs the pores of the disk and prevents the easy return of the alkali to the Erlenmeyer flask $(J)$. The titration of a $\mathrm{Ba}(\mathrm{OH})_{2}-\mathrm{BaCO}_{3}$ solution with hydrochloric acid is more accurate than that of a $\mathrm{NaOH}-\mathrm{BaCO}_{3}$ solution. For more accurate results, a glass-bead tower is recommended, although this method is slower and the technique somewhat fussy.

4. The titration of the $\mathrm{NaOH}-\mathrm{BaCO}_{3}-\mathrm{BaCl}_{2}$ solution with hydrochloric acid is subject to various errors, the most important being the following:

(a) Errors due to decomposition of the $\mathrm{BaCO}_{3}$ by $\mathrm{HCl}$ and loss of $\mathrm{H}_{2} \mathrm{CO}_{3}$ from the system. Minus errors result where the equation used is : HCl titration of the sample minus $\mathrm{HCl}$ titration of blank equals $\mathrm{HCl}$ equivalent of $\mathrm{CO}_{2}$. The loss of free $\mathrm{H}_{2} \mathrm{CO}_{3}$ is obviously most likely to occur near the end point when the concentration of $\mathrm{NaOH}$ is low. This error can be measurably reduced by slowly discharging the standard $\mathrm{HCl}$ below the surface of the constantly agitated solution. It is commonly recommended that the $\mathrm{NaOH}-\mathrm{BaCO}_{3}-\mathrm{BaCl}_{2}$ solution be made to a standard volume, the $\mathrm{BaCO}_{3}$ being allowed to settle and an aliquot of the clear liquid taken for titration. Small but consistent plus errors from this method have been noted by the present authors, apparently as a result of the adsorption of small amounts of $\mathrm{NaOH}$ by the $\mathrm{BaCO}_{3}$. Other errors may result if $\mathrm{CO}_{2}$-free pipettes and titrating flasks are not used.

(b) Errors due to the incomplete precipitation of barium carbonate $\left(\mathrm{Na}_{2} \mathrm{CO}_{3}+\mathrm{BaCl}_{2}=\mathrm{BaCO}_{3}+2 \mathrm{NaCl}\right)$. The rapidity of precipitation is governed in part by the ratio $\frac{\mathrm{BaCl}_{2}}{\mathrm{Na}_{2} \mathrm{CO}_{2}}$, a high ratio obviously favoring a more rapid precipitation; the rate will also depend upon the absolute amount of $\mathrm{Na}_{2} \mathrm{CO}_{3}$ present, higher concentrations of $\mathrm{Na}_{2} \mathrm{CO}_{3}$ leading to a more rapid precipitation. In practice it has been found that for amounts of carbon varying from 8 to $90 \mathrm{mg}, 25$ cc of $1 \mathrm{~N} \mathrm{BaCl}_{2}$ in a total volume of $175 \mathrm{ml}$ provides sufficient excess so that titration can be started at once. Errors from this source are minus, using the aforementioned equation.

(c) Errors due to an indefinite or fading end point result from the hydrolysis of $\mathrm{BaCO}_{3}$. These errors may be greatly reduced by having a good excess of $\mathrm{BaCl}_{2}$. The above quantities are sufficient to give a sharp end point when not more than $90 \mathrm{mgm}$ of carbon are present as $\mathrm{Na}_{2} \mathrm{CO}_{3}$.

5 . By carefully following a standardized technique, it has been found possible to secure results accurate to \pm 3.0 per cent, with amounts of carbon varying between 8 and $90 \mathrm{mg}$. 


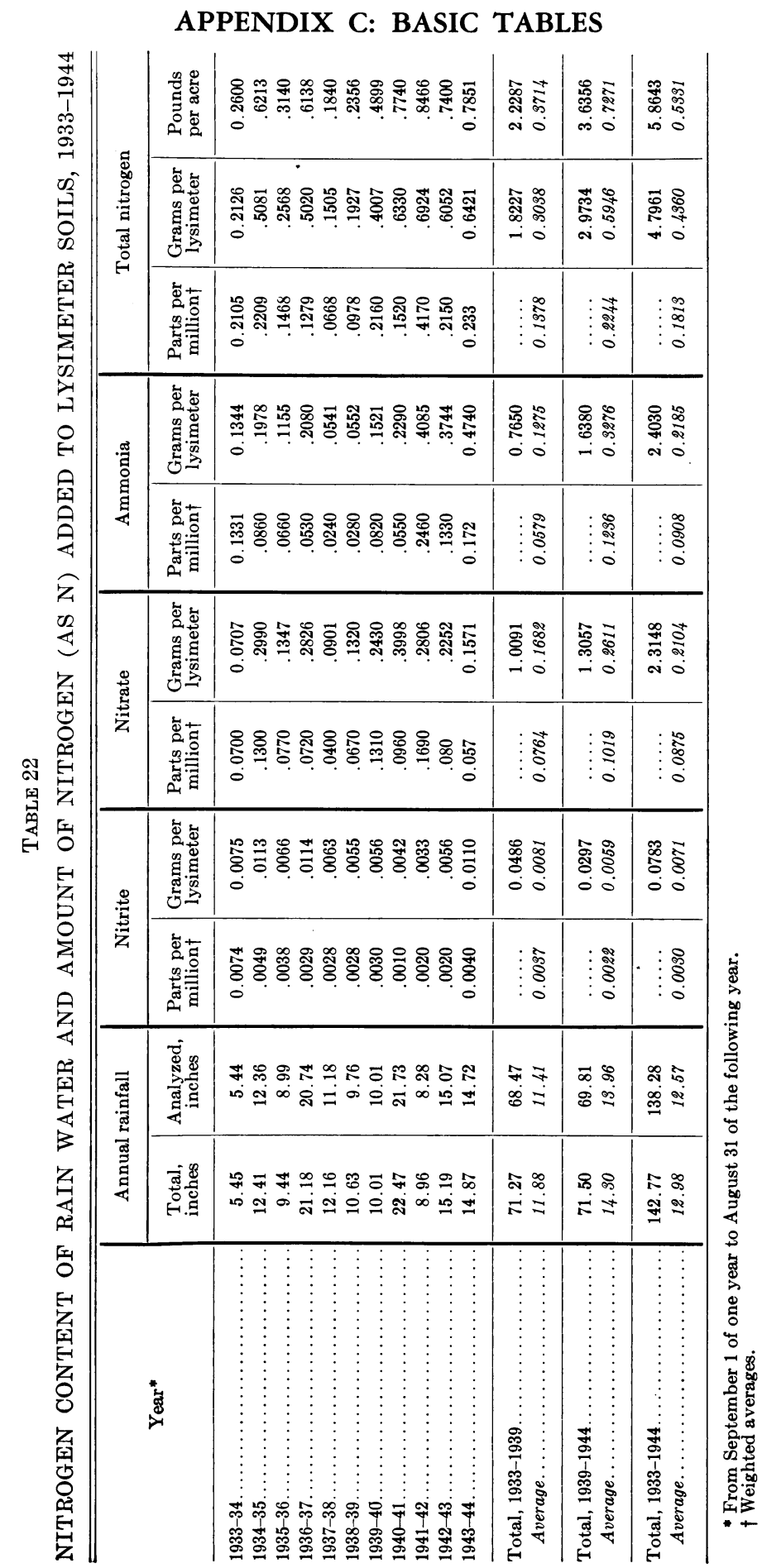




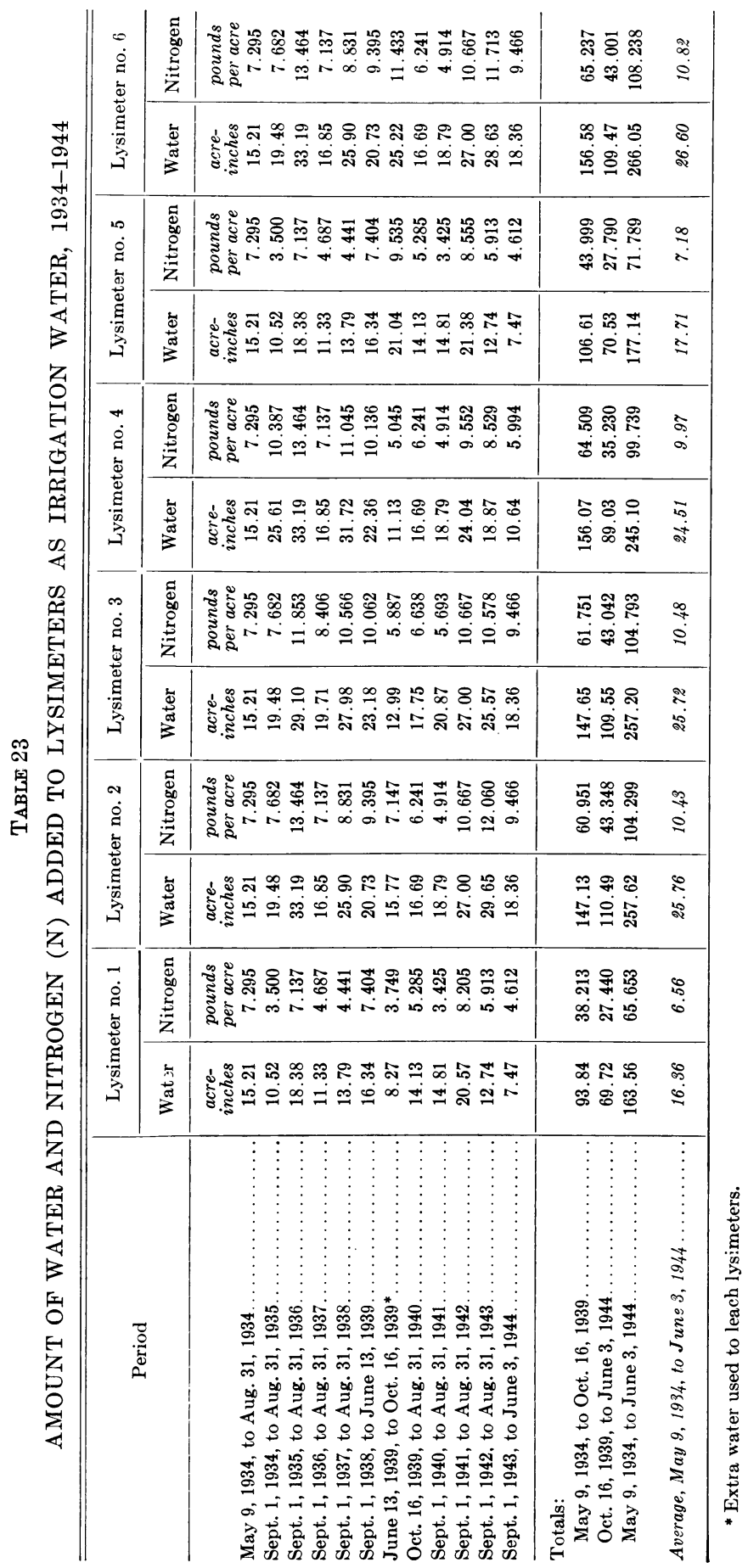




\begin{tabular}{|c|c|c|c|c|}
\hline \multirow{2}{*}{ 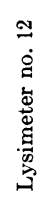 } & 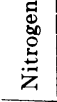 & 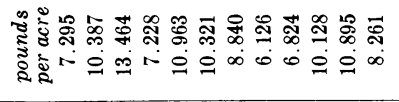 & 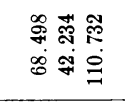 & $\begin{array}{l}\text { ò } \\
\text { a }\end{array}$ \\
\hline & 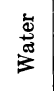 & 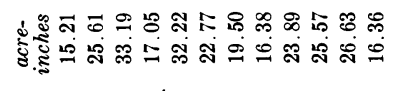 & 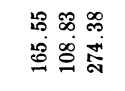 & 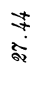 \\
\hline \multirow{2}{*}{ 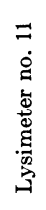 } & 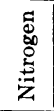 & 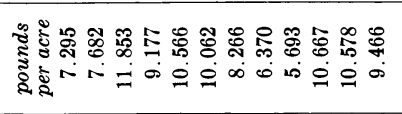 & 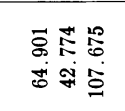 & $\begin{array}{l}\hat{2} \\
\stackrel{2}{9}\end{array}$ \\
\hline & 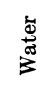 & 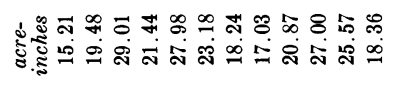 & 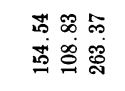 & $\begin{array}{l}\text { के } \\
\text { के } \\
\text { के }\end{array}$ \\
\hline \multirow{2}{*}{ 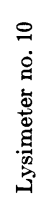 } & 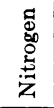 & 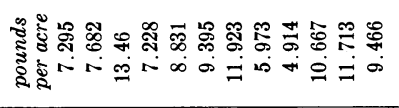 & 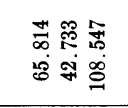 & $\begin{array}{l}\infty \\
\stackrel{\infty}{\circ} \\
\stackrel{0}{0}\end{array}$ \\
\hline & 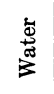 & 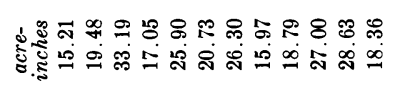 & 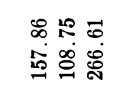 & $\begin{array}{l}: \\
\vdots \\
8\end{array}$ \\
\hline \multirow{2}{*}{ 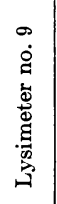 } & 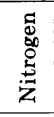 & 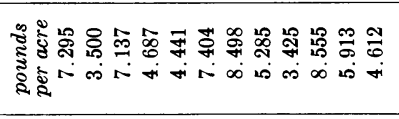 & 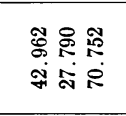 & فे \\
\hline & $\frac{\grave{\Phi}}{\Phi^{a}}$ & 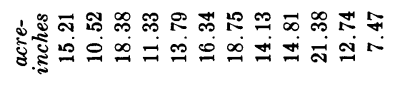 & 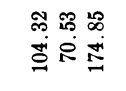 & $\stackrel{\infty}{\stackrel{\infty}{+}}$ \\
\hline \multirow{2}{*}{ 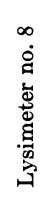 } & 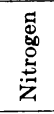 & 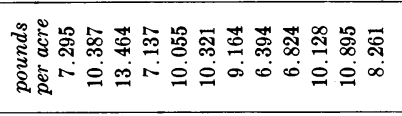 & 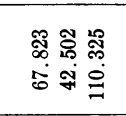 & $\stackrel{\infty}{\stackrel{\infty}{+}}$ \\
\hline & 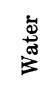 & 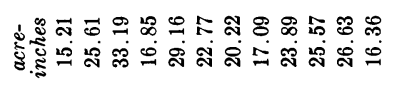 & 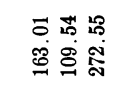 & 这 \\
\hline \multirow{2}{*}{ 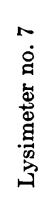 } & 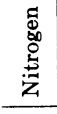 & 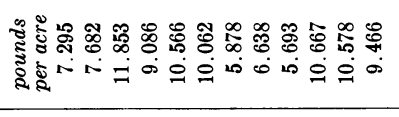 & 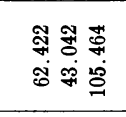 & $\begin{array}{l}\stackrel{8}{8} \\
\stackrel{8}{9}\end{array}$ \\
\hline & 点 & 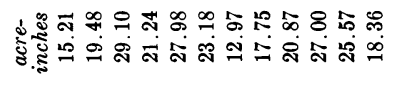 & 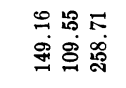 & $\begin{array}{l}\text { के } \\
\text { \&. } \\
\vdots\end{array}$ \\
\hline \multicolumn{2}{|c|}{ : } & 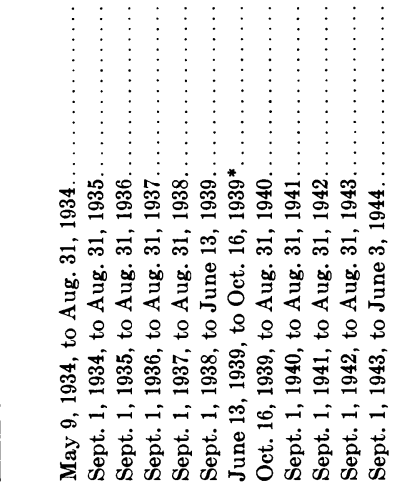 & 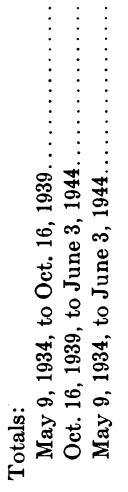 & 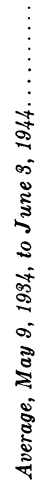 \\
\hline
\end{tabular}




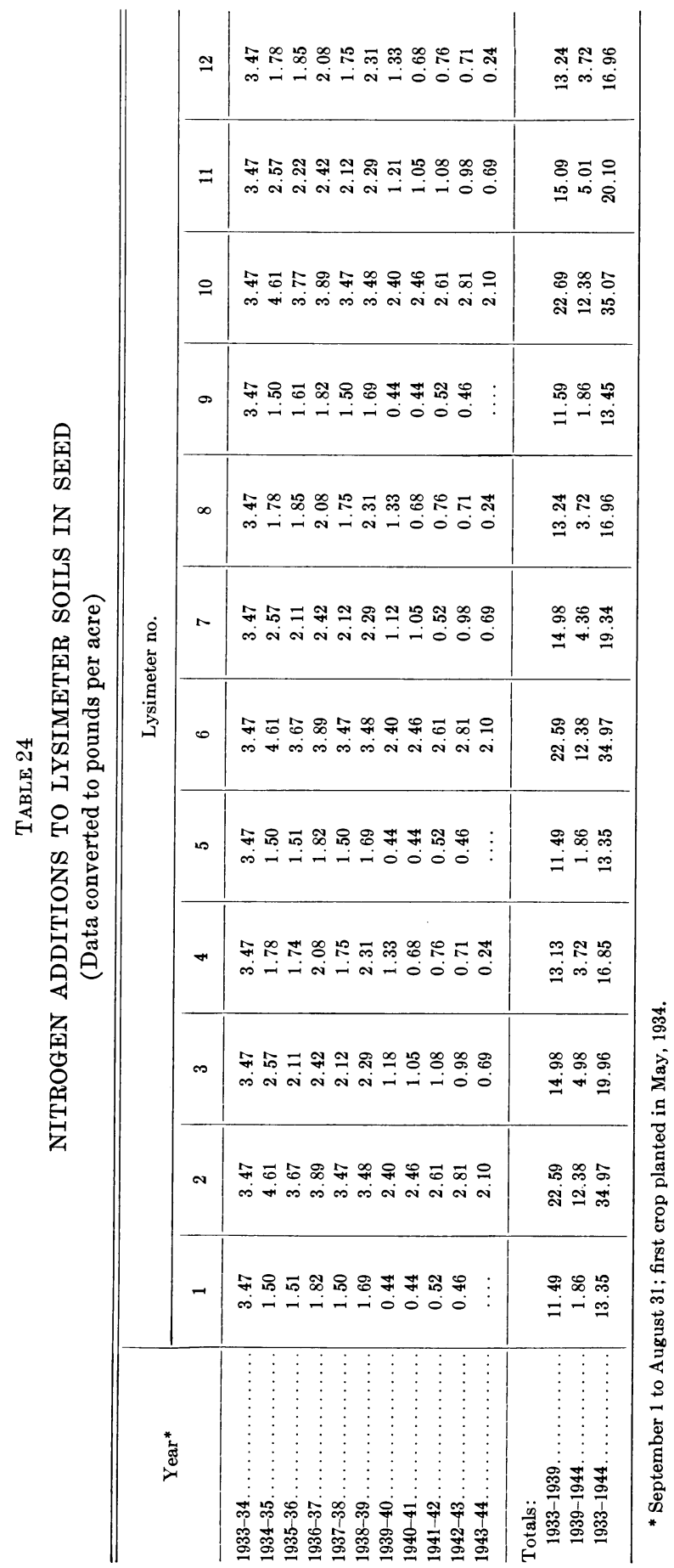




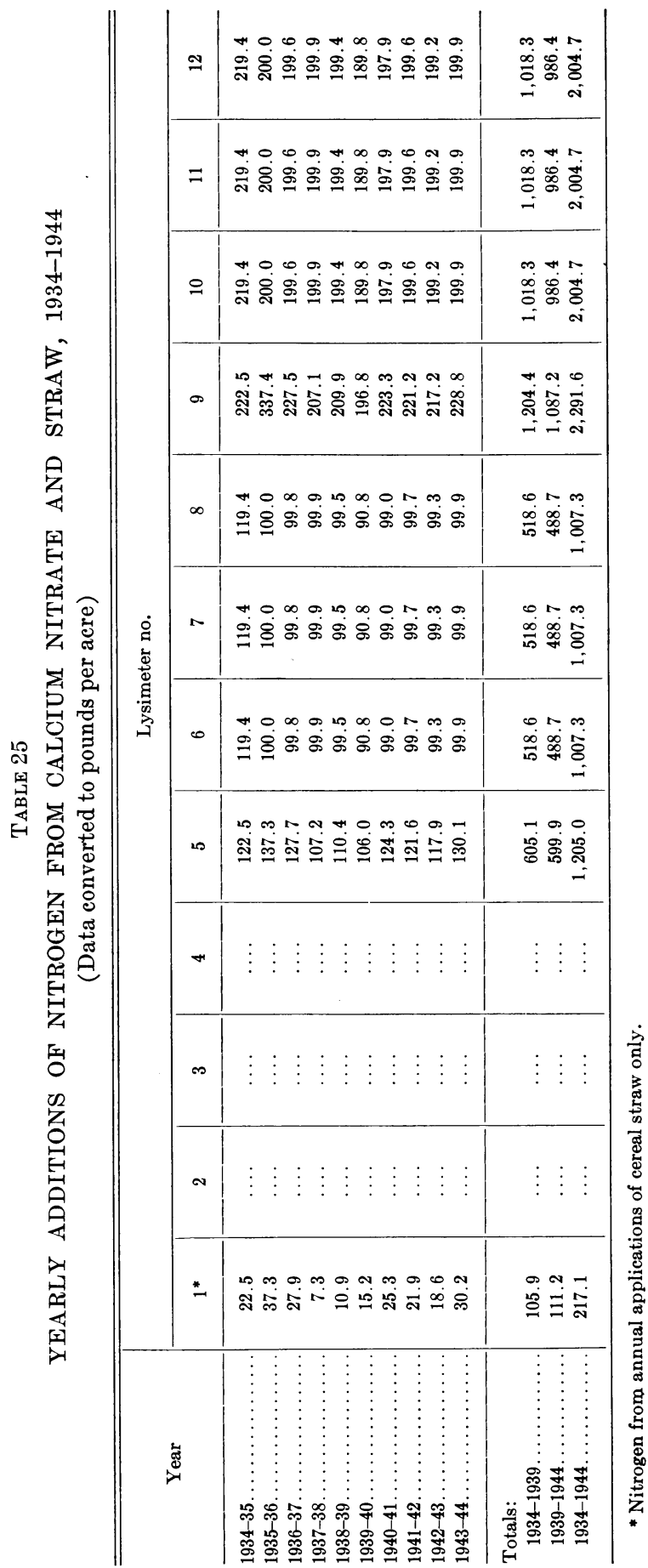




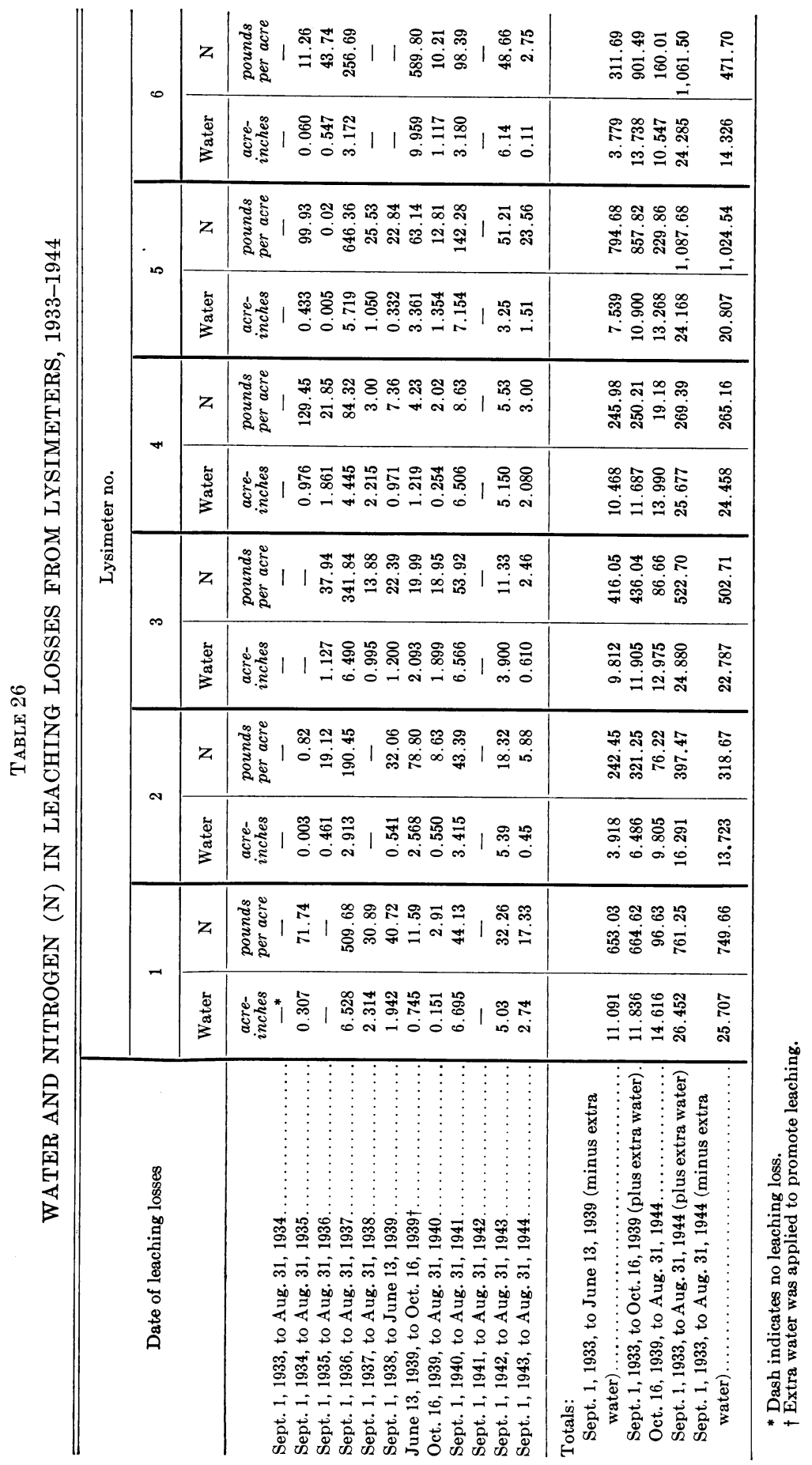




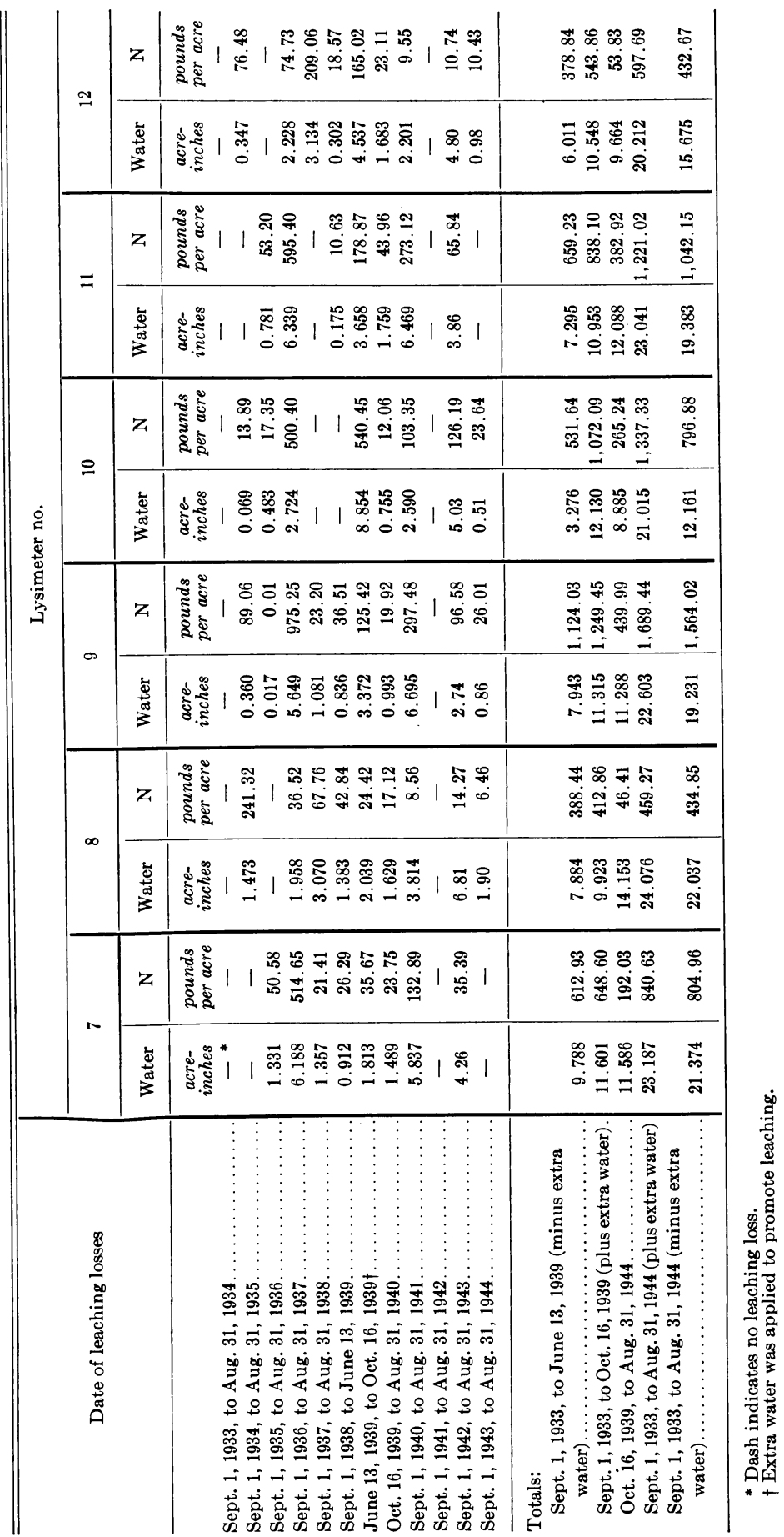




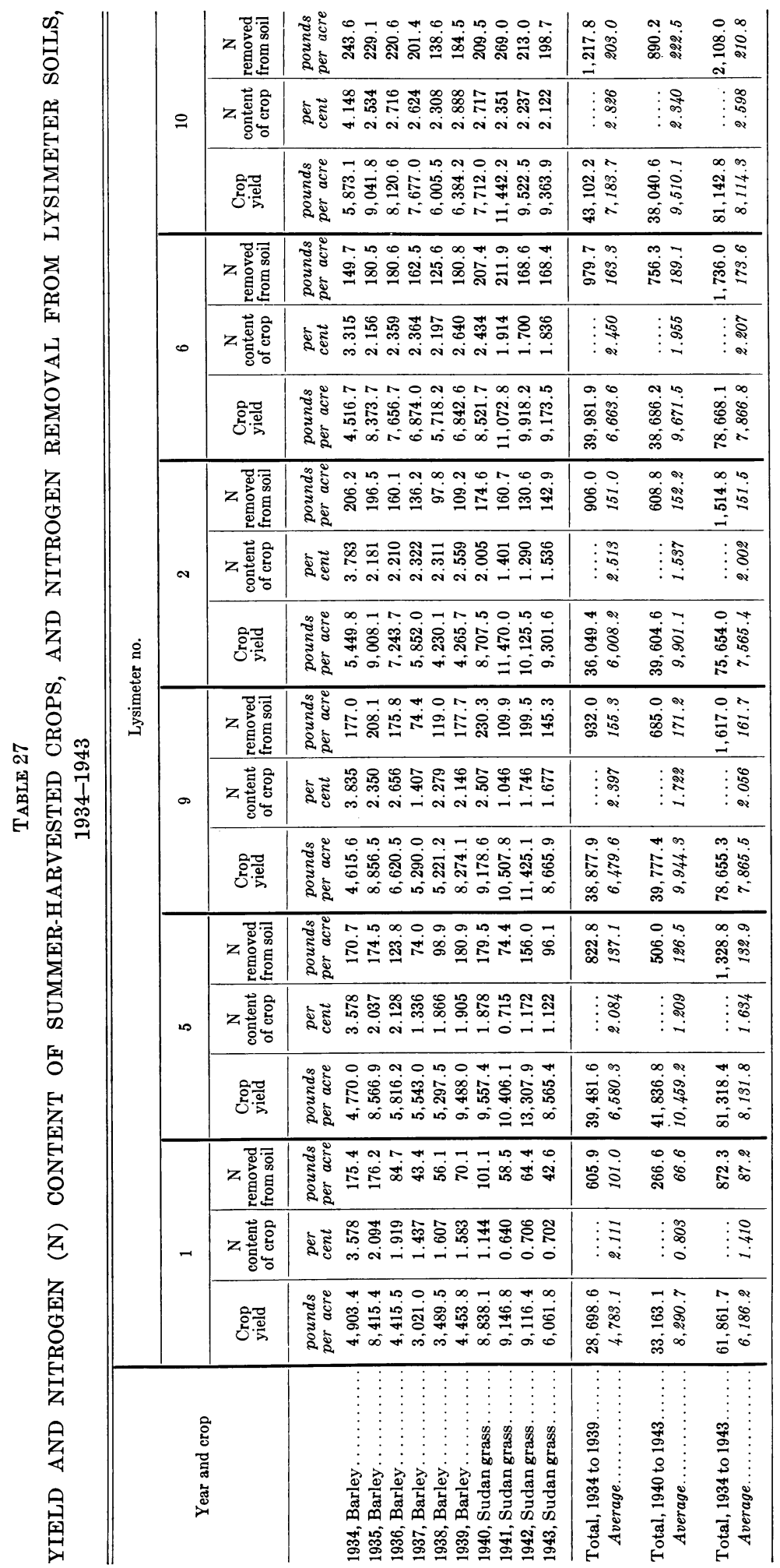




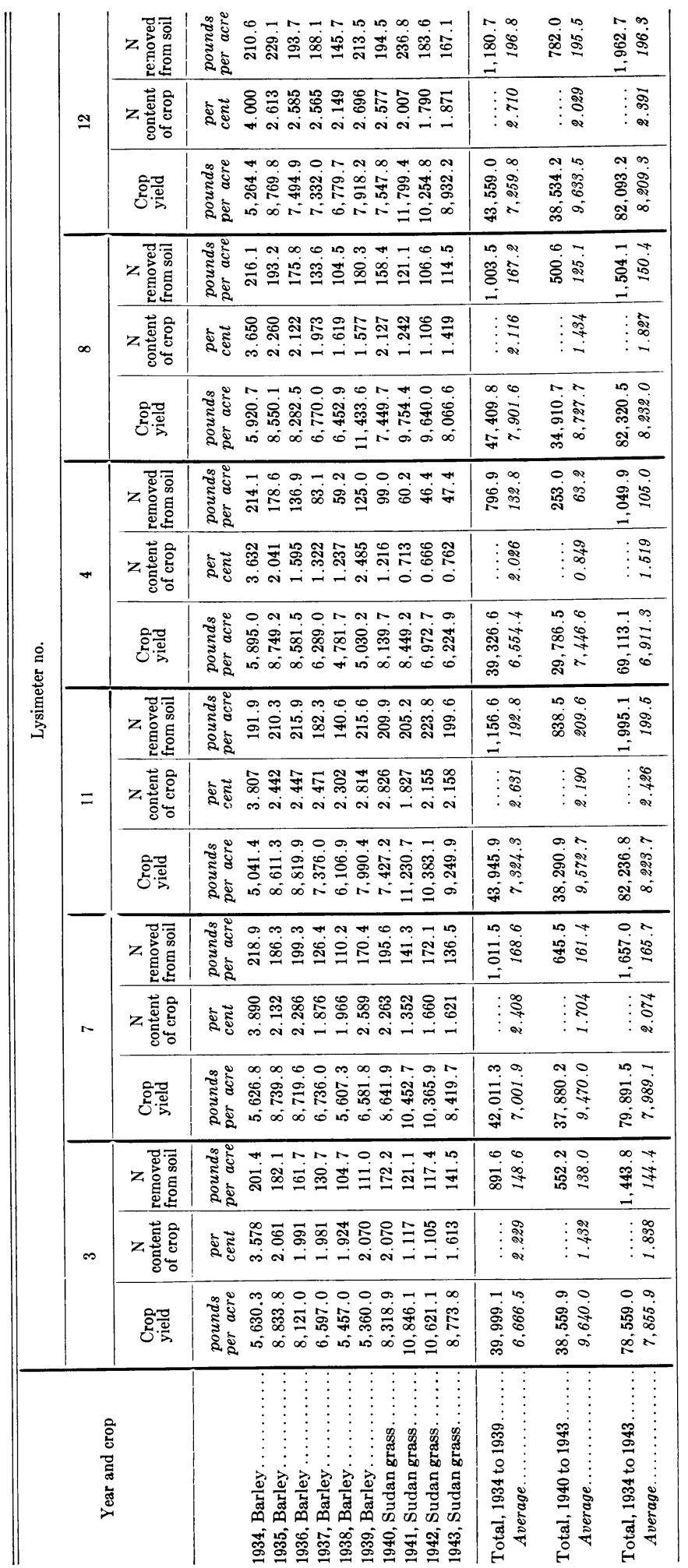




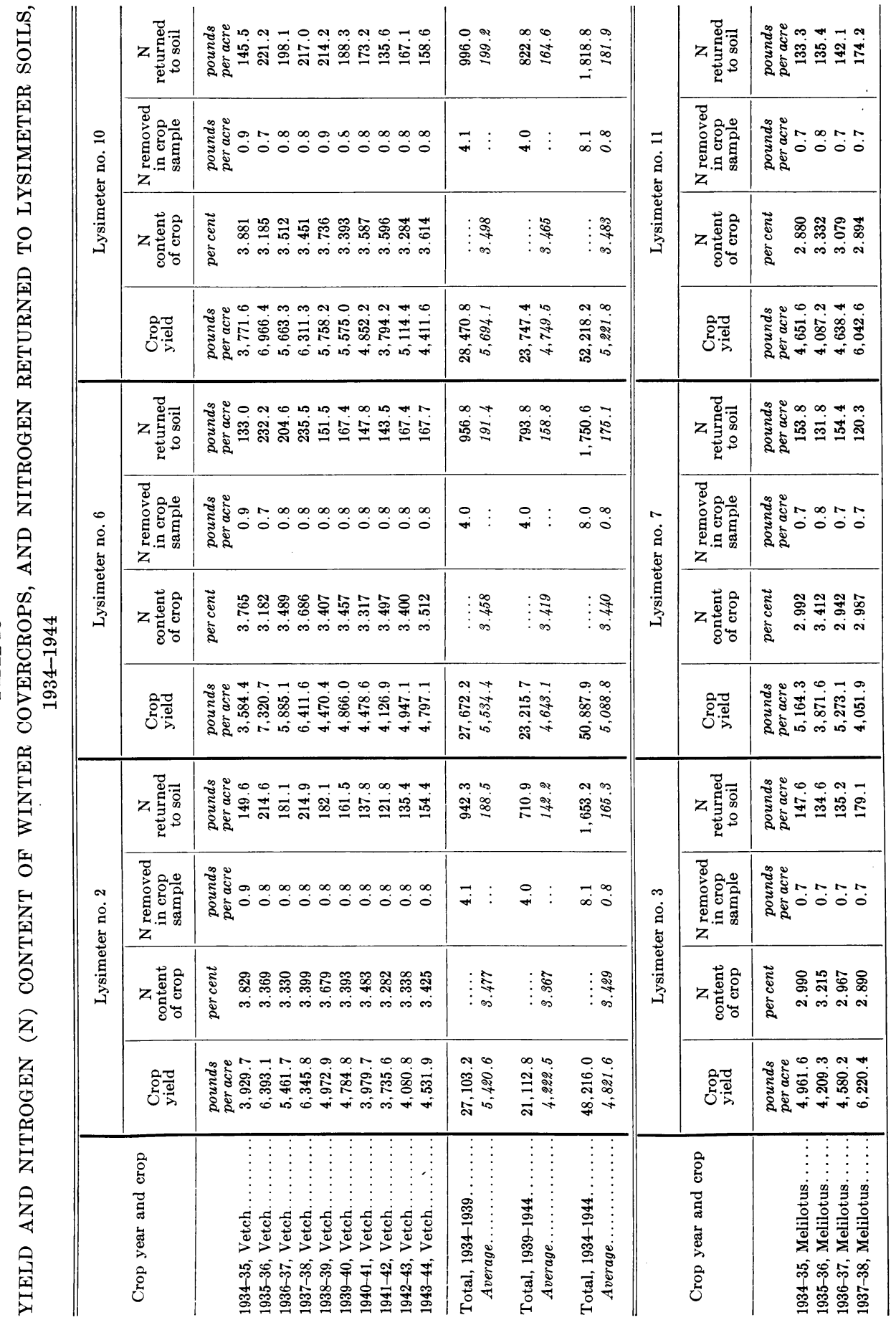




\begin{tabular}{|c|c|c|c|c|c|c|c|c|c|}
\hline 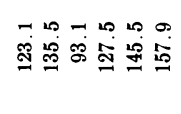 & 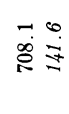 & 憵要 & 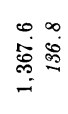 & \multirow{4}{*}{ 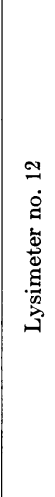 } & 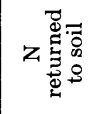 & 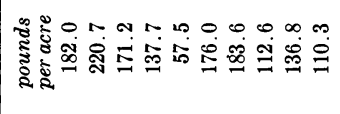 & 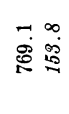 & 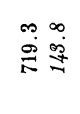 & 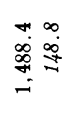 \\
\hline 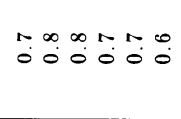 & $\ddot{\dot{\infty}}$ & $\ddot{\infty}: \because$ & $\stackrel{2}{1} 0$ & & 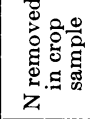 & 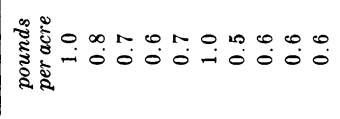 & $\begin{array}{l}\infty \\
\infty\end{array}$ & $\stackrel{\infty}{\infty}$ & $\overrightarrow{2}$ \\
\hline 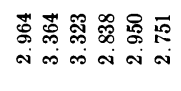 & $\underset{\infty}{\infty}$ & 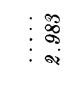 & 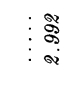 & & z若逭 & 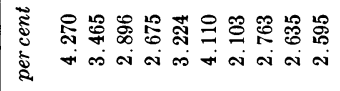 & $\begin{array}{l}\text { \&ँ. } \\
\text { के }\end{array}$ & \begin{tabular}{l}
8 \\
\hdashline \\
\hdashline
\end{tabular} & $\begin{array}{l}\text { के } \\
\text { बे } \\
\text { बे }\end{array}$ \\
\hline 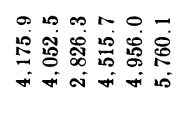 & 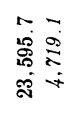 & 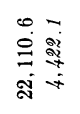 & 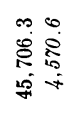 & & 융뮬 & 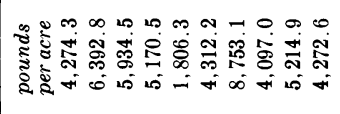 & 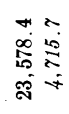 & 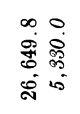 & 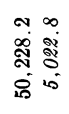 \\
\hline 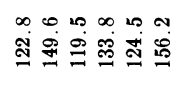 & $\begin{array}{l}-0 \\
\ddot{\infty} \mathscr{\infty}\end{array}$ & 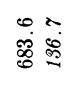 & $\ddot{\Leftrightarrow}$ & \multirow{4}{*}{ 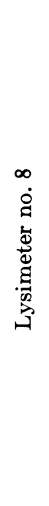 } & $\mathrm{z}$ & 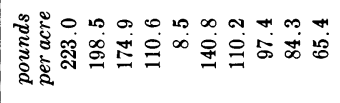 & 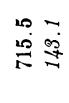 & 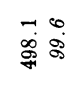 & 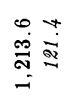 \\
\hline$\ddot{0} \ddot{0} \ddot{0} \ddot{0} \ddot{0} \ddot{0}$ & $\dot{\infty}$ & $\ddot{\infty}$ & $\because 0$ & & 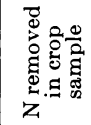 & 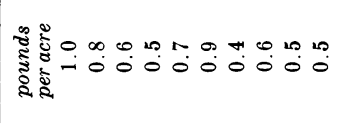 & $\dot{\infty}:$ & $\stackrel{i}{i}$ & \\
\hline 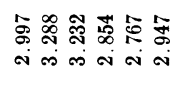 & $\begin{array}{l}\vdots \\
\vdots \\
\vdots \\
\infty\end{array}$ & $\begin{array}{l}\vdots \overline{8} \\
\vdots \\
\alpha\end{array}$ & $\underset{0}{*}$ & & z & 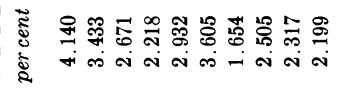 & $\begin{array}{l}\infty \\
8 \\
\infty\end{array}$ & $\begin{array}{l}\infty \\
\infty \\
\infty \\
\infty\end{array}$ & ְid \\
\hline 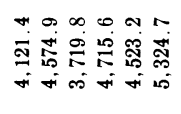 & 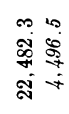 & 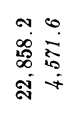 & 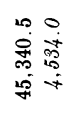 & & 递 & 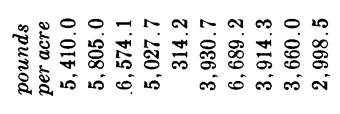 & 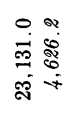 & 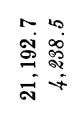 & 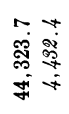 \\
\hline 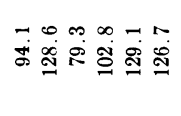 & $\ddot{\circ} \stackrel{\infty}{\circ}$ & 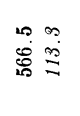 & 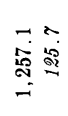 & \multirow{4}{*}{ 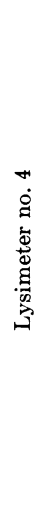 } & 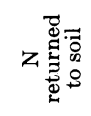 & 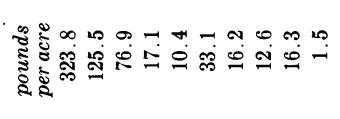 & 루웅 & $\begin{array}{l}r a \\
\beta\end{array}$ & $\stackrel{10}{\infty}$ \\
\hline 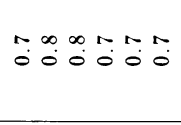 & $\stackrel{\infty}{\infty} \quad \vdots$ & $\ddot{\infty}$ & $\stackrel{1}{\sim}:$ & & 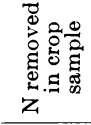 & 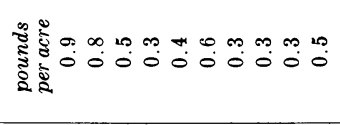 & $\stackrel{\circ}{\sim}:$ & $\stackrel{\circ}{i}$ & o \\
\hline 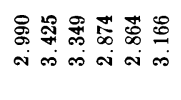 & $\begin{array}{l}\text { : } \\
\vdots \\
\vdots \\
a\end{array}$ & $\vdots \begin{array}{c}8 \\
\vdots \\
\infty\end{array}$ & के & & z & 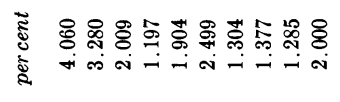 & $\vdots \frac{a}{2}$ & $\vdots \stackrel{7}{\overparen{6}}$ & 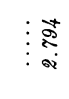 \\
\hline 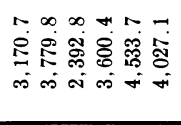 & 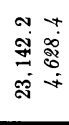 & 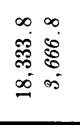 & 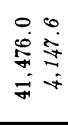 & & 울률 & 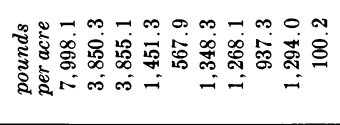 & 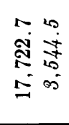 & 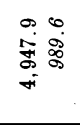 & 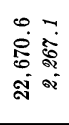 \\
\hline 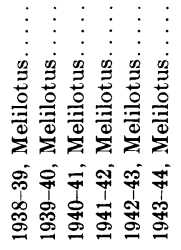 & 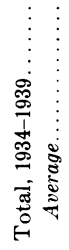 & 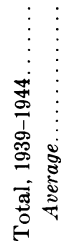 & 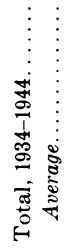 & & 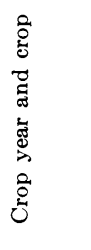 & 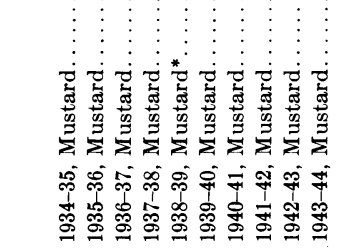 & 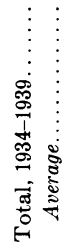 & 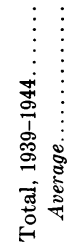 & 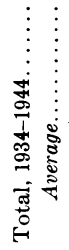 \\
\hline
\end{tabular}


[Vol. 19, No. 3

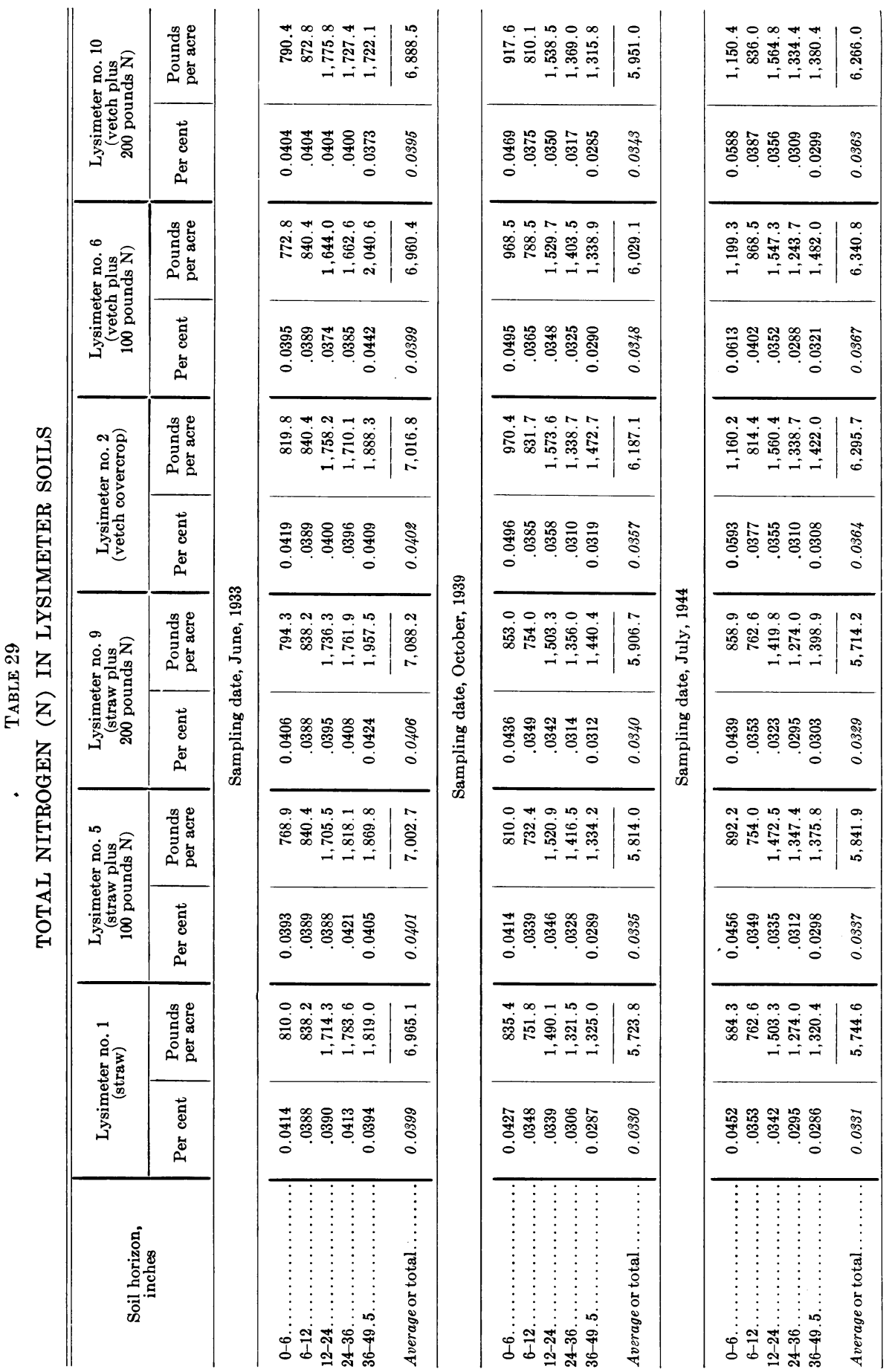




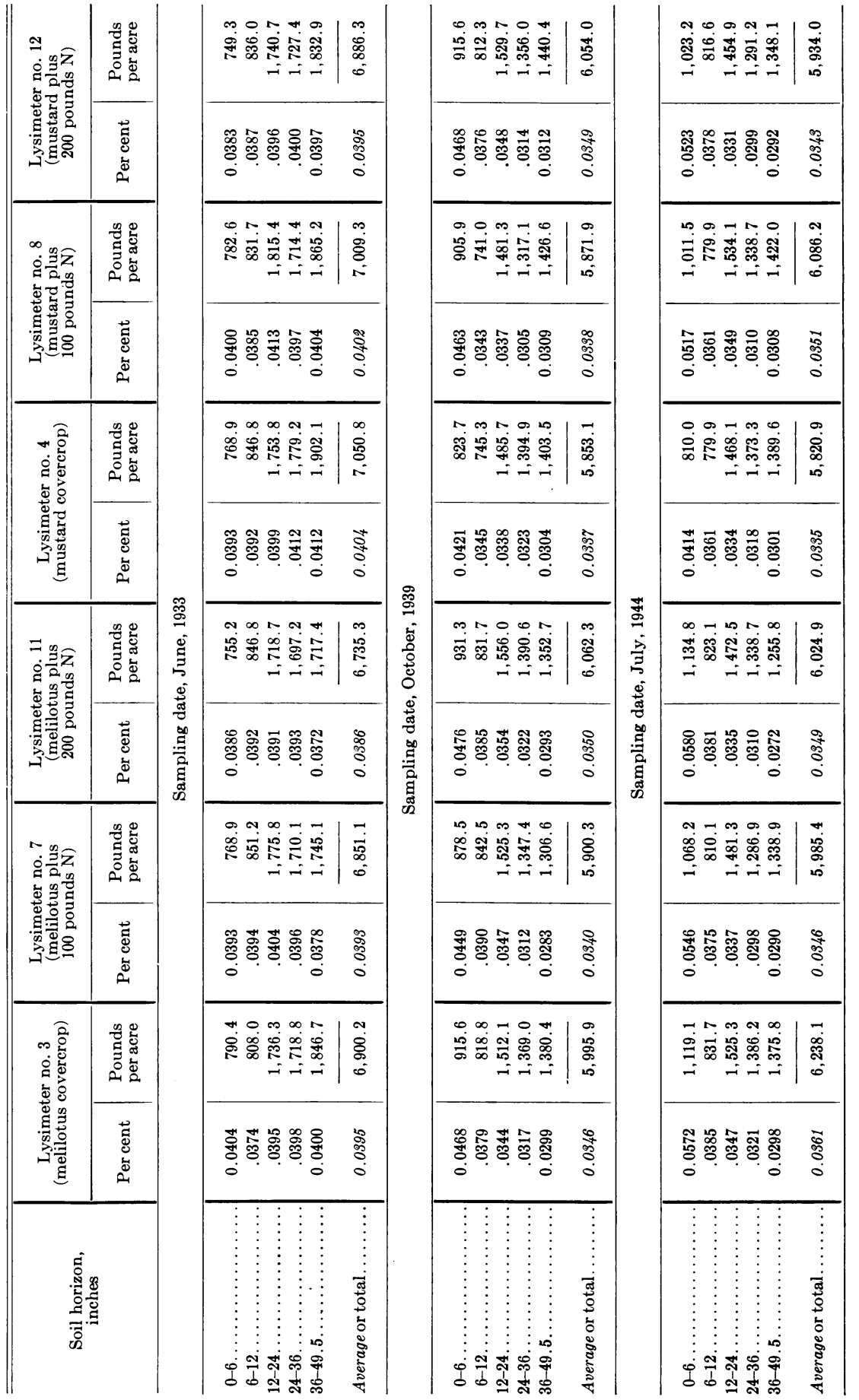


[Vol. 19, No. 3

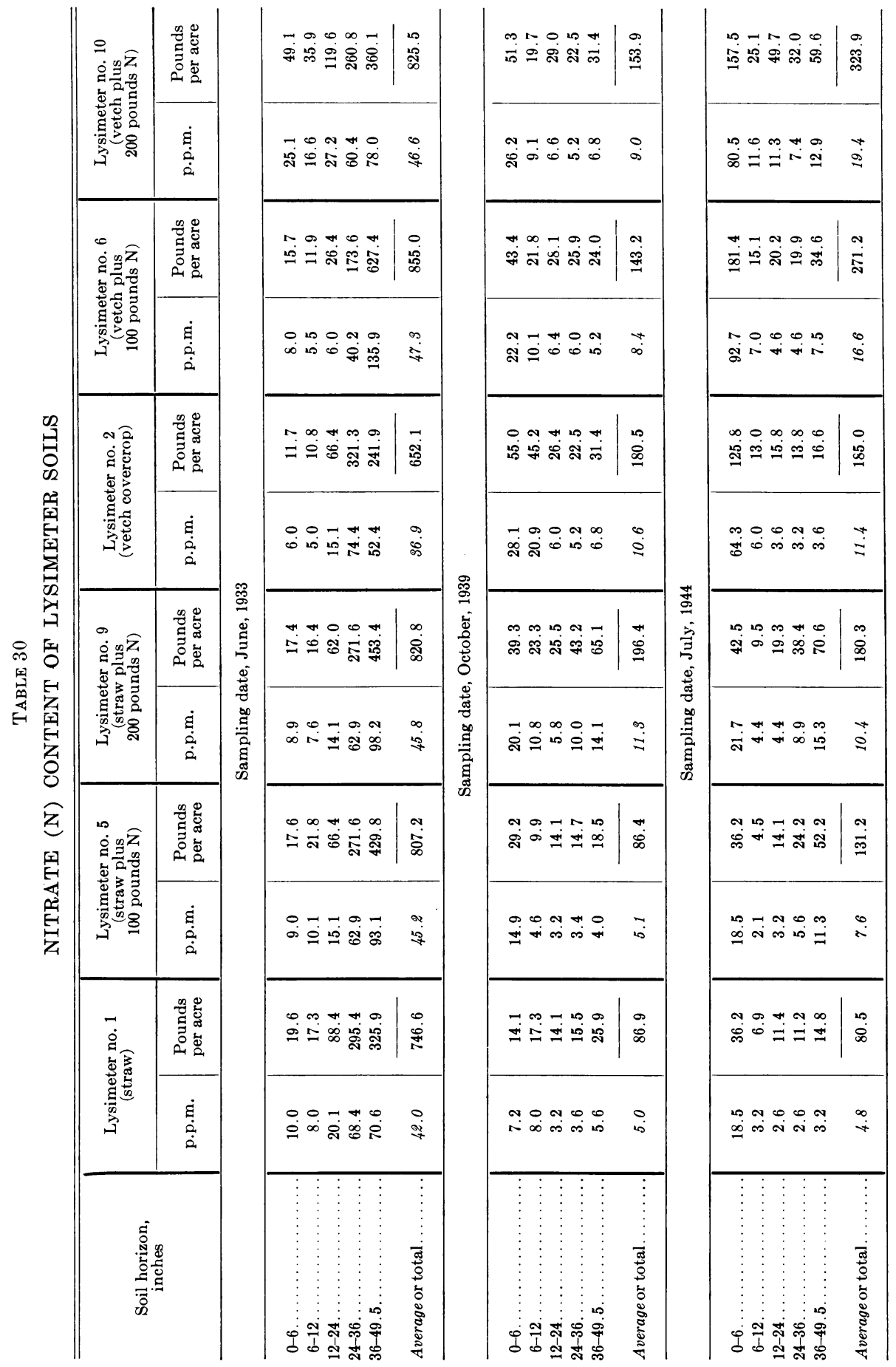




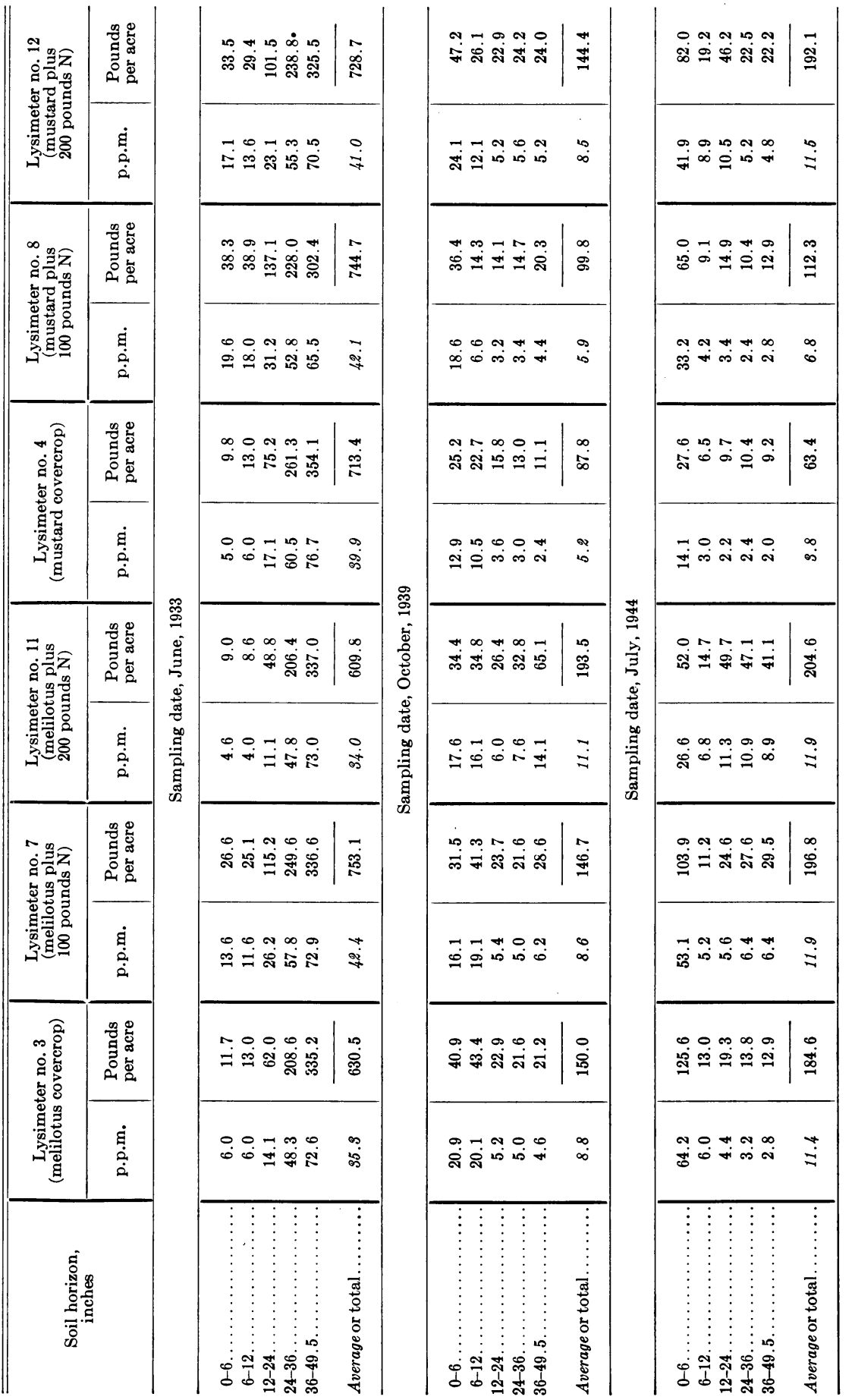


[Vol. 19, No. 3

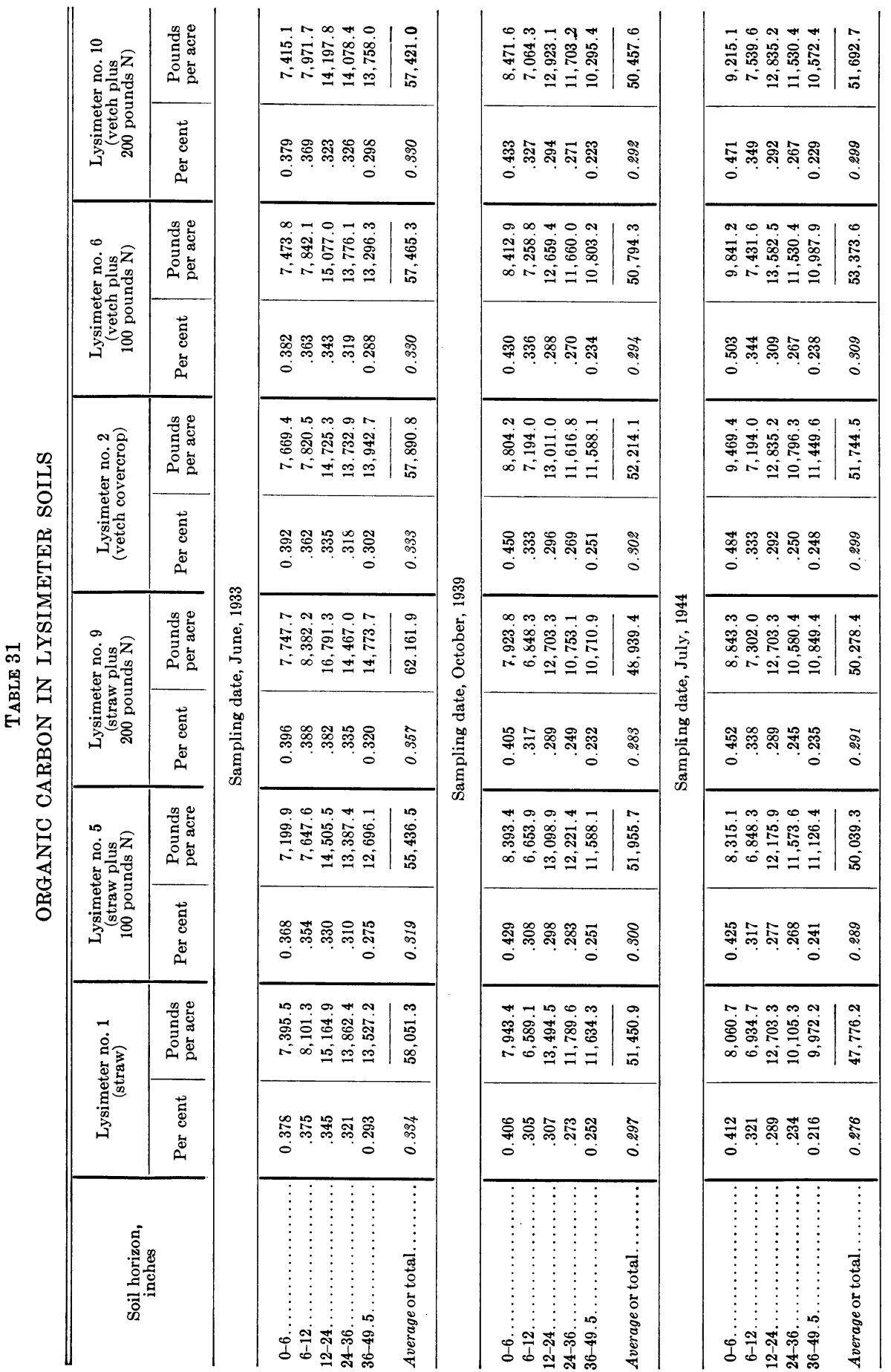




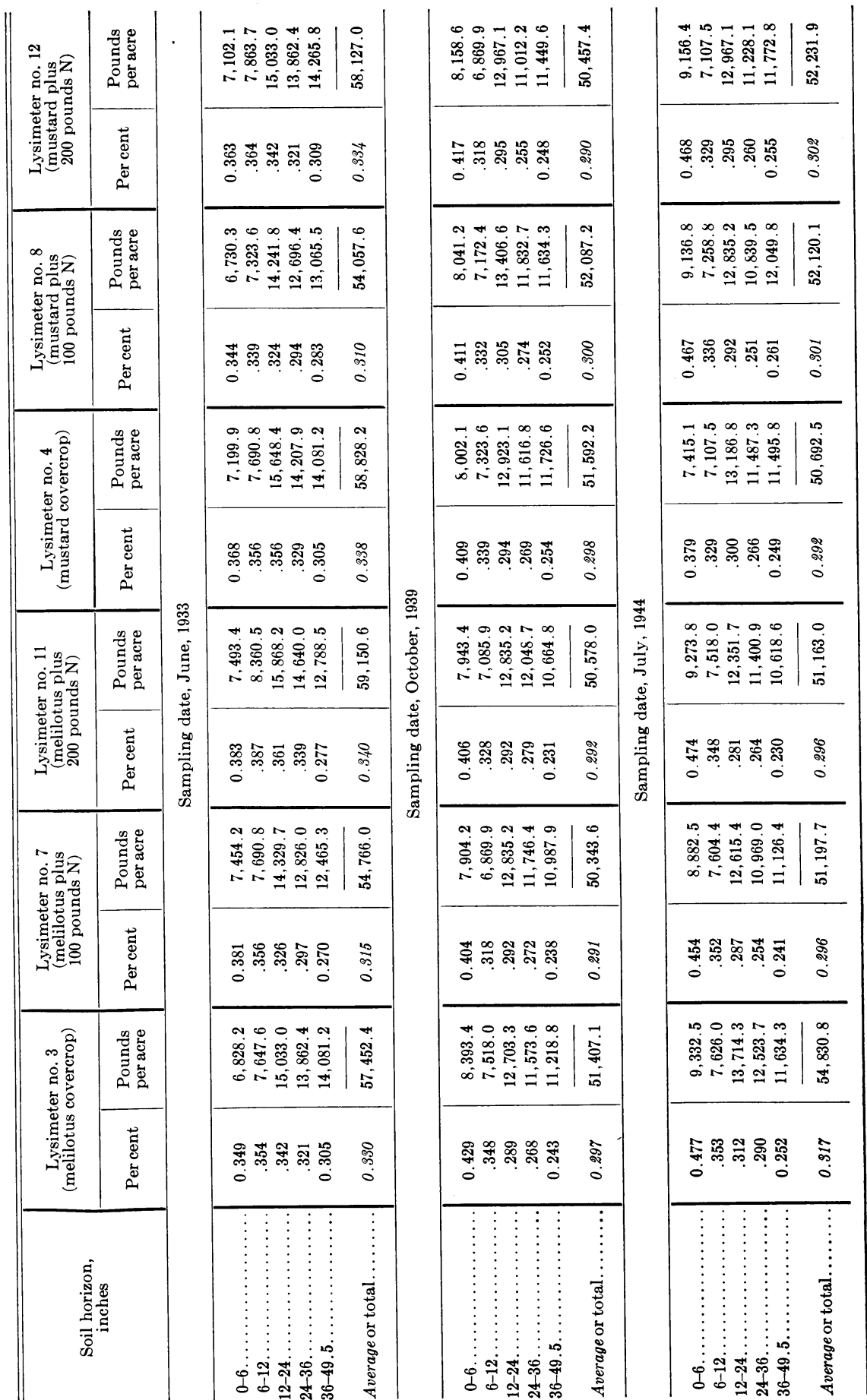




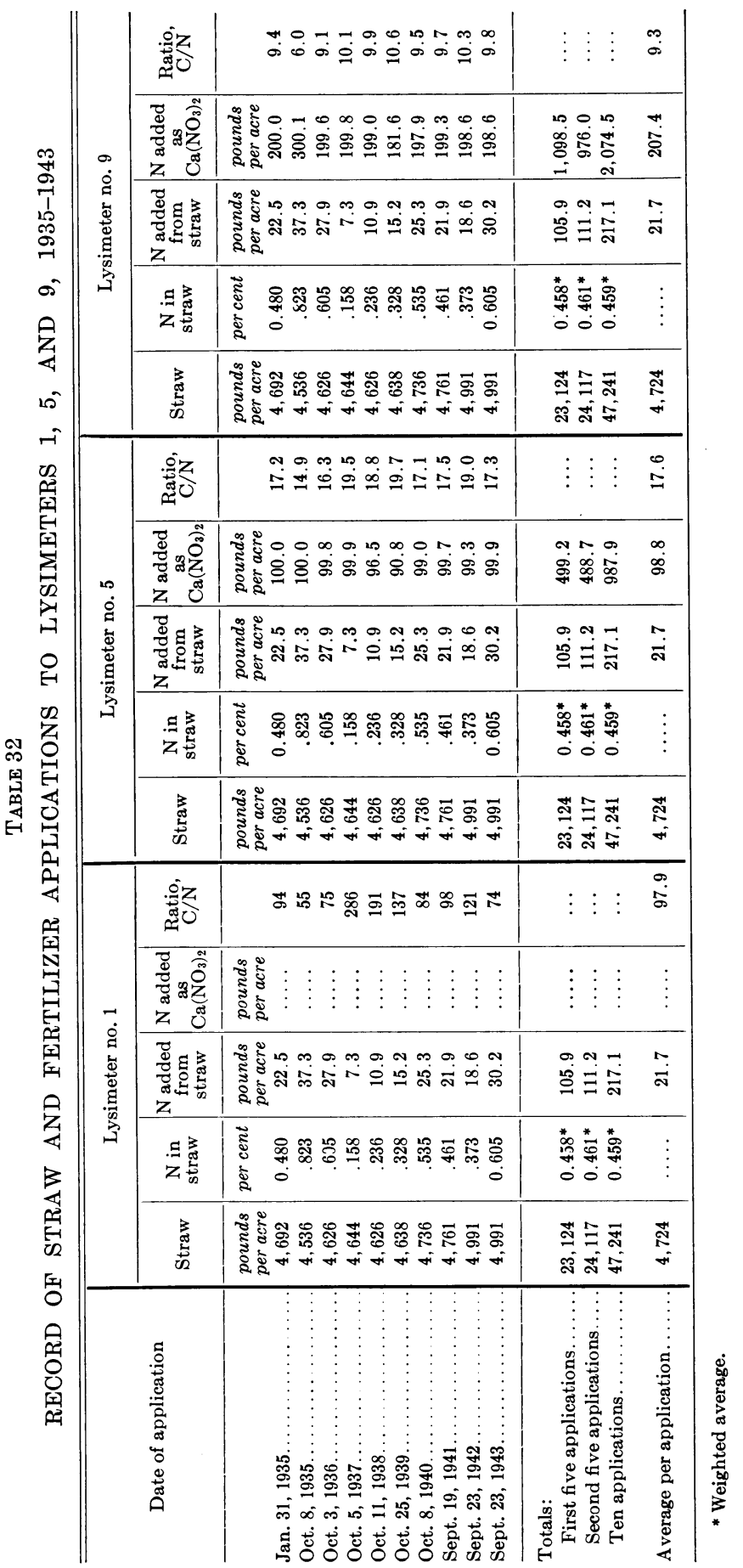




\section{CONTENTS}

Introduction . . . . . . . . . . . . . . . 57

Review of literature . . . . . . . . . . . . . . 58

Experimental procedure . . . . . . . . . . . . 62

Nitrogen additions . . . . . . . . . . . . . . 70

Leaching data . . . . . . . . . . . . . 72

Yield and nitrogen content of crops and nitrogen removal from the soil . . . . . . . . . . . . . . . . 77

Nitrogen gains, losses, and balance in lysimeter soils . . . . 83

Discussion . . . . . . . . . . . . . . . . . 89

Summary . . . . . . . . . . . . . . . . . 91

Acknowledgments . . . . . . . . . . . . . . 92

Literature cited . . . . . . . . . . . . . . . . 93

Appendix A: Discussion of error sources . . . . . . . . 95

Appendix B: Methods of analysis used in lysimeter investigation . 101 Appendix C: Basic tables . . . . . . . . . . . . . 111

In order that the information in our publications may be more intelligible it is sometimes necessary to use trade names of products or equipment rather than complicated descriptive or chemical identifications. In so doing it is unavoidable in some cases that similar products which are on the market under other trade names may not be cited. No endorsement of named products is intended nor is criticism implied of similar products which are not mentioned. 


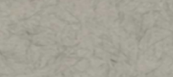

$+2 x^{2}$

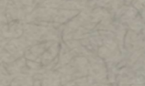

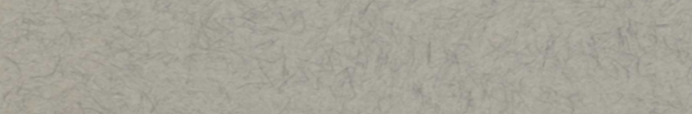

20.

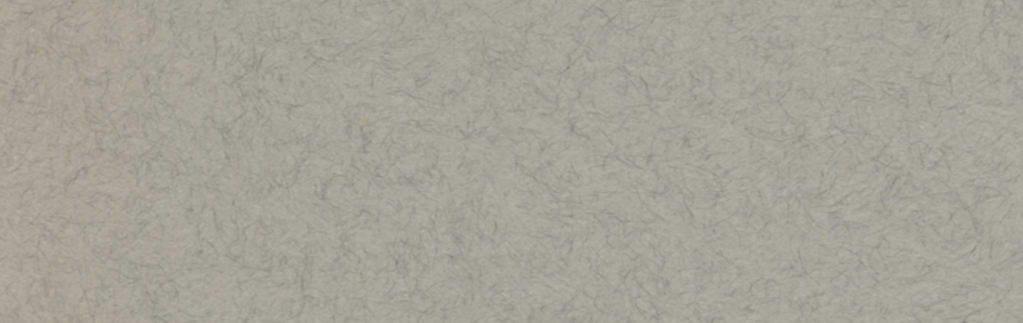

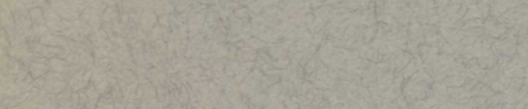

$\frac{9}{5}=x=3$
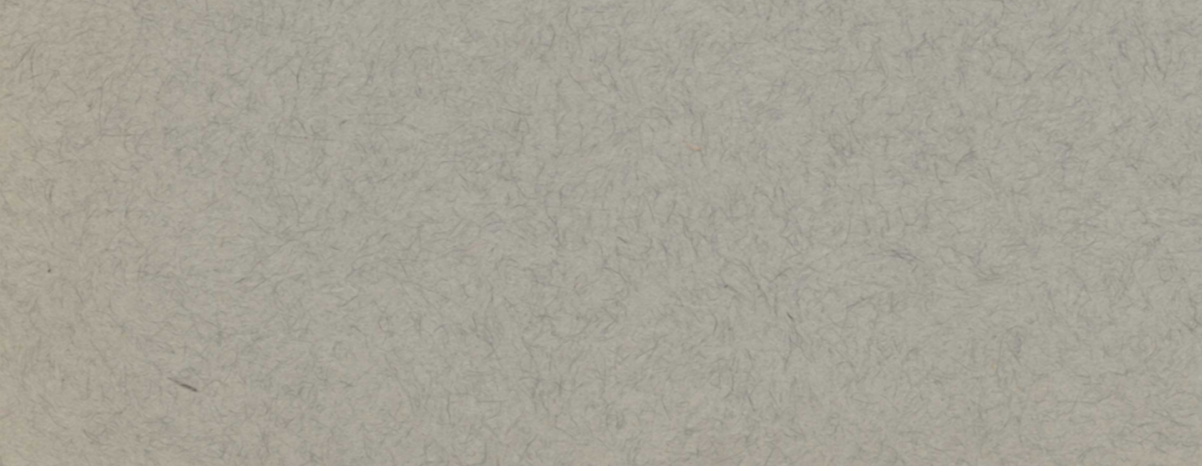

3,2 